\title{
REGIANE GONÇALVES
}

\section{ANÁLISE DE PROPAGAÇÃO DE FISSURAS POR FADIGA EM CONCRETO PELO MEF MEDIANTE A MECÂNICA DO DANO CONTÍNUO}

Dissertação apresentada à Escola de Engenharia de São Carlos, da Universidade de São Paulo, como parte dos requisitos para obtenção do Título de Mestre em Engenharia de Estruturas.

ORIENTADOR: Prof. Dr. Osvaldo Luís Manzoli 
Aos meus Pais e à minha

irmã Mariane. 


\section{AGRADECIMENTOS}

Agradeço primeiramente a Deus que tem sempre iluminado meus passos ao longo de todos estes anos.

Ao professor Osvaldo Luis Manzoli pela dedicação e excelente orientação ao longo deste trabalho e também por sua sincera amizade.

Ao professor Wilson Sérgio Venturini pelo auxílio concedido na realização deste trabalho.

Aos professores e funcionários do Departamento de Estruturas da EESC-USP que colaboraram, de forma direta ou indireta, a fim de que este trabalho pudesse ser realizado.

À Fundação de Amparo à Pesquisa do Estado de São Paulo (FAPESP), pelo indispensável apoio financeiro.

A todos os meus queridos amigos que fizeram esta etapa menos árdua pelos bons momentos que passamos juntos, em especial Alexandre, André, Artur, Daniel, Eduardo, Fernanda, Fernanda, Fernando, Isabella, Joel, Júlio, Lizandra, Luciano, Marcelo, Márcio e Zé Américo. 


\section{GONÇALVES, R. Análise de propagação de fissuras por fadiga em concreto pelo} MEF mediante a mecânica do dano contínuo. Dissertação de Mestrado, Departamento de Estruturas, Escola de Engenharia de São Carlos. São Carlos, 2003.

No presente trabalho desenvolve-se um modelo constitutivo baseado na mecânica do dano contínuo para representar o acúmulo da degradação do concreto produzido por cargas repetidas. $\mathrm{O}$ modelo de dano apresenta as condições necessárias exigidas na chamada aproximação de descontinuidades fortes proposta por Simó, Oliver e Armero e, conseqüentemente, pode ser empregado na formulação de elementos finitos com descontinuidade forte incorporada. Em decorrência de sua capacidade de descrever o comportamento do meio descontínuo independentemente da posição dos contornos do elemento finito, essa classe de formulação constitui uma alternativa valiosa para remediar a forte dependência da malha observada nos modelos de fissuras distribuídas, assim como para evitar as sofisticadas técnicas de reconstrução da malha exigidas nos modelos de fissura discreta, nos quais a fissura é introduzida na interface entre elementos. O trabalho traz contribuições no sentido de proporcionar uma ferramenta alternativa para a análise de propagação de fissuras por fadiga em elementos estruturais de concreto, dentro do contexto da mecânica do dano contínuo. Verifica-se a eficiência da formulação mediante análise numérica de problemas de fadiga em elementos estruturais de concreto.

Palavras-Chave: Fadiga em Concreto; Mecânica do Dano Contínuo; Método dos Elementos Finitos; Descontinuidade Forte; Propagação de Fissuras. 


\section{ABSTRACT}

\section{GONÇALVES, R. Finite element analysis of fatigue crack propagation in concrete by}

means of continuum damage mechanics. Dissertação de Mestrado, Departamento de Estruturas, Escola de Engenharia de São Carlos. São Carlos, 2003.

A constitutive model based on the continuum damage mechanics is proposed to describe the accumulation of the degradation produced by repeated loads in concrete materials. The proposed damage model presents the necessary conditions required in the strong discontinuity approach advocated by Simó, Oliver and Armero and, consequently, it can be used in the embedded strong discontinuity finite element approach. This class of approach has been recognized by its capability to model discontinuities independently on the element boundaries. In fracture mechanics, the embedded strong discontinuity element has been proved to be a efficient alternative to remedy the strong mesh dependence verified in smeared crack approaches, as well as to avoid the sophisticated remeshing techniques required in the discrete crack approaches, in which the crack is introduced in the element interfaces. This work provides an alternative tool for the analysis of crack propagation in concrete structures under fatigue in the context of the continuum damage mechanics. Numerical analysis of concrete elements under fatigue are performed to access the effectiveness of the proposed approach.

Keywords: Concrete Fatigue; Continuum Damage Mechanics; Finite Element Method; Strong Discontinuity, Crack Propagation. 


\section{LISTA DE FIGURAS}

$\begin{array}{ll}\text { Figura 2.1 - Microestrutura do concreto } & 7\end{array}$

Figura 2.2 - Vazios devido à direção de moldagem (Van Mier, 1997) 9

Figura 2.3 - Curva S-N para metais 12

Figura 2.4 - Curva S-N para concreto à compressão 14

Figura 2.5 - Diagrama de Goodman (CEB, 1988) 15

Figura 2.6 - Curva S-N para concreto simples em tração 17

Figura 2.7 - Curva típica do módulo de elasticidade secante para concreto em carga cíclica (Hordijk \& Reinhardt, 1992) 18

Figura 2.8 - Resposta do concreto à compressão uniaxial cíclica

(Mehta \& Monteiro, 1994)

Figura 2.9 - Resposta do concreto à tração uniaxial cíclica (adaptado de Reinhardt et al, 1986)

Figura 2.10 - Relação tensão-deformação do concreto à tração estática e cíclica (adaptado de Hordijk \& Reinhardt, 1992)

Figura 3.1 - Seção transversal nominal e degradada

Figura 3.2 - Hipótese de deformação equivalente

Figura 3.3 - Diagrama de tensão $x$ deformação uniaxial

Figura 3.4 - Comportamento com distintas leis de endurecimento / abrandamento

Figura 3.5 - Modelo de dano insensível a cargas repetidas

Figura 3.6 - Incrementos de deformação utilizados para a simulação do modelo de dano isotrópico insensível a cargas repetidas

Figura 3.7 - Modelos constitutivos simulados através do modelo de dano isotrópico insensível a cargas repetidas 
Figura 3.8 - Modelo de dano sensível a cargas repetidas (modelo 1)

Figura 3.9 - Modelo de dano sensível a cargas repetidas (modelo 2)

Figura 4.1 - Propagação de fissuras na mecânica da fratura

Figura 4.2 - Modelo idealizado de distribuição de tensões na zona coesiva (Barbirato, 1999)

Figura 4.3 - Malhas de elementos finitos adaptadas à fissura em distintos instantes Do processo de carga (Bocca, Carpinteri \& Valente, 1991)

Figura 4.4 - Evolução do colapso de uma descontinuidade fraca $(h \neq 0)$ em uma descontinuidade forte $(h \rightarrow 0)$ (Oliver, 2000)

Figura 4.5 - Representação do comportamento de um ciclo de descarga-recarga na curva $\sigma-w$ do modelo de fissura coesiva

Figura 5.1 - Decomposição do campo de deslocamentos

Figura 5.2 - Ponto de colocação sobre a interface descontínua

Figura 6.1 - Curvas tensão $x$ deformação obtidas pelo MODELO 1 para diferentes histórias de deformações cíclicas

Figura 6.2 - Curvas tensão $x$ deformação obtidas pelo MODELO 2 para diferentes histórias de deformações cíclicas

Figura 6.3 - Curvas tensão $x$ deformação obtidas pelo MODELO 2 para amplitude de tensão constante em $85 \%$ da tensão máxima

Figura 6.4 - Evolução da deformação máxima com o número de ciclos obtida pelo MODELO 2 para amplitude de tensão constante em $85 \%$ da tensão máxima

Figura 6.5 - Variação do módulo secante com o número de ciclos obtida pelo MODELO 2 para amplitude de tensão constante em $85 \%$ da tensão máxima 
Figura 6.6 - Elemento submetido a ciclos de carga para calibração dos parâmetros

Figura 6.7 - Tensão $x$ deformação para carregamento monotônico e cíclico para amplitude de tensão constante em $80 \%$ da tensão máxima, com as unidades no sistema métrico e internacional

Figura 6.8 - Deformação $x$ número de ciclos para carregamento cíclico para amplitude de tensão constante em $80 \%$ da tensão máxima, com as unidades no sistema métrico e internacional

Figura 6.9 - Curvas S-N para calibração dos parâmetros com o CEB

Figura 6.10 - Tensão $x$ deformação para carregamento monotônico e cíclico para amplitude de tensão constante em 70, 80 e 90\% da tensão máxima para os parâmetros da curva 4

Figura 6.11 - Deformação $x$ número de ciclos para carregamento cíclico com amplitudes de tensão constante em 75, 80 e $85 \%$ da tensão máxima para os parâmetros da curva 4

Figura 6.12 - Representação esquemática das provetas do ensaio realizado por Hordijk \& Reinhardt (1992)

Figura 6.13 - Malha de elementos finitos do ensaio da proveta

Figura 6.14 - Curva S-N para o ensaio da proveta

Figura 6.15 - Curva tensão $x$ deformação no elemento próximo à ponta do entalhe para carga monotônica e carga cíclica com amplitude de força constante em $83 \%$ da força máxima

Figura 6.16 - Curva força $x$ deslocamento para o ensaio da proveta para carga monotônica e carga cíclica com amplitude de força constante em $83 \%$ da força máxima

Figura 6.17 - Curva deslocamento $x$ número de ciclos para o ensaio da proveta para carga cíclica com amplitude de tensão constante em $83 \%$ da tensão máxima 
Figura 6.18 - Curva deformação $x$ número de ciclos para o ensaio da proveta para carga cíclica com amplitude de força constante em $83 \%$ da força máxima

Figura 6.19 - Esquema da viga entalhada

Figura 6.20 - Malha de elementos finitos da viga entalhada

Figura 6.21 - Esquema de aplicação do carregamento cíclico para a viga entalhada

Figura 6.22 - Curva S-N para a viga entalhada

Figura 6.23 - Curva tensão $x$ deformação no elemento próximo à ponta do entalhe para a viga entalhada para carga monotônica e carga cíclica com amplitude de força constante em $87 \%$ da força máxima

Figura 6.24 - Curva força $x$ deslocamento para a viga entalhada para carga monotônica e carga cíclica com amplitude de força constante em $87 \%$ da força máxima

Figura 6.25 - Curva deslocamento $x$ número de ciclos para a viga entalhada para carga cíclica com amplitude de força constante em $87 \%$ da força máxima

Figura 6.26 - Curva deformação $x$ número de ciclos no elemento da ponta do entalhe para a viga entalhada para carga cíclica com amplitude de força constante em $87 \%$ da força máxima

Figura 6.27 - Tensões principais máximas $\sigma_{1}\left[10^{-1} \mathrm{MPa}\right]$ atuantes na viga entalhada para carga cíclica com amplitude de força constante em $87 \%$ da força máxima

Figura 6.28 - Tensões normais $\sigma_{\mathrm{xx}}\left[10^{-1} \mathrm{MPa}\right]$ atuantes na viga entalhada para carga cíclica com amplitude de força constante em $87 \%$ da força máxima

Figura 6.29 - Curva comprimento da fissura $x$ número de ciclos para a viga entalhada para carga cíclica com amplitude de força constante em $87 \%$ da força máxima 


\section{LISTA DE TABELAS}

Tabela 6.1 - Parâmetros $B, C$ e $N$ 
SUMÁRIO

Capítulo 1 - INTRODUÇÃO

1.1 Introdução 2

1.2 Objetivos 4

1.3 Conteúdo dos Capítulos desta Dissertação 5

Capítulo 2 - COMPORTAMENTO DO CONCRETO À SOLICITAÇÃO CÍCLICA

2.1 Introdução 6

2.2 Influência da Microestrutura 7

$\begin{array}{ll}2.3 \text { Análise da Fadiga em Concreto } & 10\end{array}$

2.3.1 Curvas de Wöhler e Limite de Fadiga 11

2.3.2 Concreto em Compressão Uniaxial 13

2.3.3 Concreto em Tração Uniaxial 16

2.4 Leis Constitutivas do Concreto $\quad 19$

2.4.1 Concreto em Compressão Uniaxial 19

2.4.2 Concreto em Tração Uniaxial 20

Capítulo 3 - MECÂNICA DO DANO CONTÍNUO 23

3.1 Introdução 23

3.2 Conceitos Fundamentais $\quad 24$

3.3 Modelo Constitutivo de Dano Isotrópico 30

3.3.1 Critério de Dano $\quad 30$

3.3.2 Lei de Evolução da Variável de Dano 32

3.3.3 Integração das Equações Constitutivas 33

3.3.4 Implementação Numérica $\quad 35$

3.4 Generalização do Modelo de Dano para Ações Repetidas 38 
3.4.1 Lei de Evolução de Dano - Modelo 1

3.4.2 Implementação Numérica - Modelo 1

3.4.3 Lei de Evolução de Dano - Modelo 2

3.4.4 Parâmetros do Modelo Constitutivo 43

Capítulo 4 - IMPLEMENTAÇÃO VIA MÉTODO DOS ELEMENTOS FINITOS

4.1 Introdução 45

4.2 Modelos Teóricos Discretos 46

4.2.1 Mecânica da Fratura Linear Elástica $\quad 46$

4.2.2 Modelos de Fissura Coesiva 47

4.2.3 Simulação Numérica de Modelos Discretos pelo MEF 49

4.3 Modelo Teórico Baseado na Mecânica dos Meios Contínuos 50

4.3.1 Simulação Numérica de Modelos Contínuos pelo MEF 51

4.4 Aproximação de Descontinuidades Fortes 52

4.4.1 Introdução

4.4.2 Aproximação de Descontinuidades Fortes pelo MEF

4.5 Modelagem de Fadiga $\quad 54$

4.5.1 Modelo Discreto de Fadiga 54

4.5.2 Modelo Contínuo de Fadiga 55

4.5.3 Modelagem de Fadiga Mediante a Aproximação de Descontinuidade

Forte $\quad 55$

Capítulo 5 - ELEMENTOS FINITOS COM DESCONTINUIDADE FORTE

$\begin{array}{lr}\text { INCORPORADA } & 57\end{array}$

5.1 Decomposição do Campo de Deslocamentos

5.2 Descrição Cinemática e Estática da Parte Contínua 58

5.3 Deslocamentos Nodais 59

5.4 Princípio Variacional 59

5.5 Aproximação pelo Método dos Elementos Finitos 60

5.6 Comportamento Não-Linear da Interface $\quad 61$ 
5.7 Acoplamento entre Contínuo e Interface 63

5.8 Sistema Completo de Equações $\quad 65$

5.9 Esquema de Solução $\quad 65$

5.10 Análise de Dissipação do Modelo de Dano 66

Capítulo 6 - RESOLUÇÃo DE EXEMPLOS NUMÉRICOS

6.1 EXEMPLO1 - Tração Uniaxial: Verificação dos Modelos 69

6.2 EXEMPLO 2 - Tração Uniaxial: Calibração dos Parâmetros 75

6.3 EXEMPLO 3 - Ensaio de Provetas em Tração (Hordijk \& Reinhardt, 1992) 81

6.4 EXEMPLO 4 - Viga Bi-Apoiada $\quad 87$

Capítulo 7 - CONSIDERAÇÕES FINAIS 96

Capítulo 8 - REFERÊNCIAS BIBLIOGRÁFICAS 98 


\section{Capítulo 1}

\section{INTRODUÇÃO}

\subsection{INTRODUÇÃO}

No âmbito da Engenharia Civil as estruturas são construídas com variadas finalidades, em localidades diversas, sendo expostas a diferentes carregamentos e condições ambientais. Normalmente, no projeto de estruturas usuais, admite-se que os carregamentos podem ser considerados estáticos e os materiais trabalham dentro do regime elástico-linear. Entretanto, há casos em que os efeitos dinâmicos das cargas não podem ser desprezados. Por exemplo, quando uma estrutura é solicitada pela ação de cargas repetidas, os materiais utilizados na engenharia sofrem uma alteração mecânica, que pode produzir a ruptura da estrutura do material depois de um número mais ou menos grande de solicitações repetidas menores do que a correspondente resistência estática do mesmo (Aguado et al., 1990). Este fenômeno de perda de resistência também é chamado de fadiga dos materiais. Ventos e ondas, tráfego, maquinário em trabalho, guindastes em movimento, efeitos de temperatura e umidade são alguns exemplos de solicitações periódicas que podem fadigar uma estrutura.

Até poucos anos atrás, os materiais frágeis, como a cerâmica, a rocha e o concreto, eram considerados insensíveis aos efeitos da fadiga. Atualmente aceita-se que fadiga também pode ser responsável pelo processo de fraturamento de tais materiais.

O aumento na deformação e a formação de fissuras devido às cargas repetidas são, geralmente, os fatores mais importantes na análise de fadiga em elementos estruturais de concreto. Após um determinado número de ciclos, a fissura pode adquirir dimensões suficientes para torná-la instável, conduzindo assim à ruptura.Em geral, a ruptura não é diretamente produzida pela fadiga, mas sim é decorrente de deteriorações progressivas nas quais a fadiga é um elemento contribuinte (Fatigue of Concrete Structures - CEB, 1988). 
Com os enormes avanços dos métodos numéricos aplicados à engenharia e a introdução de ferramentas computacionais, tornou-se possível uma análise mais completa de problemas complexos de estruturas em geral, incluindo o caso da fadiga. A simulação computacional permite a consideração do comportamento mecânico dos materiais utilizados na engenharia além do limite elástico, fazendo com que a elaboração de projetos possa ser mais eficiente e segura.

Inicialmente os estudos sobre simulação da fadiga eram direcionados aos metais, tendo sido fonte de estudos de diversos trabalhos. Resultados básicos foram obtidos por Paris \& Erdogan (1963). Com base em resultados experimentais, estabeleceu-se a chamada lei de Paris, na qual a taxa de crescimento da fissura com o número de ciclos de carga depende principalmente da amplitude de variação do fator de intensidade de tensões, calculado mediante a Mecânica de Fratura Linear Elástica (MFEL).

Sabe-se que a MFEL somente tem validade nos casos nos quais a zona de processo de fraturamento é muito pequena comparada às dimensões típicas do espécime. Se essa condição não se satisfaz, o comportamento de fadiga começa a sofrer influência das dimensões do espécime. Essa dependência pode ser observada principalmente no concreto, cuja zona de processamento de fraturamento geralmente adquire dimensões que não podem ser desprezadas.

Como a lei de Paris somente é aplicável dentro dos limites de validade da MFEL, seu emprego nos casos mais gerais somente pode ser feito adequadamente mediante a introdução de correções que contemplem o efeito da dimensão (Bazant \& Xu, 1991).

Diferentemente dos modelos discretos baseados nos conceitos de fissura coesiva, os modelos baseados na mecânica do dano contínuo utilizam os conceitos macroscópicos de tensão e deformação também para representar o processo de fraturamento sob o efeito de cargas cíclicas.

Nos últimos anos os modelos de dano contínuo (Kachanov, 1986; Simo \& Ju, 1997; Lemaitre \& Chaboche, 1988) têm sido amplamente utilizados na mecânica computacional para modelar o complexo comportamento mecânico do concreto. Tais modelos apresentam a base teórica fundamentada no processo de degradação do material, caracterizado pela formação, crescimento e interconexão de microfissuras e de microporos do concreto.

Esse tipo de degradação do material é tratado como um processo não-linear termodinamicamente irreversível, expresso em termos de variáveis de estado 
macroscópicas (Simó \& Ju, 1997). Dada a sua consistência teórica e versatilidade, a mecânica de dano contínuo tem sido bastante empregada para descrever o processo de fraturamento em materiais frágeis, submetidos a cargas monotônicas. A formação da macrofissura associa-se ao caso limite do processo de localização de deformações em bandas estreitas.

Além de reproduzir o efeito de dimensão, os modelos baseados na mecânica do dano contínuo são capazes de reproduzir os aspectos essenciais do comportamento de descarga-recarga sem depender explicitamente do número de ciclos. Inclusive são capazes de lidar naturalmente (sem recorrer a fatores empíricos) com casos nos quais a amplitude das solicitações varia muito durante o processo de carga, como em geral ocorre nos casos práticos. Além disso, como a formação de macrofissuras provém da concentração da degradação, tais modelos são capazes de analisar casos sem defeitos ou falhas iniciais, o que não é possível no âmbito da MFEL.

Para representar o processo de acúmulo de degradação produzido por cargas cíclicas, desenvolveram-se algumas adaptações de modelos de dano contínuo, tornando-os aptos a descrever o crescimento da degradação durante cada ciclo de descarga-recarga (Papa et al., 1991; Bhattacharya \& Ellingwood, 1998). 


\subsection{OBJETIVOS}

O objetivo do trabalho é gerar uma formulação do Método dos Elementos Finitos (MEF) para a análise da formação e propagação de fissuras por fadiga em elementos estruturais bidimensionais de concreto solicitados por ações cíclicas. Como a teoria em si é bastante vasta, optou-se por tratar mais detalhadamente o concreto sob solicitação periódica sem inversão de sinal, aqui referenciada como cíclica ou repetida.

A idéia básica é elaborar um modelo constitutivo baseado no modelo de dano isotrópico (insensível a ações repetidas) proposto por Oliver et al. (1990), que seja capaz de representar o acúmulo da degradação do material produzido por cargas repetidas. $\mathrm{O}$ modelo de dano isótropo adotado deve ser analisado em seus aspectos fundamentais: hipóteses básicas, critério de inicio e propagação de dano, lei de evolução da variável escalar representativa do processo de deterioração. Como o modelo original é limitado ao caso de carregamento monotônico, propõe-se uma extensão para o caso de carregamento cíclico.

O modelo proposto deve ser consistente com campos de deformações não limitados (distribucionais), próprios do regime de descontinuidade forte, a fim de que possa ser introduzido no código de elementos finitos existente, desenvolvido para simular a propagação de descontinuidades fortes em sólidos bidimensionais.

Finalmente, mediante algumas análises numéricas representativas, objetiva-se estudar as potencialidades da formulação do MEF com interface de descontinuidade incorporada munida do modelo constitutivo proposto na análise de fadiga. 


\subsection{CONTEÚDO DOS CAPÍTULOS DESTA DISSERTAÇÃO}

Este trabalho trata em particular da simulação do fenômeno da fadiga em um dos materiais de grande uso na engenharia civil: o concreto. Por isso o segundo capítulo mostra um pouco do comportamento deste material quando submetido à ação de carregamentos cíclicos.

A simulação é feita através da elaboração de um modelo constitutivo utilizando-se a mecânica do dano contínuo, cujo embasamento teórico é apresentado no terceiro capítulo. Inicialmente, é feita a caracterização geral do modelo de dano e em seguida é desenvolvido um modelo constitutivo específico para o concreto submetido à solicitação cíclica. Comentam-se alguns aspectos relativos à implementação computacional do modelo de dano. Discute-se em particular a integração do modelo constitutivo e o processo incremental-iterativo de resolução do problema. O modelo inicialmente elaborado para a análise unidimensional é generalizado para múltiplas dimensões e inserido num programa de elementos finitos. Esse modelo também faz parte do desenvolvimento da chamada aproximação de descontinuidades fortes (Oliver, 1996), que apresenta vantagens numéricas na simulação de problemas de localização.

No capítulo 4 apresenta-se uma breve revisão dos modelos discretos e contínuos existentes para a simulação de propagação de fissuras. O capítulo 5 é dedicado à formulação do método de elementos finitos com interface descontínua incorporada.

No capítulo 6 são apresentadas análises numéricas do comportamento de elementos estruturais de concreto, a fim de validar a formulação proposta. 


\section{Capítulo 2}

\section{COMPORTAMENTO DO CONCRETO À SOLICITAÇÃO CÍCLICA}

\subsection{INTRODUÇÃO}

Neste trabalho dá-se ênfase ao estudo das características do comportamento do material concreto sob a ação de solicitação cíclica. Por isso este capítulo é dedicado ao estudo de tal material, já que somente com o aprimoramento das técnicas experimentais torna-se possível a observação do comportamento microestrutural e o desenvolvimento de modelos constitutivos específicos para diferentes materiais, permitindo descrever com boa precisão o comportamento de uma estrutura, desde sua fase elástica até a fase anelástica que antecede a ruptura.

De fato, fenômenos que conduzem a um comportamento diferenciado da estrutura do concreto podem ser mais facilmente modelados quando se entendem as alterações que ocorrem no material a nível microscópico. Por exemplo, explicações para deformações plásticas, deformação lenta, rupturas frágeis e dúcteis e fraturamento do concreto são encontradas no estudo da microestrutura.

No caso das ações cíclicas, duas características e pontos importantes são: primeiro, que a ruptura pode ocorrer para carregamentos menores que aqueles necessários no caso de carregamento estático; e segundo, que mesmo o mais dúctil dos materiais rompe sem revelar deformação anelástica macroscópica, com o agravante que a dimensão e localização das fissuras formadas pelo processo de solicitação cíclica freqüentemente fazem de sua detectação durante a inspeção de rotina uma tarefa difícil.

O Fatigue of Concrete Structures - CEB (1988) explica que a fissuração devido à fadiga no concreto não tem uma superfície topográfica identificável, por isso é extremamente difícil identificá-la em estruturas de concreto. A fadiga pode ocorrer num 
elemento de concreto estrutural quando se desenvolve fissuração excessiva sob cargas repetidas de serviço.

Em estruturas de concreto armado a fadiga está intimamente relacionada com as propriedades de seus materiais componentes, concreto e aço e a interação entre eles. Assim, para elementos sub-armados sob a ação cíclica de momento fletor o comportamento à fadiga está diretamente relacionado com a resistência à fadiga da armadura. Para elementos super-armados ou aqueles nos quais o cisalhamento e a aderência são fatores determinantes, a previsão do comportamento é mais complexa (Driemeier, 1995). No entanto o presente trabalho contemplará o estudo da fadiga em concreto simples, sem considerar o efeito da armadura.

Em vigas de concreto armado, a fissuração é produzida pela aplicação repetida de aproximadamente metade da carga estática de fissuração (Mehta \& Monteiro, 1994), mas a ruptura completa não ocorre a menos que a carga cíclica esteja entre $60 \%$ e $70 \%$ da carga estática. Segundo Forrest (1970), a fissuração por solicitação cíclica do concreto pode ser evitada limitando-se a tensão máxima para metade da tensão estática requerida para produzir fissuração.

\subsection{INFLUÊNCIA DA MICROESTRUTURA}

Em nível microscópico o concreto não é um material homogêneo, sendo constituído por três fases distintas: agregado graúdo (material inerte envolvido pela argamassa), matriz de argamassa (agregado miúdo envolvido por uma pasta de cimento e água) e zona de transição (Figura 2.1).

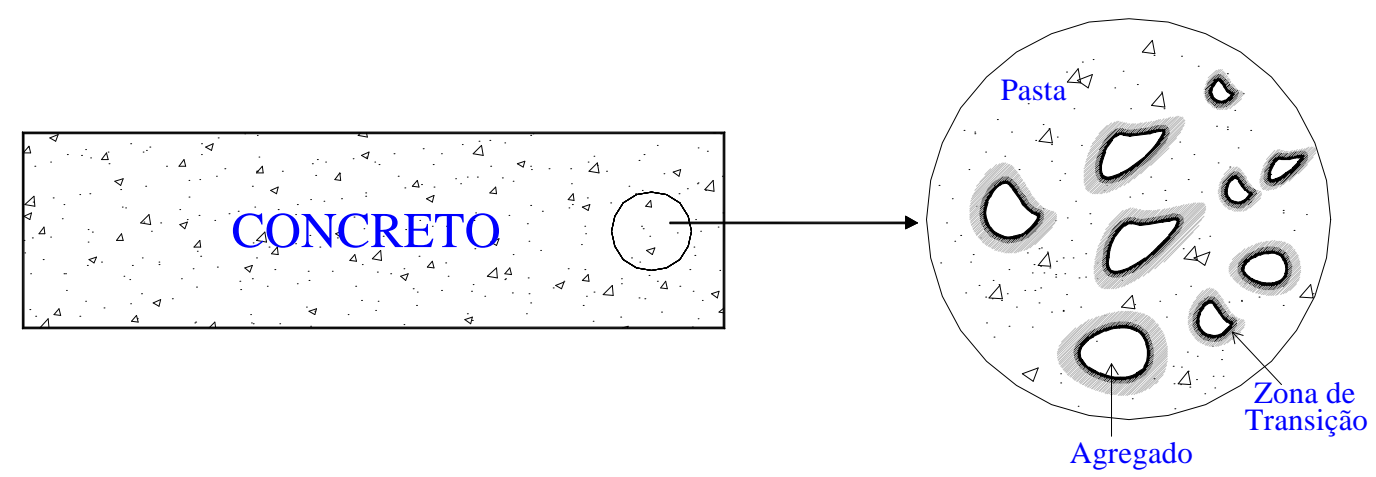

Figura 2.1. Microestrutura do concreto. 
A zona de transição é uma camada delgada presente ao redor do agregado graúdo, na interface agregado-cimento. Segundo Maso (1980), citado em Mehta \& Monteiro (1994), em um concreto recentemente compactado, um filme de água forma-se ao redor das partículas grandes de agregado (exsudação). Isto leva a uma relação água/cimento mais elevada na proximidade do agregado graúdo do que longe dele. Daí origina-se a região denominada zona de transição, considerada o elo mais fraco da corrente, a fase de resistência limite no concreto.

Sendo geralmente mais fraca do que os outros dois componentes principais do concreto, a zona de transição exerce uma influência maior do que se poderia esperar visto sua espessura.

É devido à presença da zona de transição que o concreto, por exemplo, rompe a níveis de tensão consideravelmente mais baixos do que a resistência dos dois principais constituintes: agregado e matriz.

A quantidade de água usada no concreto é geralmente maior que a necessária na reação química, buscando maior trabalhabilidade. Uma parte do excesso de água, chamada água evaporável, é fixada por adsorção aos micro-cristais, e o restante, chamada de água capilar, permanece dispersa nos vazios capilares, formando uma rede capilar.

Os vazios capilares constituem os espaços não preenchidos pelos componentes sólidos da pasta, que se formam devido ao fato da densidade média dos produtos da hidratação ser consideravelmente menor do que a densidade do cimento.

A estrutura da zona de transição, especialmente o volume de vazios e microfissuras presentes têm grande influência sobre a rigidez e o módulo de elasticidade, além de influenciar a durabilidade do concreto. Além disso, na zona de transição podem formar-se defeitos de aderência e vazios associados à direção de moldagem (Figura 2.2). 


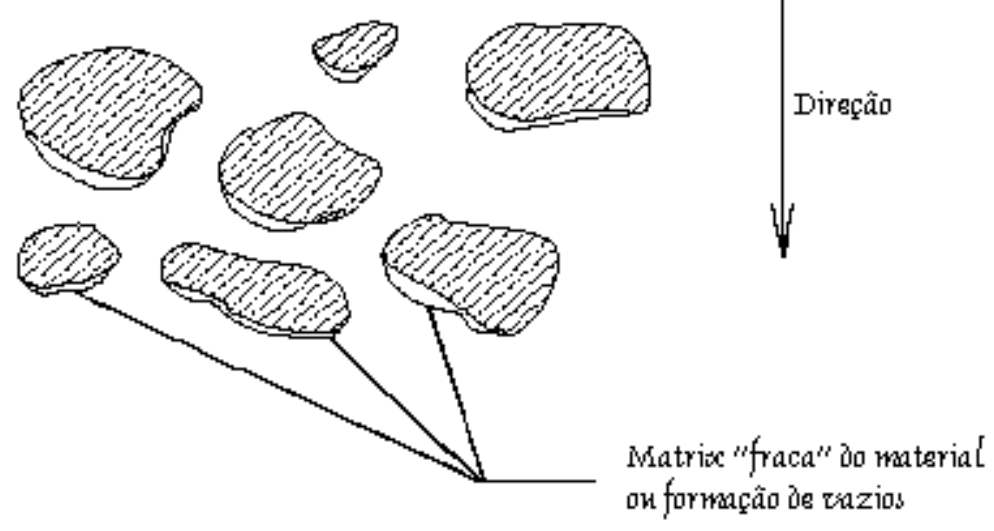

Figura 2.2. Vazios devido à direção de moldagem (Van Mier, 1997).

É graças às microfissuras e vazios iniciais existentes mesmo antes de qualquer solicitação, principalmente na zona de transição, que torna-se difícil separar os fenômenos de deformação e ruptura no concreto (Driemeier, 1995).

Segundo Mehta \& Monteiro (1994), sob condições normais de cura, existe uma fase inicial em que a deformação pode ser considerada como o resultado de movimentos quase reversíveis de átomos e, portanto, elástica. Durante este período, as fissuras da zona de transição permanecem estáveis.

Além do limite elástico, na medida em que a tensão aumenta, as microfissuras na zona de transição começam a progredir, produzindo deformações permanentes que se superpõem às elásticas, fazendo com que a curva tensão-deformação desvie de uma linha reta. Este desvio é sensível até a formação de microfissuras na matriz. Em estágio mais avançado, fissuras macroscópicas, resultantes da localização das microfissuras, também passam a colaborar nos mecanismos de deformação irreversível e de ruptura, caracterizando o ramo decrescente ("softening") do diagrama tensão-deformação.

Como é necessária uma energia considerável para formação e propagação de fissuras na matriz sob carga de compressão, o concreto tem uma resposta relativamente dúctil à compressão e frágil à tração, possuindo resistência última à compressão de cerca de uma ordem de grandeza maior que à tração.

Os ensaios de tração do concreto com carregamento controlado apresentam uma resposta linear até um certo nível a partir do qual segue-se uma brusca queda na tensão, em correspondência à repentina formação de uma fissura. Com testes de deslocamento controlado, torna-se possível a caracterização do ramo de encruamento negativo pós- 
ruptura ("softening") associado à dissipação de uma significativa quantidade de energia por unidade de volume.

Assim, no concreto, com o objetivo de formular leis constitutivas mais coerentes, é importante conhecer melhor os fenômenos observados na microestrutura, relacionados à formação e evolução de fissuras.

\subsection{ANÁLISE DA FADIGA DO CONCRETO}

Para muitas aplicações o concreto é sujeito a cargas estáticas com pouca ou nenhuma flutuação, mas quando variações apreciáveis na carga ocorrem, a fadiga é um dos prováveis fenômenos associados à ruptura.

Tecnicamente, fadiga é a diminuição gradual da resistência de um material por efeito de solicitações periódicas. A perda de rigidez vem normalmente acompanhada de perda de resistência.

Aguado et al. (1990) afirmam que a fadiga se intensifica para condições de alternância de cargas em tração e compressão, e parece ser semelhante na tração ou compressão puras. Há de se destacar que os tipos de solicitações podem ser combinados de diversos modos e de acordo com as características destas combinações de solicitações simultâneas, se obtêm respostas diferentes no comportamento do material à fadiga.

As fissuras decorrentes da solicitação repetida no concreto não apresentam superfície identificável, uma vez que na maioria dos casos práticos o que se observa é uma deterioração progressiva do material desde a iniciação de microfissuras, sua propagação até a formação das macrofissuras.

Segundo Forrest (1970), se um espécime de concreto é sujeito a uma história de carregamento repetido com amplitude constante, tanto a deformação total quanto a deformação permanente aumentam gradualmente, tendendo a valores estáveis em baixos níveis de tensão, mas aumentando continuamente até a ruptura em níveis mais altos de tensão.

Testes comprovam que a resistência à fadiga pode ser aumentada pelo alívio dos níveis de tensão ou pelos "períodos de folga", períodos em que a estrutura não está sujeita a carregamentos cíclicos. A frequência do ciclo de tensão, porém, tem efeito insignificante 
no aumento da resistência. Segundo Aguado et al. (1990) as frequências entre 1 e $15 \mathrm{~Hz}$ produzem pequenos efeitos, influindo pouco no fenômeno da fadiga.

De acordo com o Fatigue of Concrete Structures - CEB (1988), existem essencialmente duas formas básicas que podem ser adotadas na avaliação da fadiga de elementos estruturais. Um destes métodos é baseado na mecânica da fratura e considera uma análise de propagação de fissuras num ponto específico, via método numérico, o qual é explorado neste trabalho. O segundo método baseia-se no uso de curvas empíricas $\mathrm{S}-\mathrm{N}$ (amplitude de tensão por número de ciclos na ruptura), algumas vezes chamadas de diagrama de Wohler. Tais curvas são derivadas de dados experimentais obtidos de testes de fadiga e são apresentadas no próximo item.

\subsubsection{Curvas de Wöhler e Limite de Fadiga}

Desde os primeiros testes de solicitação cíclica alternada realizados por Wöhler em 1858, as curvas S-N (amplitude de tensão por número de ciclos na ruptura) têm servido de base para a interpretação da fadiga, sendo muito usadas em projetos que envolvam o fenômeno. Estas curvas resultam de uma análise estatística sobre dados de inúmeros testes experimentais realizados em materiais sob tensão repetida e são em geral construídas usando-se escalas (mono-log) ou (log-log).

Segundo Buch (1988), no caso de metais, a curva mono-log é praticamente linear de $10^{4}$ a $10^{6}$ ciclos. Acima de $10^{7}$ ciclos, a curva é horizontal indicando que, se um espécime não romper antes de serem alcançados $10^{7}$ ciclos, então ele não irá romper depois de um número infinito de ciclos (Figura 2.3).

Deste modo, a curva S-N é usada para determinar o limite de fadiga, ou seja, o nível de tensão máximo que se pode admitir, de modo a não haver ruptura mesmo depois de um grande número de ciclos. O número de ciclos de referência para o cálculo deste nível de tensão máximo é conhecido como número básico $\mathrm{N}_{\mathrm{d}}$. 


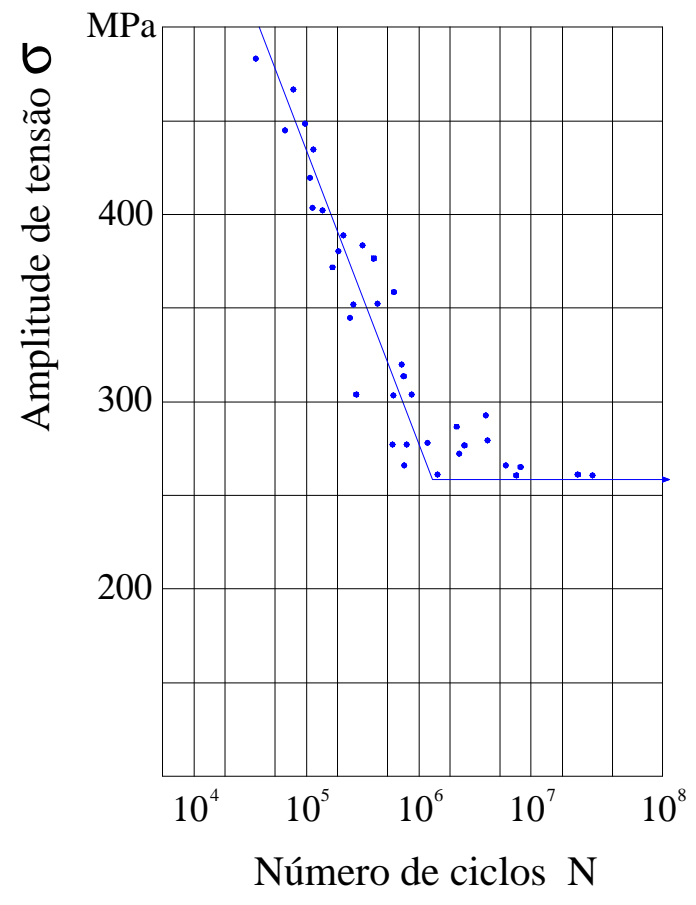

Figura 2.3. Curva S-N para metais.

Uma curva S-N completa pode ser dividida em duas porções: faixa de baixo ciclo e faixa de alto ciclo. Não há uma linha de separação definida entre as duas, devendo portanto, ser estabelecido um limite arbitrário: menos de $10^{4}$ ciclos considera-se de baixo ciclo e de $10^{4}$ ciclos até $10^{7}$ ou mais considera-se de alto ciclo. A maioria das estruturas existentes se encontram na faixa de alto ciclo (pavimentos, pontes rodoviárias e ferroviárias). $\mathrm{O}$ avanço tecnológico também tem dado lugar a estruturas que podem estar

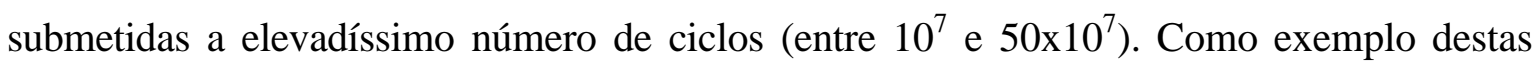
estruturas pode-se citar as estruturas marinhas (Aguado et al., 1990).

$\mathrm{Na}$ faixa de baixo ciclo a resistência à fadiga do material está perto da resistência estática. Em faixas de alto ciclo a resistência à fadiga cai progressivamente em relação à resistência estática.

Como no caso dos metais, no concreto subdivide-se a fadiga em baixo ou alto ciclo. Fadiga de baixo ciclo, que ocorre, por exemplo, em estruturas submetidas a ciclos de sismo, manifesta-se numa faixa entre 0 e $10^{3}$ ciclos; a fadiga de alto ciclo, para o caso de pavimentos de aeroportos, pontes, base de máquinas, varia entre $10^{3}$ e $10^{7}$ ciclos; e para o caso de estruturas marítimas ("off-shore") a variação está entre $10^{7}$ e $5 \times 10^{8}$ ciclos. Normalmente, os maiores problemas ocorrem para situações com elevado número de ciclos, de $10^{3}$ a $10^{8}$. 
Diferentemente dos metais, não há evidência experimental de um limite para redução da resistência com o número de ciclos. A resistência em correspondência a 10 milhões de ciclos, para compressão, tração ou flexão, é aproximadamente $55 \%$ a $60 \%$ da resistência sob solicitação estática.

Segundo Aguado et al. (1990) é possível diferenciar três intervalos de níveis máximos de tensões com comportamentos distintos no concreto sob solicitações repetidas. O primeiro intervalo caracteriza um nível de tensões até $30 \%$ da tensão de ruptura. O material se compacta ligeiramente em cada ciclo, podendo-se chegar até $10^{8}$ ciclos sem se romper. Parece, pois, que para este nível não há um limite de fadiga, ao menos para um número significativo de ciclos de carga.

O segundo intervalo corresponde a um nível de carga médio, de $30 \%$ a $80 \%$ da carga de ruptura, onde em princípio há um processo de consolidação, passando depois, de forma brusca, a uma fase de expansão que conduz rapidamente à ruptura. Finalmente, para um nível de carga elevado, acima de $80 \%$ da carga de ruptura, não se chega a produzir a fase de consolidação, iniciando a fase de expansão desde o começo, e a ruptura se processa rapidamente.

\subsubsection{Concreto em Compressão Uniaxial}

A curva S-N típica é uma representação semi-logarítmica com valores de $\sigma_{\text {máx }} /$ $f_{\mathrm{cm}}$ ao longo das ordenadas (sendo $f_{\mathrm{cm}}$ a resistência média a compressão do concreto) e o número de ciclos $N$ em escala logarítmica no eixo das abcissas.

Como testes de fadiga exibem uma razoável dispersão na determinação do número $N$ de ciclos que causam a ruptura, com dependência sobre o tipo particular de concreto estudado, normalmente associa-se às curvas uma probabilidade $P$ de ruptura em relação ao número de ciclos (Figura 2.4) 


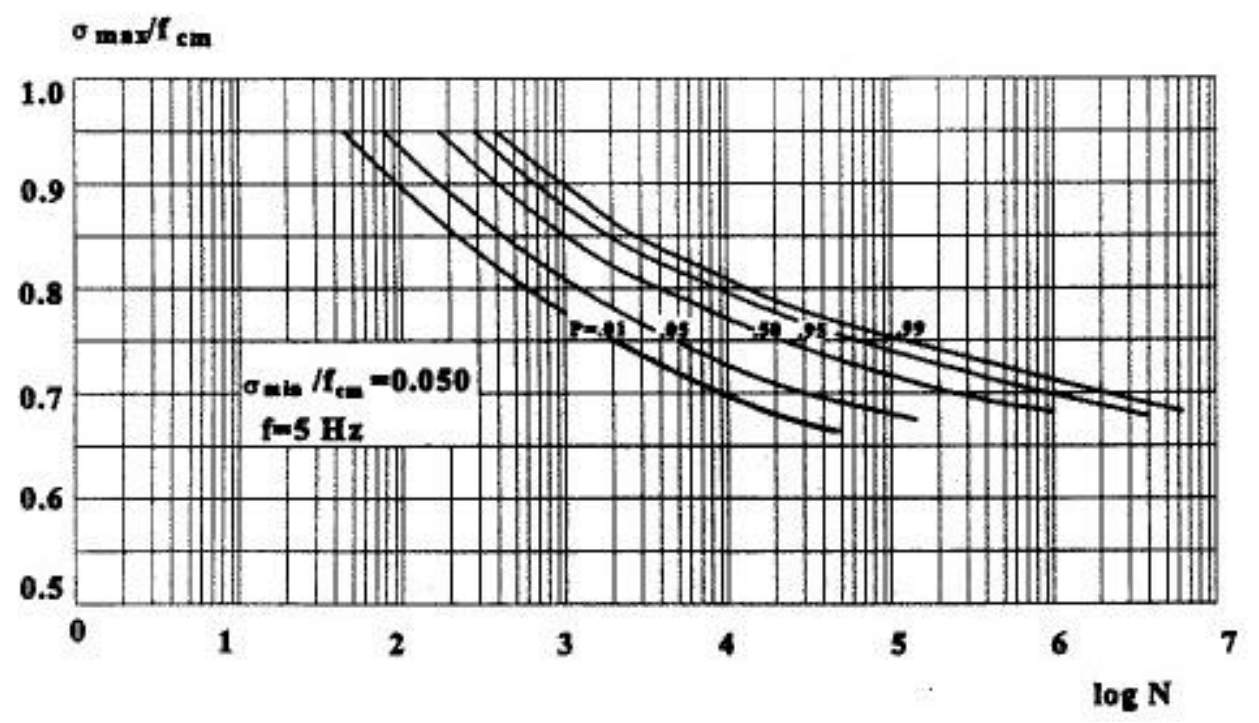

Figura 2.4. Curva S-N para concreto à compressão. (CEB, 1988)

Como se pode ver, o número de ciclos é altamente influente no fenômeno da fadiga, ou talvez, a solicitação que efetivamente vem a gerar o fenômeno, já que está diretamente relacionado com a acumulação das micro-deformações na matriz do material nas fontes de microfissuração, para distintos níveis de solicitações (Aguado et al., 1990).

A resistência à fadiga depende das tensões máximas e mínimas do ciclo. Esse efeito pode ser representado pelo diagrama de Goodman, mostrado na Figura 2.5. Observase que um aumento no nível de tensão mínima, com conseqüente diminuição da amplitude de tensão do ciclo, resulta num aumento da resistência em correspondência a um dado número de ciclos.

No caso de amplitudes variáveis, algumas conclusões indicam que os danos aumentam. Mas em presença de pequenas amplitudes, constantes ou não-constantes, há uma tendência de diminuição do dano, ou seja, pequenas amplitudes são favoráveis (Aguado et al., 1990). 


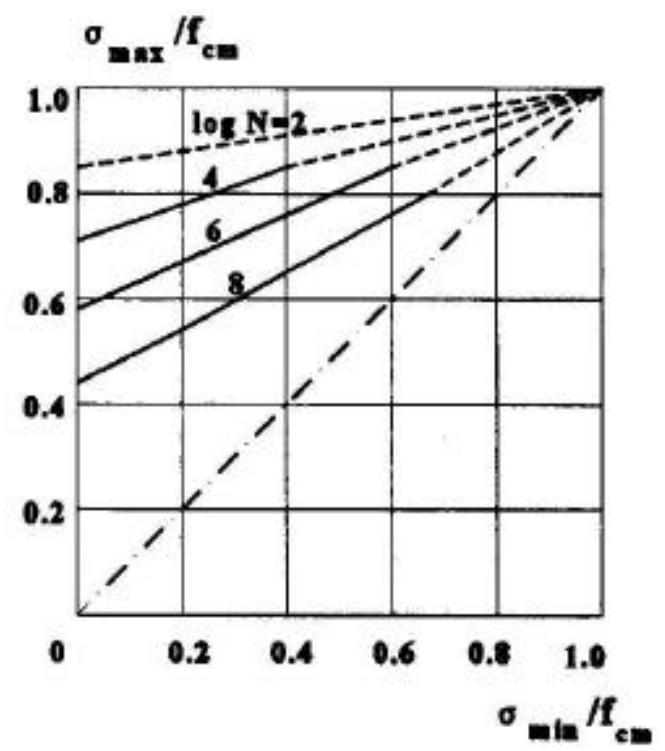

Figura 2.5. Diagrama de Goodman. (CEB, 1988)

Incluindo-se a relação entre os níveis mínimo e máximo como uma terceira variável na relação S-N, pode-se expressar o número de ciclos para ruptura em função da tensão máxima de modo que (Tepfers \& Kutti, 1979):

$$
\frac{\sigma_{\text {max }}}{f_{c m}}=1-\beta \cdot(1-R) \cdot \log N
$$

onde $R$ é dado por $\frac{\sigma_{\text {min }}}{\sigma_{\text {máx }}}$ e $\beta$ é uma constante do material que varia entre 0,064 e 0,080 .

O Fatigue of Concrete Structures - CEB (1988) cita que através de ensaios, Holmen (1979) concluiu que, a cada etapa de recarregamento, a deformação elástica aumenta progressivamente através da redução do módulo secante de elasticidade. Segundo o pesquisador, a deformabilidade transversal também é afetada, pois o coeficiente de Poisson aumenta a cada ciclo para todos os espécimes ensaiados até a ruptura. 


\subsubsection{Concreto em Tração Uniaxial}

Através da análise das propriedades do concreto exposto a tensões de tração pura pode-se estudar o comportamento da estrutura de concreto e sua tendência à fissuração sob solicitação cíclica (Driemeier, 1995).

Isto justifica-se pelo comportamento do concreto sob carga cíclica ter uma grande interdependência com a relação entre tensão e abertura de fissuras (Hordijk \& Reinhardt, 1992), sendo tal relação determinada através de ensaios de tração uniaxial com deformação controlada.

Enquanto em carregamentos estáticos faz-se distinção entre os diversos tipos de cargas, tais como compressão, tração e flexão, Hordijk \& Reinhardt (1992) acreditam que os carregamentos cíclicos apresentam qualitativamente mais ou menos os mesmos resultados para os diferentes tipos de cargas. Entretanto, Aguado et al. (1990), através de ensaios experimentais, realizaram uma comparação direta entre vigas armadas e corpos-deprova prismáticos de mesmas dimensões e qualidade do concreto da zona comprimida da viga. O resultado foi que as vigas, que romperam por fadiga do concreto comprimido, resistiram $70 \%$ de sua carga última estática durante $10^{7}$ ciclos, sendo que os prismas resistiram somente $60 \%$.

Conseqüentemente se está a favor da segurança aplicando-se valores de fadiga correspondentes a tensões de compressão centrada ao caso de zonas comprimidas de vigas à flexão.

Segundo o Fatigue of Concrete Structures - CEB (1988), testes têm mostrado que o concreto sujeito à tração apresenta a mesma equação que a apresentada para tensões de compressão:

$$
\frac{\sigma_{\text {máx }}}{f_{c t m}}=1-\beta \cdot(1-R) \cdot \log N
$$

onde $R$ é dado por $\frac{\sigma_{\text {min }}}{\sigma_{\text {máx }}}$ e $\beta$ é uma constante do material, sendo sugerido igual a 0,0685 . 


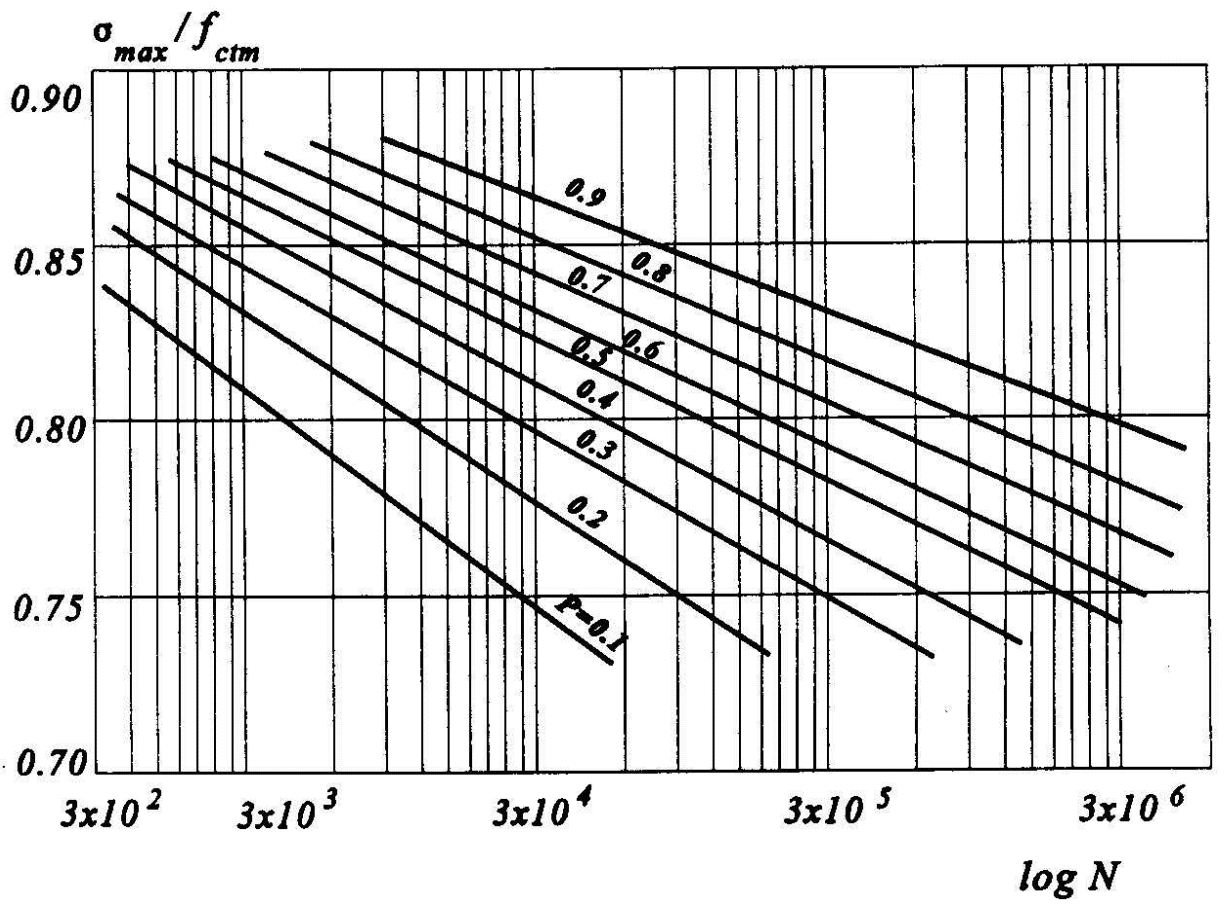

Figura 2.6. Curva S-N para concreto simples em tração. (CEB, 1988)

Porém, as curvas S-N ilustradas na Figura 2.6 referem-se a testes feitos por Saito \& Imai (1983), cujos resultados seguem a equação para uma probabilidade de ruptura de $50 \%(P=0,5)$ :

$$
\frac{\sigma_{\text {máx }}}{f_{c t m}}=-0.041 . \log N+0.987
$$

onde $\sigma_{\min }=0,08 \cdot f_{c t m}$

Ainda de acordo com o Fatigue of Concrete Structures - CEB (1988), as rigidezes variam pouco nas curvas $\sigma-\varepsilon$ para ensaios de tração cíclica com baixo nível de tensão máxima, levando a um aumento pequeno na deformação em ciclos sucessivos. Pode-se concluir que a resposta do material se caracteriza por um aumento de deformação total e residual, enquanto a deformação elástica permanece constante. Este é o comportamento esperado para baixos níveis de tensão em ensaios onde não ocorre ruptura do corpo de prova.

Apesar das curvas S-N terem grande validade do ponto de vista prático, Hordijk \& Reinhardt (1992) afirmam que tais curvas não podem explicar as causas e os mecanismos 
do comportamento do concreto à fadiga. Para obter maior conhecimento deste mecanismo é necessário estudar a base teórica do fenômeno da fadiga, que segundo os autores, baseiase no crescimento da fissuração. As fissuras iniciam-se em pontos de concentração de tensão, que podem ocorrer por falhas presentes no material, ou por descontinuidades geométricas da estrutura. Após iniciada a fissuração, sua propagação pode ser estudada com o auxílio da mecânica da fratura.

Fortalecendo o acima exposto, Aguado et al. (1990) afirmam que no concreto submetido a cargas cíclicas são produzidas deformações progressivas e permanentes, que se traduzem em um dano acumulativo. Estas deformações podem dar início a uma certa microfissuração, que se traduz posteriormente em uma progressiva propagação de fissuras, cada vez mais profundas, que, com a repetição dos ciclos de carga, reduzem a seção transversal, chegando-se finalmente à ruptura frágil do material por concentração dos esforços.

Os autores Hordijk \& Reinhardt (1992) apresentam uma curva típica do módulo de elasticidade secante $\left(E_{s}\right)$ com o número de ciclos relativo $(n / N$, onde $n$ é número de ciclos e $N$ é o número de ciclos que levam o material à ruptura) para o concreto sob a atuação de carga cíclica obtido por resultados experimentais. Esta curva pode ser visualizada na Figura 2.7.

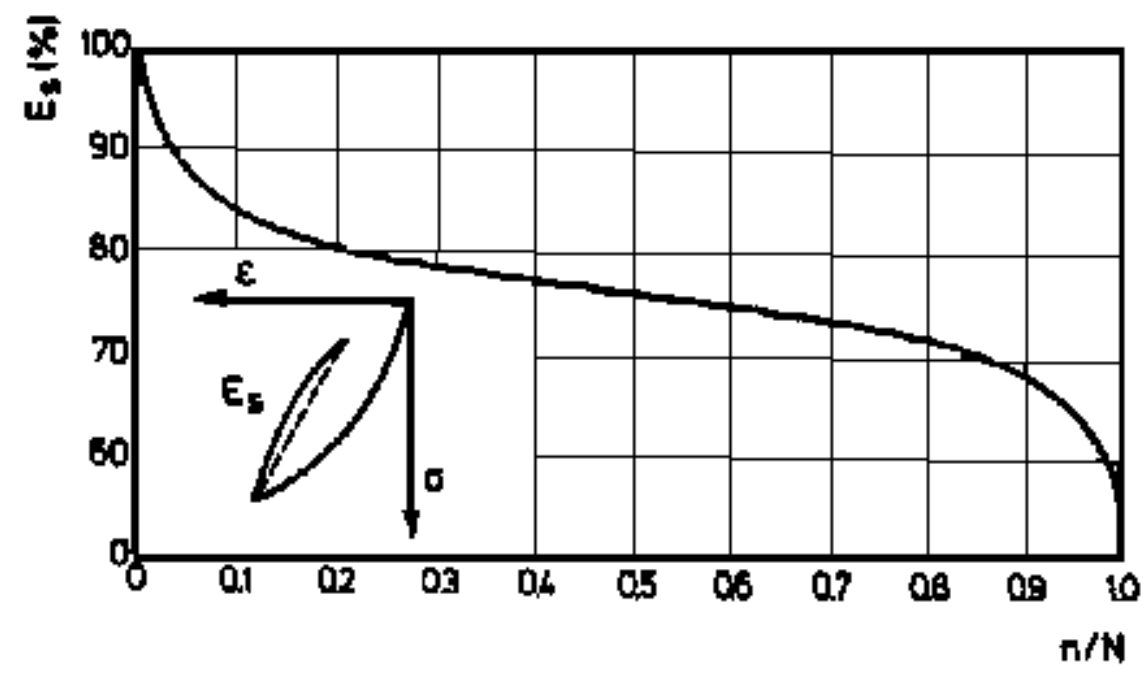

Figura 2.7. Curva típica do módulo de elasticidade secante para concreto em carga cíclica.

(Hordijk \& Reinhardt, 1992) 
Pode-se observar na figura acima que o módulo de elasticidade secante se desenvolve em três etapas distintas: primeiramente ocorre um rápido decremento, até aproximadamente $10 \%$ do total de ciclos. Em seguida o decremento do módulo de elasticidade torna-se uniforme até aproximadamente $80 \%$ do total de ciclos, e logo se produz de novo uma rápida diminuição deste módulo até a ruptura. Tal comportamento também foi confirmado por Aguado et al. (1990).

\subsection{LEIS CONSTITUTIVAS DO CONCRETO}

\subsubsection{Concreto em Compressão Uniaxial}

O comportamento típico do concreto comum submetido a carregamento cíclico de compressão é mostrado na Figura 2.8, extraído de Mehta \& Monteiro (1994). Para níveis de tensão entre 50 e $75 \%$ da tensão de ruptura, uma degradação gradual ocorre tanto no módulo de deformação como na resistência à compressão. À medida que o número de ciclos de carregamento aumenta, as curvas de descarregamentos apresentam nãolinearidades, e uma curva característica de histerese é formada no recarregamento. Para níveis de tensão próximos de $75 \%$ de tensão de ruptura, as curvas de carga e descarga apresentam uma não-linearidade acentuada (ou seja, as propriedades elásticas do material se deterioraram consideravelmente).

No início, a área da curva de histerese diminui a cada ciclo sucessivo, mas depois aumenta antes da ruptura por fadiga. A Figura 2.8 mostra que a curva tensão-deformação para carregamento monotônico é praticamente a envoltória para os valores de pico das tensões do concreto sob carregamento cíclico. 


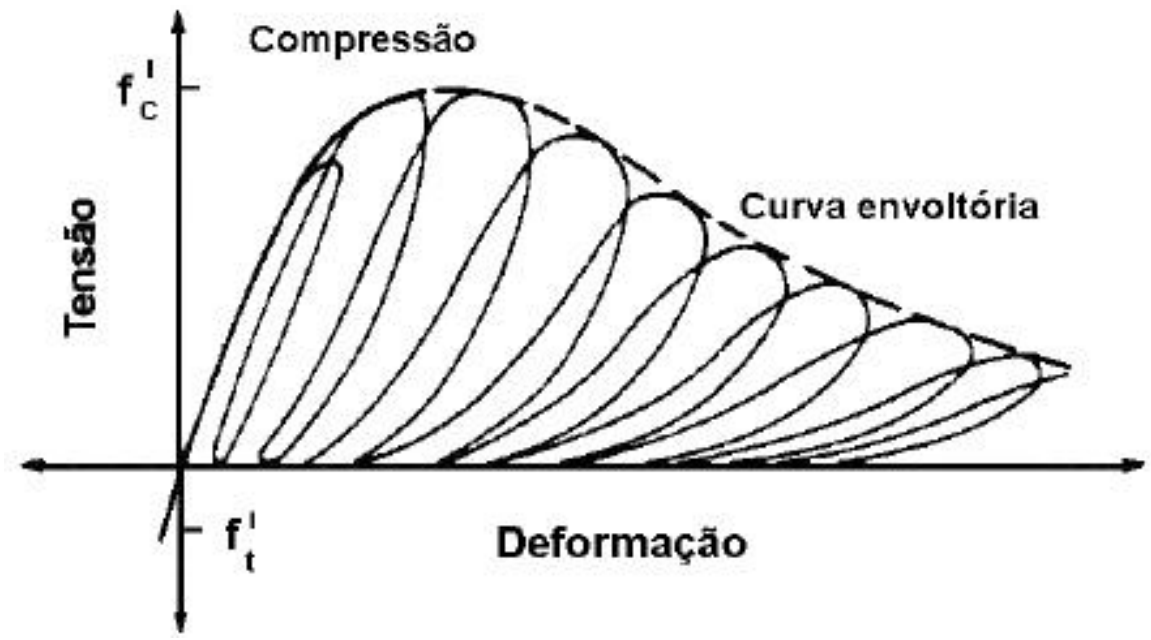

Figura 2.8. Resposta do concreto à compressão uniaxial cíclica. (Mehta \& Monteiro, 1994)

Quando um elemento de concreto é descarregado, a recuperação instantânea ou elástica é aproximadamente da mesma ordem de grandeza da deformação elástica quando da primeira aplicação da carga. Em seguida ocorre a chamada recuperação por deformação lenta que, embora ocorra mais rapidamente do que a deformação lenta propriamente dita, não é total. Uma causa da reversibilidade pode ser atribuída à deformação elástica retardada do agregado. Um aspecto de importância é a resposta do material comparando-se as etapas de recarregamento em ciclos sucessivos. A abertura de fissura e a tensão transmitida são proporcionais, com redução de rigidez (Horii et al., 1992). Além disso a tensão máxima durante o recarregamento é diminuída de $15 \%$ em média em relação à anterior. Esta degradação no processo de recarregamento é considerada, pelos autores, como fundamental no desenvolvimento da fissura.

\subsubsection{Concreto em Tração Uniaxial}

Uma relação tensão-deformação típica para o concreto em tração cíclica é apresentado na Figura 2.9. Da mesma forma que para o concreto em compressão cíclica, em tração a envoltória da curva é única também, e pode ser considerada uma propriedade do material. 


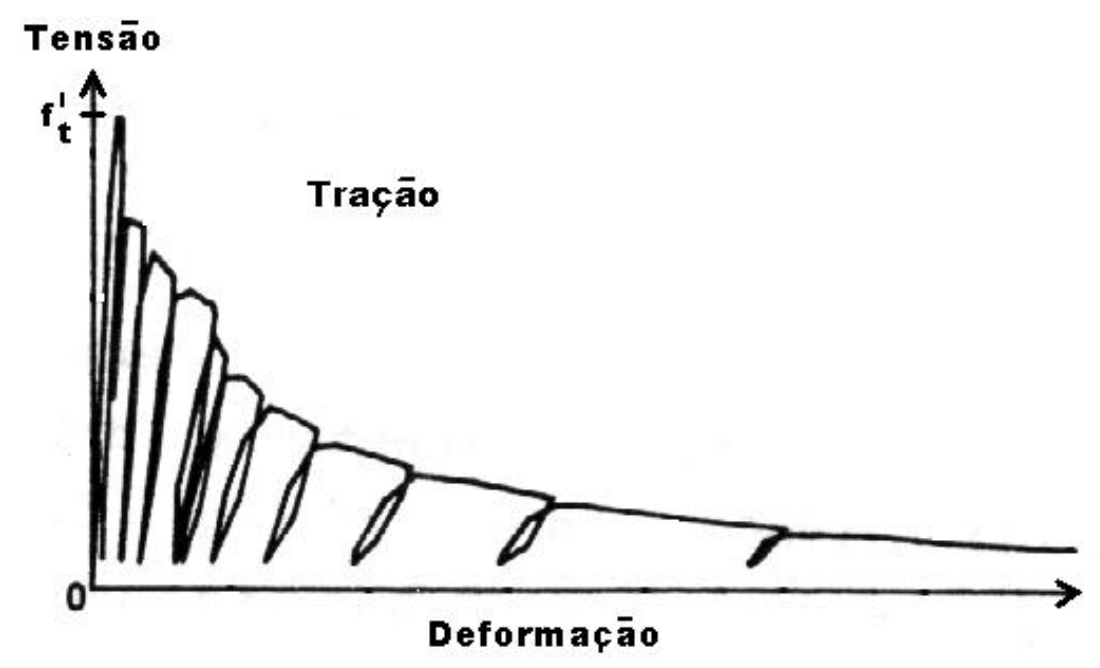

Figura 2.9. Resposta do concreto à tração uniaxial cíclica. (adaptado de Reinhardt et al, 1986)

A relação entre abertura de fissura e tensão é tão importante quanto a envoltória da curva tensão-deformação para o concreto em tração cíclica na aplicação da mecânica da fratura não-linear ao concreto. Ao redor da fissura, uma zona de micro-fissuras é formada na qual tensões podem ser transferidas dependendo da magnitude da deformação (CEB, 1988).

Segundo Aguado et al. (1990), a curva tensão deformação do concreto em tração apresenta três zonas diferenciadas, conforme se pode observar na Figura 2.9. Uma zona inicial em regime elástico, no qual a distribuição de tensões é diretamente proporcional às deformações. Uma zona seguinte, em regime anelástico, no qual há maiores deformações, maior degradação do material, e portanto, menor capacidade para absorver tensões. Esta zona caracteriza-se pelo ramo descendente do diagrama completo. É nesta zona que ocorre o início da fissuração. E por último, uma zona livre de esforços, em que a fissura já está formada, e portanto, só se poderiam transmitir tensões de compressão.

Um fato interessante a ser acrescentado é o critério de ruptura em solicitações por cargas cíclicas. Segundo análises experimentais realizadas por Hordijk \& Reinhardt (1992), a ruptura por fadiga em peças de concreto ocorre quando a curva tensãodeformação das cargas cíclicas interceptam a curva tensão-deformação da carga monotônica, conforme Figura 2.10. 


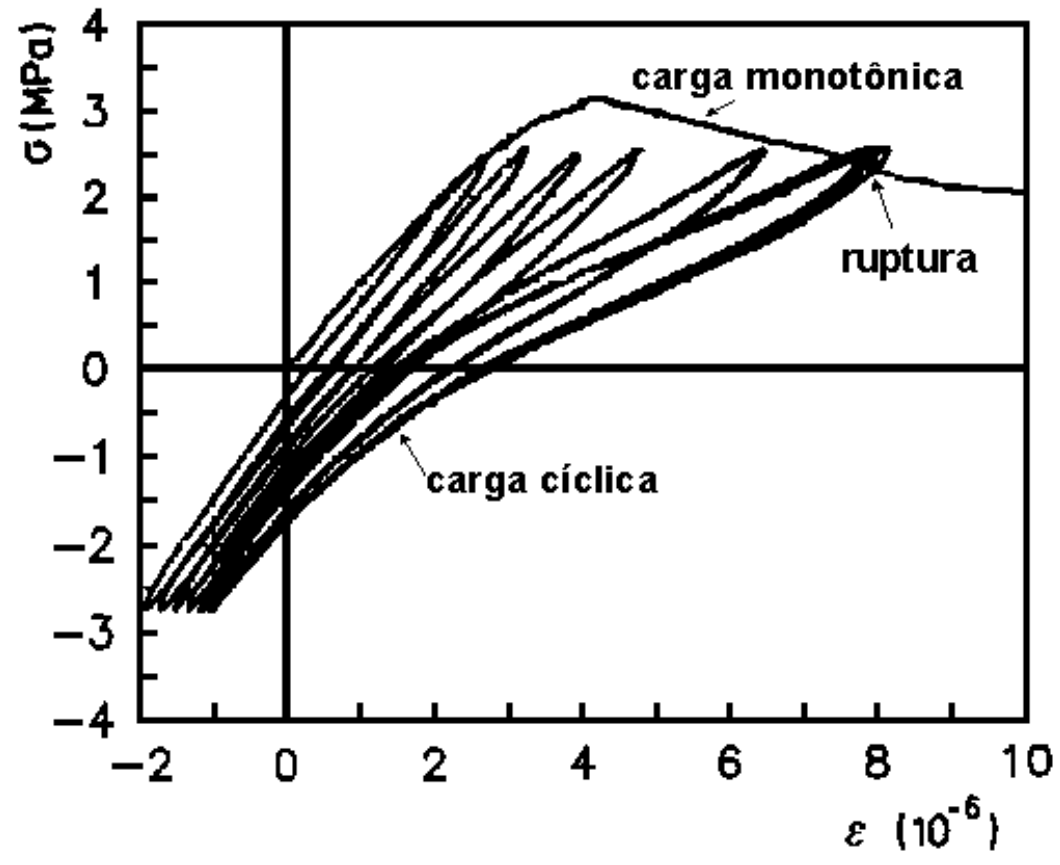

Figura 2.10. Relação tensão-deformação do concreto à tração estática e cíclica. (adaptado de Hordijk \& Reinhardt, 1992) 


\section{Capítulo 3}

\section{MECÂNICA DO DANO CONTÍNUO}

\subsection{INTRODUÇÃO}

Nos últimos anos os modelos de dano contínuo têm sido amplamente aceitos como alternativa para a simulação de comportamentos constitutivos dos materiais que apresentam perda de rigidez com a evolução da fissuração interna e o surgimento de macrofissuras, como é o caso do concreto.

Fisicamente, a degradação das propriedades mecânicas do material é resultado do surgimento e crescimento de microdefeitos, entre eles, microporos e microfissuras, oriundos dos processos de retração e cura do concreto. O desenvolvimento do dano pode ser considerado contínuo iniciando-se a partir de tensões superiores a 30\% da resistência última.

A teoria de dano contínuo está baseada na termodinâmica de processos irreversíveis e na teoria geral de variáveis internas de estado. A definição da variável de dano para o concreto deve levar em consideração fatores como a forma das fissuras, orientação, crescimento, anisotropia do material, etc., o que pode conduzir a formulações complexas, modeladas através da introdução de variáveis internas que podem ser escalares (Lemaître, 1984), ou tensoriais, indo desde uma forma vetorial (Krajcinovic, 1983), passando por tensores de segunda ordem (Kachanov, 1980) e tensores de $4^{\mathrm{a}}$ ordem (Ortiz, 1984), até, inclusive, tensores de $8^{\mathrm{a}}$ ordem (Chaboche, 1979).

Entre as distintas possibilidades que os modelos de dano contínuo oferecem, a mais simples corresponde aos chamados modelos de dano isotrópico, nos quais o comportamento não-linear do material é representado mediante uma variável de dano escalar. Graças à sua simplicidade, eficiência e aplicabilidade em muitos casos práticos, as 
formulações de dano isotrópico gozam de crescente aceitação. Isso se deve também à sua capacidade de representar as principais características do comportamento mecânico do concreto, além de estarem fundamentadas de maneira rigorosa na teoria de equações termodinamicamente consistentes.

A mecânica do dano fundamenta-se nos princípios gerais da termodinâmica e constitui-se num modelo constitutivo para materiais com defeitos em sua microestrutura. A particularidade do formalismo termodinâmico está no conjunto de hipóteses fundamentais admitidas: os processos irreversíveis são levados em conta por um número finito de variáveis internas e o estado em que se encontra o meio e a resposta que possa apresentar a um certo processo a que venha a ser submetido, dependem exclusivamente dos valores atuais das variáveis internas que o caracterizam, denominadas variáveis de estado.

O formalismo seguido pela mecânica do dano apresenta três aspectos fundamentais: a escolha das variáveis internas, a forma a ser adotada para a função de energia interna e as equações que exprimem as leis de evolução das variáveis internas.

À parte inevitáveis questionamentos relativos às considerações teóricas, particularmente sobre as simplificações adotadas, atendidos os três aspectos pode-se formular modelos constitutivos fenomenológicos, termodinamicamente consistentes e que refletem, através do conjunto de variáveis internas, os principais fenômenos físicos observados na microestrutura.

\subsection{CONCEITOS FUNDAMENTAIS}

O modelo de dano isotrópico supõe que o comportamento mecânico das microfissuras e microporos independem da orientação e dependem de uma variável escalar chamada variável de dano (ou de degradação), $d$. Assim, para um elemento submetido a um carregamento uniaxial, a variável de dano é dada por:

$$
d=\frac{A_{D}}{A}
$$

onde $A_{D}$ é área com defeitos (fissuras) e $A$ é a área total (nominal) da seção transversal (Figura 3.1). 


\section{Seção Transversal S Seção Fissurada}
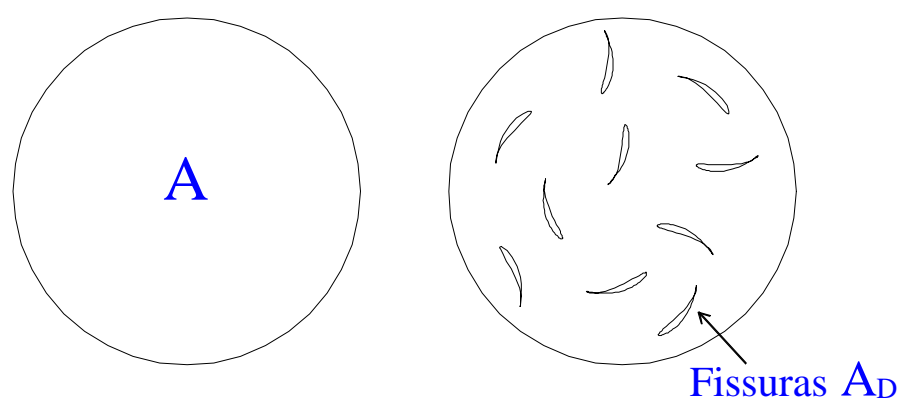

Figura 3.1 Seção transversal nominal e degradada.

O parâmetro de dano é uma variável escalar normalizada, limitada por $0 \leq d \leq 1$.

O valor $d=0$ corresponde a um estado íntegro do material $\left(A_{D}=0\right)$, ao passo que valores como $d \leq 1$ não nulos correspondem a estados degradados. Um valor $d=1$ define, a nível local, um colapso completo $\left(A_{D}=A\right)$.

Para um elemento unidimensional submetido à ação de uma força axial $\mathrm{F}$, definem-se dois valores de tensão: a tensão nominal, que está associada à área total da seção transversal, e a tensão efetiva, associada à área efetiva (sem defeitos), ou seja:

$$
\begin{array}{ll}
\sigma=\frac{F}{A} & \text { (tensão nominal) } \\
\bar{\sigma}=\frac{F}{\bar{A}} & \text { (tensão efetiva) }
\end{array}
$$

onde: $\quad \bar{A}=A-A_{D}$

Levando-se a equação (3.1) nas equações (3.2) e (3.3), têm-se:

$$
\bar{\sigma}=\frac{\sigma}{1-d}
$$

Estendendo esta teoria para o estado de tensões triaxiais, pode-se escrever:

$$
\overline{\mathbf{o}}=\frac{\text { ó}}{1-d}
$$


onde ó é o tensor de tensões de Cauchy e ó é o tensor de tensões efetivas.

Segundo a interpretação de que o parâmetro de dano é dado como a relação local entre a superfície danificada e a superfície nominal do material, Lemaître (1984) introduziu a hipótese de equivalência de deformações: "a deformação associada a um estado danificado, quando submetido à tensão aplicada, é equivalente à deformação associada ao estado inalterado, quando submetido à tensão efetiva”, conforme Figura 3.2.

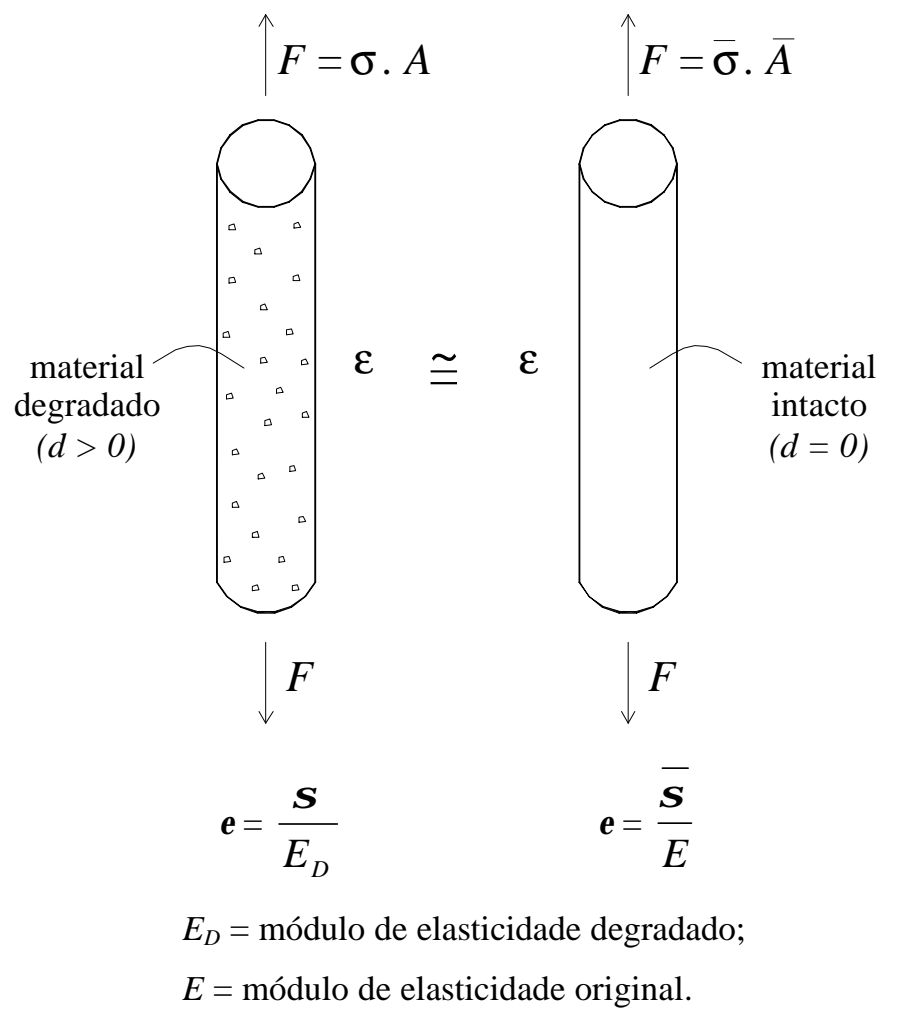

Figura 3.2. Hipótese de deformação equivalente.

Igualmente pode-se propor a hipótese de equivalência de tensões: "a tensão associada a um estado danificado, quando submetido à deformação aplicada, é igual à tensão associada ao estado inalterado, quando submetido à deformação efetiva".

E, como no caso de tensões, pode-se definir o conceito de deformação efetiva, utilizando-se a equivalência de tensões, generalizado para um estado multiaxial:

$$
\overline{\mathbf{a}}=(1-d) . \overline{\mathbf{a}}
$$


onde $\breve{a}$ e $\bar{a}$ são os tensores de deformações do material degradado e de deformações efetivas, respectivamente.

Como se pode observar, as bases dos modelos de dano consistem em definir uma transformação entre o espaço físico e um espaço fictício, chamado de espaço efetivo, onde o material está inalterado. Isso permite a utilização de modelos simples para representar o comportamento do material. A transformação de um a outro espaço se dá através das hipóteses de equivalência, já mencionadas. O conceito de tensão efetiva e a hipótese de equivalência de deformações constituem as bases dos modelos de dano formulados para deformações. Isso faz com que o modelo resultante seja particularmente adequado para sua utilização no método dos elementos finitos (MEF), baseado em deslocamentos.

Igualando-se as deformações nos dois casos da Figura 3.2, tem-se:

$$
E_{D}=(1-d) . E
$$

A partir da equação (3.7) pode-se escrever a relação constitutiva total para um modelo de dano isotrópico e estado de tensão uniaxial:

$$
\begin{aligned}
& \sigma=E_{D} \cdot \varepsilon \quad \text { ou } \\
& \sigma=(1-d) . E . \varepsilon
\end{aligned}
$$

E, generalizando-se para mais dimensões, obtém-se:

$$
\dot{\mathbf{o}}=(1-d) \mathbf{C}: \stackrel{\mathbf{a}}{=}=(1-d) \overline{\mathbf{o}}
$$

onde ó e ă são os tensores de tensões e deformações, respectivamente e C é tensor de constantes elásticas.

Segundo a equação (3.9) observa-se que a característica básica do modelo é a conservação da isotropia do material, uma vez que sua rigidez só é afetada pelo fator escalar $(1-d)$.

O modelo constitutivo definido pela equação (3.9) fica totalmente determinado se o valor do parâmetro de dano puder ser calculado para cada momento do processo de deformação. Para tal efeito, o modelo conta com as seguintes estratégias: 
- $\quad$ as deformações ou tensões são aplicadas em pequenos incrementos;

- a cada incremento verifica-se as condições de "carga", "descarga" ou "recarga" através de uma norma escalar $\tau$, do tensor de deformações, ou alternativamente, do tensor de tensões efetivas, utilizada para comparar diferentes estados de deformação;

- se $\tau$ indicar uma condição de descarga, não há aumento de degradação do material, ou seja, a variável de dano $d$ permanece inalterada;

- se $\tau$ não indicar uma condição de descarga, o material pode estar em carga ou recarga. Então, verifica-se o início do processo de deformação anelástica através de um critério de dano formulado no espaço de deformações ou de tensões efetivas;

- matematicamente, este critério pode ser escrito como uma função $F(\tau, r) \leq 0$, onde $\tau$ é a deformação equivalente e $r$ o valor limite de dano. $\mathrm{O}$ seu valor inicial, $r_{o}$, é uma propriedade do material, que é definida em função da resistência característica;

- para simular a degradação, a lei de evolução do valor limite de dano $r$ assume o maior valor da norma $\tau$ ao longo do processo de carga.

- confirmada a evolução do processo de deformação anelástica, utiliza-se uma lei de evolução para a variável de dano $d$, em função do valor limite de dano $r$. Esta lei pode ser escrita na forma incremental ou integrada, permitindo definir o processo de evolução da deformação anelástica.

A Figura 3.4 representa esquematicamente uma curva uniaxial de tensão versus deformação, distinguindo-se os ramos de carga / descarga / recarga. Observa-se que $(1-d)$ é um fator de redução da rigidez secante do material. 


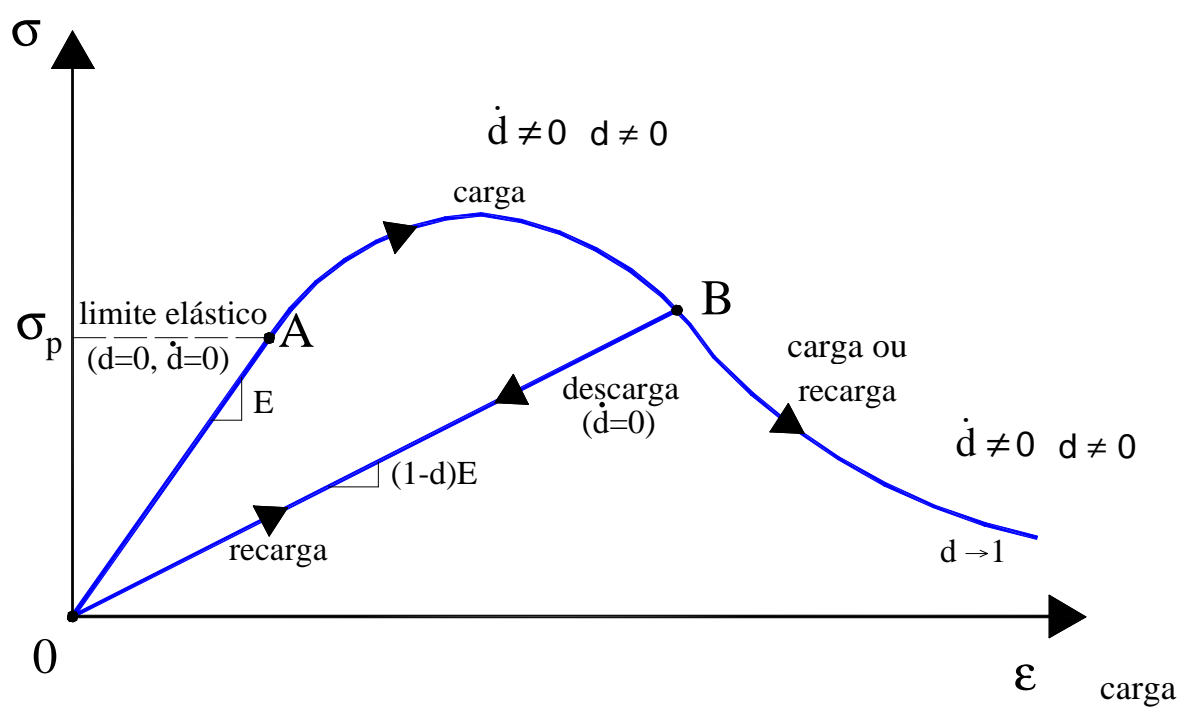

Figura 3.3. Diagrama de tensão $x$ deformação uniaxial.

O trecho $\overline{\mathrm{OA}}$ corresponde ao regime elástico linear sem evolução de dano $(\dot{d}=0)$, ao passo que o trecho $\overline{\mathrm{AB}}$ descreve o regime anelástico com evolução de dano $(\dot{d} \neq 0)$. Já os trechos $\overline{\mathrm{B} 0}$ e $\overline{\mathrm{OB}}$ correspondem, respectivamente, às situações de descarga e recarga, ambas sem evolução de dano.

O ponto sobre a variável indica a derivada com respeito ao "tempo", ou seja:

$$
(\bullet)=\frac{\partial \bullet}{\partial t}
$$

No presente trabalho trata-se apenas de problemas que não dependem do tempo. A variável $t$ nesse caso indica um pseudo-tempo relacionado ao processo de carga quaseestático e a derivada com respeito ao tempo representa a taxa de variação ao longo do processo de carga.

A definição de cada um dos elementos do modelo de dano desenvolvido neste trabalho será definido a seguir, no item 3.3. 


\subsection{MODELO CONSTITUTIVO DE DANO ISOTRÓPICO}

\subsubsection{Critério de Dano}

Com o objetivo de estabelecerem-se as condições de carga, descarga e recarga, define-se o critério de degradação, ou critério de dano, empregando-se o conceito de tensão efetiva e o critério de energia, da seguinte forma:

$$
F(\tau, r)=\tau(\overline{\mathbf{o}})-r \leq 0
$$

onde a função $\tau$ retorna um valor escalar, denominado tensão efetiva equivalente, que permite a comparação entre diferentes estados de tensões efetivas tridimensionais (ou indiretamente de deformações, já que as tensões efetivas dependem exclusivamente das deformações). A função $\tau$ deve cumprir o seguinte requisito:

$$
\tau(\alpha . \overline{\mathbf{o}})=\alpha . \tau(\overline{\mathbf{o}}), \quad \forall \alpha \in \mathrm{R}^{+}
$$

Uma norma escalar $\tau$ que satisfaz este requisito, e será empregada nos modelos formulados no presente trabalho, é o modelo proposto por Oliver et. al. (1990), onde emprega-se uma norma energética em deformações, definida como:

$$
\tau=\sqrt{\mathbf{a}: \mathbf{C}: \mathbf{a}}=\sqrt{\overline{\mathbf{o}}: \mathbf{C}^{-1}: \overline{\mathbf{o}}}=\tau(\overline{\mathbf{o}})
$$

No caso uniaxial, no qual somente intervém as componentes $\varepsilon_{\mathrm{x}}$ e $\sigma_{\mathrm{x}}$, a norma (3.12) fica reduzida a:

$$
\tau=\varepsilon_{x} \sqrt{E}=\frac{\bar{\sigma}_{x}}{\sqrt{E}}
$$

onde $E$ é o módulo de elasticidade longitudinal.

A variável interna tipo deformação $r$ estabelece o limite de dano corrente e controla a dimensão do domínio elástico no espaço de tensões efetivas, delimitado pela superfície de dano $F(\tau, r)=0$. No estágio inicial de carregamento, antes da aplicação de 
cargas, atribui-se um valor inicial $r_{\mathrm{o}}$ ao limite de dano, ou seja, $\left.r\right|_{\mathrm{t}=0}=r_{\mathrm{o}}$. Esse valor inicial é considerado uma propriedade do material e pode ser relacionada à resistência uniaxial de tração mediante (3.13):

$$
r_{o}=\frac{f_{t}}{\sqrt{E}}
$$

onde $f_{t}$ é a resistência uniaxial à tração.

Outro critério de degradação também pode ser escrito no espaço de tensões, multiplicando-se a expressão (3.10) por $(1-d)$, chegando-se a:

$$
F(\overline{\mathbf{o}}, r)(1-d)=g(\dot{\mathbf{o}}, q)=\tau(\text { ó })-q \leq 0
$$

onde $q$ é a variável interna tipo tensão, dada por:

$$
q=(1-d) r
$$

No desenvolvimento de (3.15), levou-se em conta a definição de tensão efetiva (3.9) e a propriedade da função $\tau$ (3.11).

Fazendo-se uma analogia com a teoria da plasticidade, a lei de evolução do limite de dano pode ser definida por:

$$
\dot{r}=\lambda
$$

onde $\lambda$ é o parâmetro de consistência de dano, que define as condições de carga e descarga de acordo com as relações de Kuhn-Tucker:

$$
\begin{aligned}
& \lambda \geq 0 \\
& \mathrm{~F}(\overline{\mathbf{o}}, r) \leq 0 \\
& \lambda . F(\overline{\mathbf{o}}, r)=0
\end{aligned}
$$

A relação 3.18 estabelece que: 


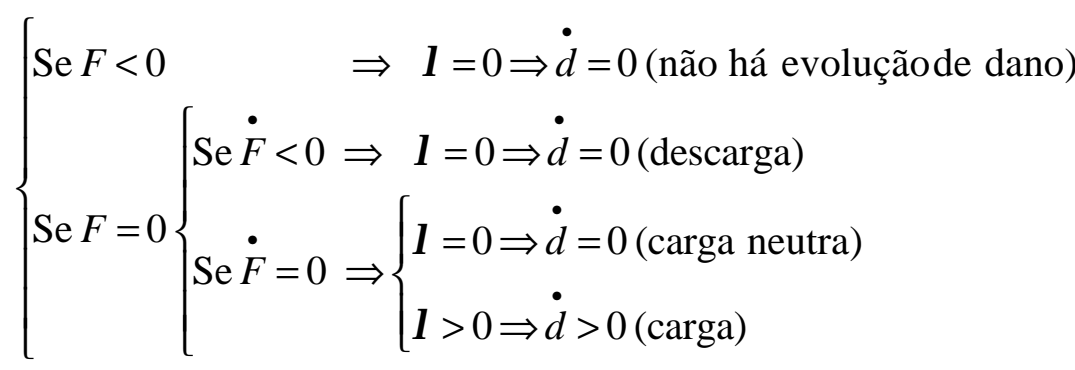

\subsubsection{Lei de Evolução da Variável de Dano}

Alguns exemplos de comportamentos segundo diferentes leis de evolução de dano são apresentados na Figura 3.4: no item (a) mostra-se um material elasto-degradável perfeito, no item (b) encruamento linear positivo (endurecimento), no item (c) encruamento linear negativo (abrandamento) e no item (d) abrandamento exponencial. A variável $H$ é chamada de módulo de endurecimento / abrandamento do material.

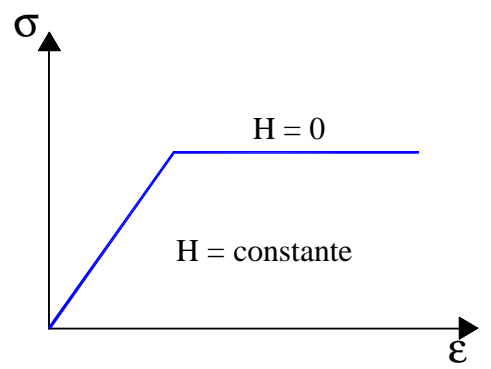

(a)

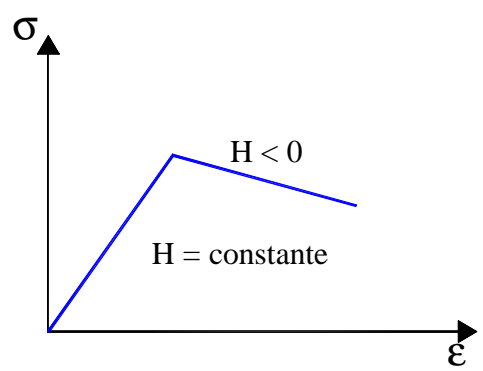

(c)

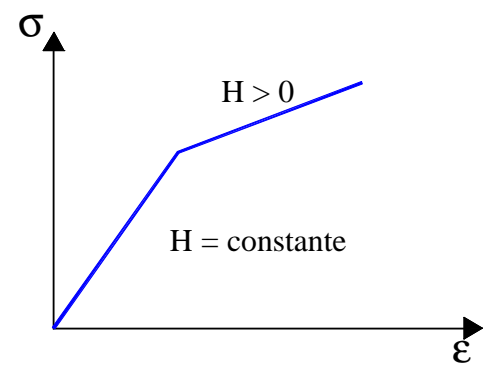

(b)

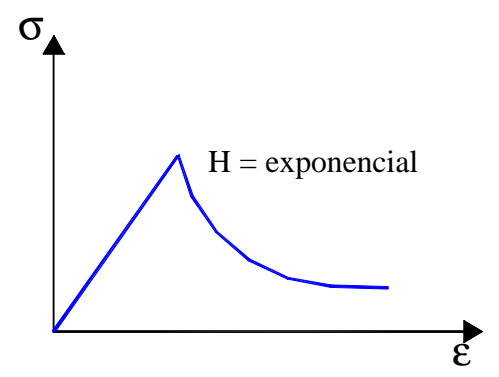

(d)

Figura 3.4. Comportamentos de distintas leis de endurecimento / abrandamento. 
$\mathrm{Na}$ teoria do dano contínuo isotrópico a regra de endurecimento pode ser descrita pela seguinte relação entre as variáveis internas do tipo tensão e deformação (Manzoli, 1998):

$$
\dot{q}=\frac{H}{1+H} \dot{r}
$$

Tendo em conta que a função $\tau$ ( ó ) é homogênea de primeiro grau, e utilizando-se da lei de evolução (3.17) juntamente com a regra de endurecimento descrita em (3.20), Manzoli (1998) obteve uma lei de evolução da variável de dano, para carregamentos monotônicos, dada pela seguinte equação diferencial:

$$
\dot{d}=\left(\frac{1}{1+H}-d\right) \frac{\dot{r}}{r}
$$

Para satisfazer os princípios da termodinâmica, o processo de deformação deve ser irreversível ( $\dot{d} \geq 0$ ), ou seja, na equação (3.21) deve-se cumprir em qualquer instante do processo de carga a seguinte limitação: $-1<H<1-d$.

É importante destacar que, mediante a relação (3.21), $H$ pode variar através de qualquer função em termos de $r$. Além disso, é possível representar o comportamento de materiais considerando que o módulo $H$ varia em função de qualquer outra variável do problema, tais como tensões, deformações, temperaturas em problemas termo-mecânicos e, inclusive, variáveis químicas em problemas termo-quimo-mecânicos. Portanto, a relação diferencial generaliza bastante as possibilidades de emprego do modelo constitutivo.

\subsubsection{Integração das Equações Constitutivas}

A variável interna tipo deformação em um determinado tempo $t$ do processo de carga, $r_{t}$, é obtida integrando-se a equação (3.17). A forma particular de evolução dessa variável estabelecida pelas equações (3.18) permite deduzir-se a seguinte expressão de evolução: 


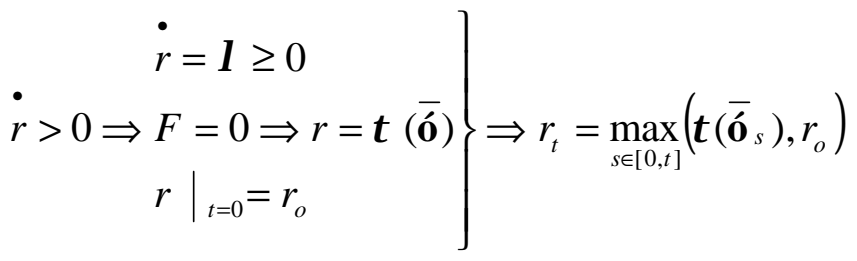

ou seja, a variável interna $r$ assume o maior valor atingido pela função $\tau(\overline{\mathbf{o}})$ ao longo do processo de carga. É importante destacar-se que, como ó depende exclusivamente das deformações, a variável $r$ é determinada em termos do tensor de deformações corrente.

No caso particular no qual o módulo de endurecimento se defina como uma função de $r$, é possível obter-se a expressão fechada da evolução da variável de dano, resolvendo-se a relação diferencial (3.21). Nesse caso, obtém-se:

$$
d(r)=1-\frac{q(r)}{r}
$$

onde:

$$
q(r)=\int \frac{H(r)}{1+H(r)} d r,\left.\quad q\right|_{r=r_{o}}=r_{o}
$$

Uma vez conhecidas as deformações $\varepsilon$, a variável interna $r$ é calculada mediante (3.22) e os valores da variável de dano e das tensões podem então ser obtidas de forma fechada diretamente das expressões (3.23) e (3.9), respectivamente.

No caso em que o módulo $H$ é considerado constante, as expressões (3.23) e (3.24) fornecem a seguinte lei de dano linear:

$$
d=\frac{1}{1+H}\left(1-\frac{r_{o}}{r}\right)
$$

Outra opção consiste em utilizar-se a seguinte expressão exponencial:

$$
H(r)=\frac{1}{1+A \cdot e^{A\left(1-\frac{r}{r_{0}}\right)}-1}
$$


onde $A$ é um parâmetro que depende da energia de fratura do material e define a forma da parte anelástica da curva tensão $x$ deformação com lei exponencial. Então, obtém-se a lei exponencial de evolução de dano sugerida por Oliver et al. (1999):

$$
d=1-\frac{r_{o}}{r} e^{A \cdot\left(1-\frac{r}{r_{o}}\right)}
$$

As leis de evolução linear e exponencial (3.25) e (3.27) são soluções analíticas particulares da equação diferencial (3.21). Observa-se facilmente que a evolução linear (3.25) satisfaz a equação (3.21) se $H=$ cte.

Inclusive é possível fazer-se uma identificação paramétrica destas variáveis experimentalmente. Observando as equações (3.7) e (3.8), se a cada passo de carga forem medidas a tensão e a deformação de um corpo de prova, o quociente da tensão pela deformação fornece o módulo de elasticidade degradado $E_{D}$, que com o módulo de elasticidade $E$ medido na fase elástico-linear fornecem a variável de dano $d$, a cada passo de carga.

\subsubsection{Implementação Numérica}

O algoritmo numérico, correspondente à forma integrada no tempo das equações constitutivas do modelo de dano conduzido pelas deformações, fornece um esquema completamente fechado de integração das tensões.

O algoritmo apresentado na Figura 3.5 esquematiza os passos para a determinação do tensor de tensões para um dado tensor de deformações em cada passo de tempo do processo de carga. Cada passo de tempo tem início no tempo $t_{n}$, no qual todas as variáveis de estado são conhecidas, e termina no tempo $t_{n+1}$, com as variáveis de estado atualizadas de acordo com o tensor de deformações dado. 
ENTRADA: $r_{n}, \boldsymbol{\varepsilon}_{n+1}$

DADOS DO MATERIAL: C $q(r), r_{o}$

\begin{tabular}{|c|l|}
\hline 1 & Calcular o tensor de tensões efetivas: $\overline{\mathbf{o}}_{n+1}=\mathbf{C}: \mathbf{a ̊}_{n+1}$ \\
\hline 2 & Calcular a tensão efetiva equivalente $(3.12): \tau_{n+1}=\tau\left(\overline{\mathbf{o}}_{n+1}\right)$ \\
\hline 3 & $\begin{array}{c}\text { Verificar se } \tau_{n+1}>r_{n} \\
\text { VERDADEIRO: } r_{n+1}=\tau_{n+1} \\
\text { FALSO: } r_{n+1}=r_{n}\end{array}$ \\
\hline 4 & $\begin{array}{c}\text { Atualizar a variável de tensão conforme }(3.24): \\
q_{n+1}=q\left(r_{n+1}\right)\end{array}$ \\
\hline 5 & $\begin{array}{c}\text { Atualizar a variável de dano de acordo com }(3.23): \\
d_{n+1}=1-\frac{q_{n+1}}{r_{n+1}}\end{array}$ \\
\hline 6 & Determinar o tensor de tensões finais: $\boldsymbol{\sigma}_{n+1}=(1-d) \overline{\mathbf{o}}_{n+1}$ \\
\hline
\end{tabular}

SAÍDA: $r_{n+1}, \sigma_{n+1}$

Figura 3.5. Modelo de dano insensível a cargas repetidas.

A fim visualizar o comportamento do modelo de dano insensível a cargas repetidas, segundo o algoritmo apresentado na Figura 3.5, foi simulada a aplicação de incrementos de deformações uniaxiais em um material com módulo $H$ constante. Estas deformações foram aplicadas conforme mostra a Figura 3.6. Aplicou-se uma deformação crescente de 0 a $1,3 \mathrm{~mm} / \mathrm{m}$ (com incrementos de $0,1 \mathrm{~mm} / \mathrm{m}$ ), então retirou-se a deformação com incrementos decrescentes até 0 . Em seguida foram reaplicados os incrementos de deformação sempre com incrementos de $0,1 \mathrm{~mm} / \mathrm{m}$. 


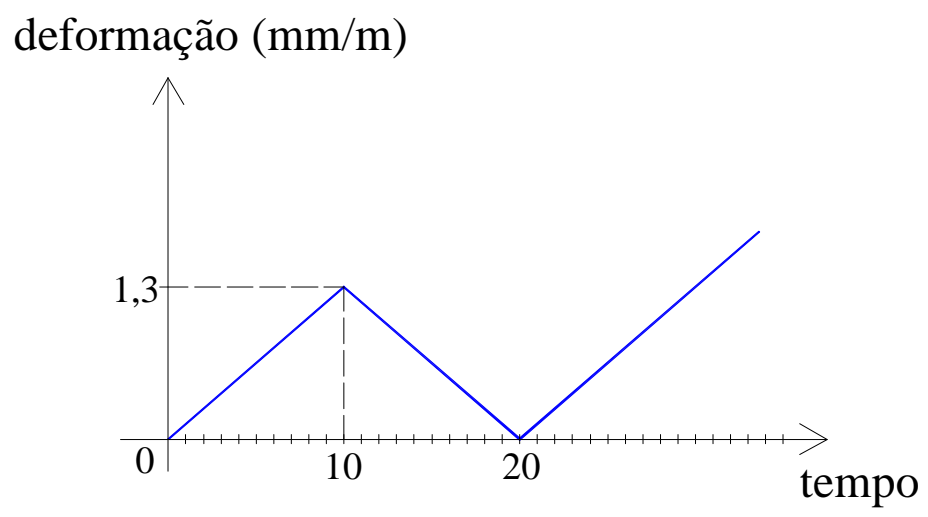

Figura 3.6. Incrementos de deformação utilizados para a simulação do modelo de dano isotrópico insensível a cargas repetidas.

Foram testados três diferentes módulos $H$ : $-0,2,0$ e $+0,2$ (encruamento linear negativo, elasto-degradável perfeito e encruamento linear positivo, respectivamente). Os diagramas tensão-deformação obtidos pelo modelo podem ser visualizados na Figura 3.7.

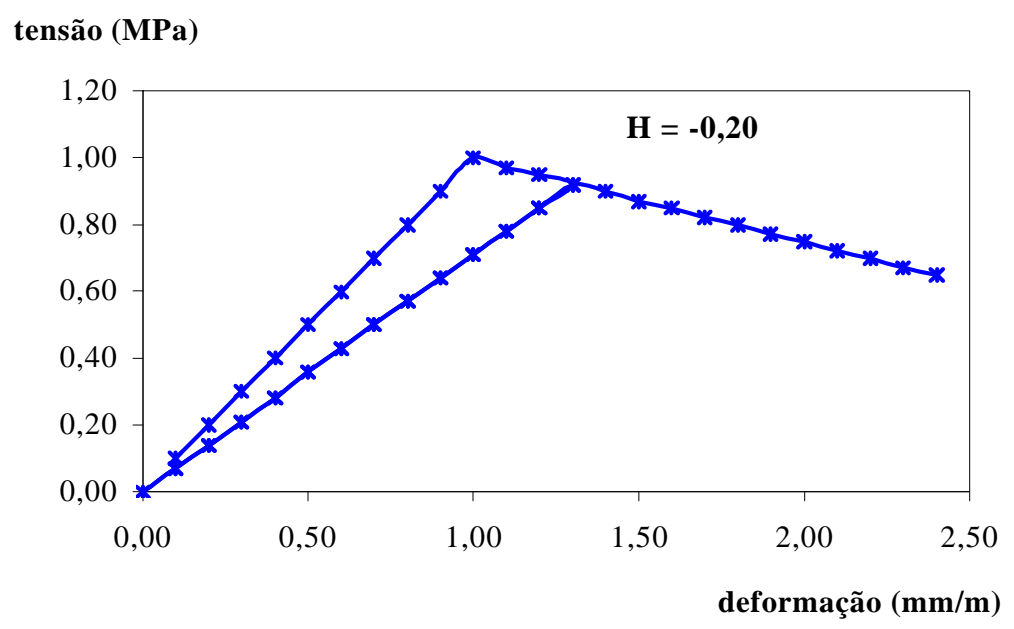

(a) encruamento linear negativo 


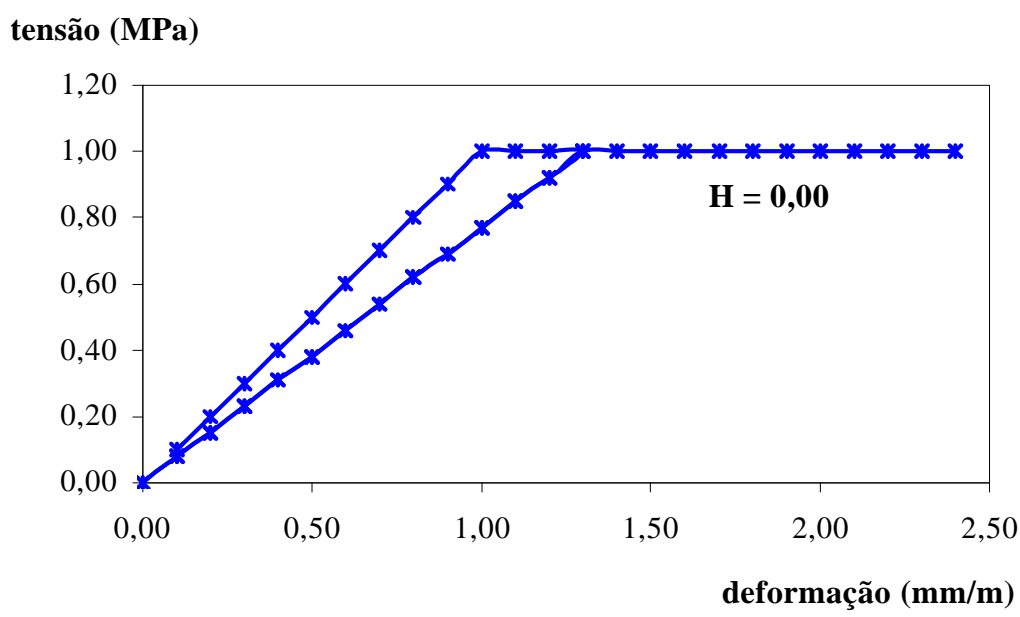

(b) elasto-degradável perfeito

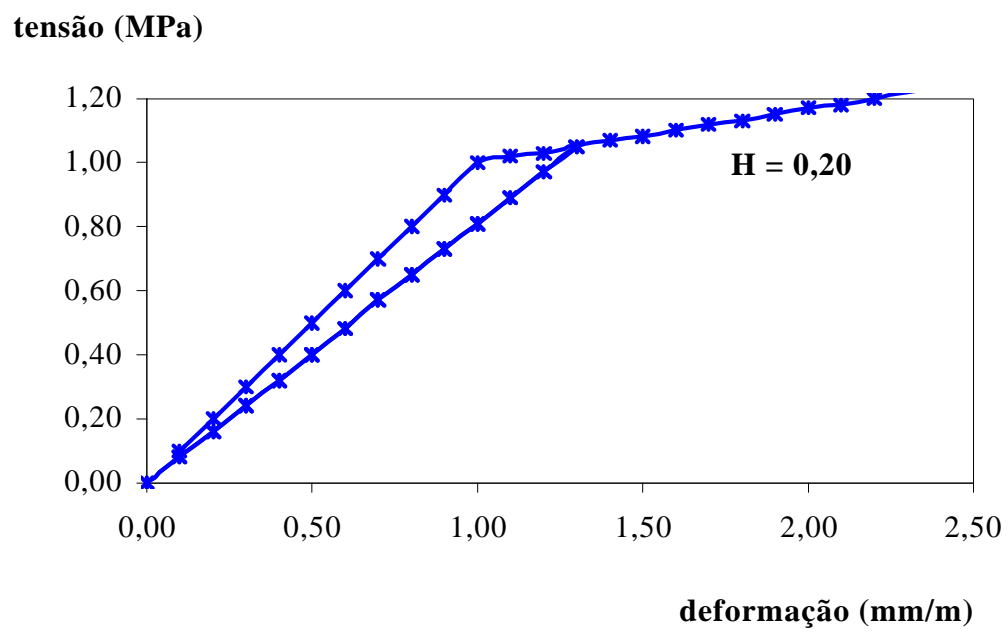

(c) encruamento linear positivo

Figura 3.7. Modelos constitutivos simulados através do modelo de dano isotrópico insensível a cargas repetidas.

\subsection{GENERALIZAÇÃO DO MODELO DE DANO PARA AÇÕES REPETIDAS}

O modelo constitutivo apresentado acima não é capaz de proporcionar acréscimo de degradação produzido por ações repetidas. Note-se que somente há evolução da degradação se a norma das deformações $\tau$ ultrapassa o maior valor atingido anteriormente. No caso de ações repetidas de amplitude constante, por exemplo, ocorreria evolução da degradação somente no primeiro ciclo de carregamento. 
Para contemplar o acréscimo de degradação por ações repetidas, propõem-se a generalização do modelo constitutivo mediante a redefinição da lei de evolução da variável de dano (3.21). Para essa finalidade, avaliam-se duas opções distintas.

\subsubsection{Lei de Evolução de Dano - Modelo 1}

Baseado na proposta de Papa et al. (1991), define-se a seguinte variação da lei de evolução de dano (3.21) para o caso de ações repetidas:

$$
\dot{d}=\left(\frac{1}{1+H}-d\right) \frac{\dot{\hat{o}}>}{\hat{o}} \phi\left(\frac{\hat{o}}{r}, d\right)
$$

onde $\langle>$ representa os parênteses de Macaulay $(\langle x\rangle=x$ se $x \geq 0$ e $\langle x\rangle=0$ se $x<0)$ e $\Psi$ é uma função crescente, tal que $\Psi(0, d)=0$ e $\Psi(1, d)=1, \forall d \in[0,1]$. A evolução da variável interna $r$ continua definida de maneira fechada por (3.22).

\subsubsection{Implementação Numérica - Modelo 1}

A relação diferencial (3.28) não pode ser integrada analiticamente como no caso anterior, mesmo que o módulo $H$ dependa somente da variável $r$. Nesse caso, a integração de (3.28) pode ser feita numericamente utilizando-se a regra de pontos centrais generalizada, na qual a variável de dano em um passo de carga $n+1$ pode ser obtida através da seguinte expressão:

$$
d_{n+1}-d_{n}=\left(\frac{1}{1+H_{\alpha}}-d_{\alpha}\right) \frac{<\tau_{n+1}-\tau_{n}>}{\tau_{\alpha}} \psi\left(\frac{\tau_{\alpha}}{r_{\alpha}}, d_{\alpha}\right)
$$

onde $H_{\alpha}, r_{\alpha}, \tau_{\alpha}$ e $d_{\alpha}$ representam, respectivamente, o módulo de endurecimento / abrandamento, o limite de dano, a norma escalar e a variável de dano calculados através de uma combinação linear entre essas variáveis no início e no final do incremento, ou seja: 


$$
\begin{aligned}
& H_{\alpha}=(1-\alpha) H_{n}+\alpha H_{n+1} \\
& r_{\alpha}=(1-\alpha) r_{n}+\alpha r_{n+1} \\
& \tau_{\alpha}=(1-\alpha) \tau_{n}+\alpha \tau_{n+1} \\
& d_{\alpha}=(1-\alpha) d_{n}+\alpha d_{n+1}
\end{aligned}
$$

sendo $\alpha$ um valor compreendido no intervalo $0 \leq \alpha \leq 1$.

Para $\alpha=0$ a equação (3.29) corresponde ao chamado forward-Euler difference scheme, na qual a variável de dano pode ser obtida explicitamente. Para $\alpha=1$ a equação (3.29) corresponde ao esquema de integração backward-Euler. Já $\alpha=0,5$ corresponde à regra trapezoidal, que em geral é incondicionalmente estável com precisão de segunda ordem, permitindo o uso de grandes intervalos de tempo do processo de carga.

No caso em que o módulo $H$ depende apenas da variável $r$, pode-se calcular $H_{\alpha}$ diretamente da lei de endurecimento:

$$
H_{\alpha}=H\left(r_{\alpha}\right)
$$

Da equação (3.29) pode-se explicitar a variável de dano atualizada, obtendo-se:

$$
d_{n+1}=\frac{d_{n}+\left[\frac{1}{1+H_{\alpha}}-(1-\alpha) d_{n}\right] \frac{<\tau_{n+1}-\tau_{n}>}{\tau_{\alpha}} \psi\left(\frac{\tau_{\alpha}}{r_{\alpha}}, d_{\alpha}\right)}{1+\alpha \frac{<\tau_{n+1}-\tau_{n}>}{\tau_{\alpha}} \psi\left(\frac{\tau_{\alpha}}{r_{\alpha}}, d_{\alpha}\right)}
$$

A Figura 3.8 apresenta o correspondente esquema de integração das tensões em um procedimento conduzido pelas deformações. 
ENTRADA: $\tau_{n}, r_{n}, d_{n}, \boldsymbol{\varepsilon}_{n+1}$

DADOS DO MATERIAL: C, $H(r), r_{o}, d_{o}=0$

\begin{tabular}{|c|l|}
\hline 1 & Calcular o tensor de tensões efetivas: $\overline{\mathbf{o}}_{n+1}=\mathbf{C}: \stackrel{\mathbf{a}}{n+1}_{n+1}$ \\
\hline 2 & Calcular a tensão efetiva equivalente $(3.12): \tau_{n+1}=\tau\left(\overline{\mathbf{o}}_{n+1}\right)$ \\
\hline 3 & $\begin{array}{c}\text { Verificar se } \tau_{n+1}>r_{n} \\
\text { VERDADEIRO: } r_{n+1}=\tau_{n+1} \\
\text { FALSO: } r_{n+1}=r_{n}\end{array}$ \\
\hline 4 & Calcular $\tau_{\alpha}, r_{\alpha}$, de acordo com $(3.31)$ e $(3.32)$, respectivamente \\
\hline 5 & Calcular $\mathrm{H}_{\alpha}$ de acordo com a lei de endurecimento: $H_{\alpha}=H\left(r_{\alpha}\right)$ \\
\hline 6 & Atualizar a variável de dano, $d_{n+1}$, de acordo com $(3.35)$ \\
\hline 7 & Determinar o tensor de tensões finais: $\sigma_{n+1}=\left(1-d_{n+1}\right) \overline{\mathbf{o}}_{n+1}$ \\
\hline
\end{tabular}

SAÍDA: $\tau_{n+1}, r_{n+1}, d_{n+1}, \boldsymbol{\sigma}_{n+1}$

Figura 3.8. Modelo de dano sensível a cargas repetidas (modelo 1).

\subsubsection{Lei de Evolução de Dano - Modelo 2}

Outra opção consiste em combinar as expressões (3.21) e (3.28). Nesse caso, a variável $r$ não é obtida pela forma fechada (3.22).

Utilizando-se a regra de pontos centrais e levando-se em consideração as definições (3.30) - (3.33), as equações (3.21) e (3.28) podem ser reescritas respectivamente por:

$$
\left\{\begin{array}{l}
R_{1}\left(r_{\alpha}, d_{\alpha}\right)=d_{n}-d_{\alpha}+\left(\frac{1}{1+H_{\alpha}}-d_{\alpha}\right) \frac{r_{\alpha}-r_{n}}{r_{\alpha}}=0 \\
R_{2}\left(r_{\alpha}, d_{\alpha}\right)=d_{n}-d_{\alpha}+\left(\frac{1}{1+H_{\alpha}}-d_{\alpha}\right) \frac{<\tau_{\alpha}-\tau_{n}>}{\tau_{\alpha}} \psi\left(\frac{\tau_{\alpha}}{r_{\alpha}}, d_{\alpha}\right)=0
\end{array}\right.
$$


As equações (3.36) perfazem um sistema de equações não-lineares em termos de $r_{\alpha}$ e $d_{\alpha}$, que pode ser resolvida numericamente pelo método iterativo de Newton-Raphson, dado por:

$$
\left\{\begin{array}{c}
r_{\alpha}^{i+1} \\
d_{\alpha}^{i+1}
\end{array}\right\}=\left\{\begin{array}{l}
r_{\alpha}^{i} \\
d_{\alpha}^{i}
\end{array}\right\}-\left[\begin{array}{ll}
\frac{\partial R_{1}}{\partial r_{\alpha}} & \frac{\partial R_{1}}{\partial d_{\alpha}} \\
\frac{\partial R_{2}}{\partial r_{\alpha}} & \frac{\partial R_{2}}{\partial d_{\alpha}}
\end{array}\right]^{-1}\left\{\begin{array}{l}
R_{1}\left(r_{\alpha}^{i}, d_{\alpha}^{i}\right) \\
R_{2}\left(r_{\alpha}^{i}, d_{\alpha}^{i}\right)
\end{array}\right\}
$$

onde $r_{\alpha}^{i+1}$ e $d_{\alpha}^{i+1}$ são uma aproximação melhorada da solução exata obtida da aproximação prévia, $r_{\alpha}^{i}$ e $d_{\alpha}^{i}$. O procedimento incremental tem início com $i=0\left(\operatorname{com} r_{\alpha}^{o}=r_{n}\right.$ e $\left.d_{\alpha}^{o}=d_{n}\right)$ e termina quando um critério de convergência pré-estabelecido é satisfeito. Uma vez obtidos os valores de $r_{\alpha}$ e $d_{\alpha}$, determinam-se os correspondentes valores atualizados no tempo $t_{n+1}$ mediante as definições (3.31) e (3.33), ou seja:

$$
\begin{aligned}
& d_{n+1}=d_{n}+\frac{d_{\alpha}-d_{n}}{\alpha} \\
& r_{n+1}=r_{n}+\frac{r_{\alpha}-r_{n}}{\alpha}
\end{aligned}
$$

A Figura 3.9 apresenta o correspondente esquema de integração das tensões para este segundo modelo, em um procedimento conduzido por deformações. 
ENTRADA: $\tau_{n}, r_{n}, d_{n}, \boldsymbol{\varepsilon}_{n+1}$

DADOS DO MATERIAL: C, $H(r), r_{o}, d_{o}=0$

\begin{tabular}{|c|l|}
\hline 1 & Calcular o tensor de tensões efetivas: $\overline{\mathbf{o}}_{n+1}=\mathbf{C}: \mathbf{a}_{n+1}$ \\
\hline 2 & Calcular a tensão efetiva equivalente $(3.12): \tau_{n+1}=\tau\left(\overline{\mathbf{o}}_{n+1}\right)$ \\
\hline 3 & Calcular $\tau_{a}$ a partir da equação (3.32) \\
\hline 4 & $\begin{array}{l}\text { Determinar os valores de } r_{\alpha} \text { e } d_{\alpha} \text { resolvendo-se o sistema não- } \\
\text { linear (3.37) }\end{array}$ \\
\hline 5 & $\begin{array}{l}\text { Calcular os valores atualizados } r_{n+1} \text { e } d_{n+1} \text { através das equações } \\
(3.38)\end{array}$ \\
\hline 6 & Atualizar a variável de dano, $d_{n+1}$, de acordo com $(3.35)$ \\
\hline 7 & Determinar o tensor de tensões finais: $\sigma_{n+1}=\left(1-d_{n+1}\right) \overline{\mathbf{o}}_{n+1}$ \\
\hline
\end{tabular}

SAÍDA: $\tau_{n+1}, r_{n+1}, d_{n+1}, \sigma_{n+1}$

Figura 3.9. Modelo de dano sensível a cargas repetidas (modelo 2).

\subsubsection{Parâmetros do Modelo Constitutivo}

A fim de representar o comportamento do concreto submetido à tração cíclica, optou-se por utilizar a lei de abrandamento exponencial $(3.26,3.27)$, que melhor se aproxima do comportamento real do concreto tracionado.

Inicialmente definiu-se a seguinte possibilidade para a função $\psi$ da equação (3.28):

$$
\psi=\left(\frac{\tau_{\alpha}}{r_{\alpha}}\right)^{M}
$$

onde $M$ seria um parâmetro constante a ser calibrado com resultados experimentais. Verifica-se que quando $M \rightarrow \infty$, recupera-se o modelo original insensível a ações repetidas. 
No entanto alguns testes preliminares indicaram que o expoente $M$ constante não representava apropriadamente as três fases do processo de fadiga observadas nos experimentos de Hordijk \& Reinhardt (1992) apresentadas na Figura 2.7. Então propôs-se a utilização de uma expressão no expoente da equação 3.39, obtendo-se a seguinte formulação para a função $\psi$, que é a formulação utilizada neste trabalho:

$$
\psi=\left(\frac{\tau_{\alpha}}{r_{\alpha}}\right)^{B\left[1-\left(1-d_{\tilde{a}}^{N}\right)\right]+C}
$$

onde $B, C$ e $N$ são parâmetros adicionais do modelo, a serem calibrados com resultados experimentais. 


\section{Capítulo 4}

\section{MODELOS TEÓRICOS E NUMÉRICOS DE PROPAGAÇÃO DE FISSURAS}

\subsection{INTRODUÇÃO}

Do ponto de vista macroscópico, a propagação de fissuras pode ser considerada como efeito do comportamento não-linear irreversível no interior de uma zona estreita onde se processa o fraturamento (fracture process zone).

$\mathrm{Na}$ simulação das zonas de fraturamento em um elemento estrutural existem dois grandes grupos de modelos: os modelos teóricos contínuos e os modelos teóricos discretos.

Os modelos teóricos contínuos consideram o meio contínuo e utilizam relações constitutivas entre tensões e deformações para representar o comportamento não-linear produzido pelas fissuras. Nesse contexto destacam-se a teoria da plasticidade e a mecânica do dano contínuo, nos quais a fissuração do material é considerada distribuída nas respectivas zonas plastificadas ou degradadas.

Já os modelos teóricos discretos consideram que o meio é descontínuo desde o início do processo de formação da fissura. Nos casos nos quais a zona de processo de fratura não pode ser negligenciada, representa-se o comportamento não-linear da zona de fraturamento mediante uma relação constitutiva do tipo discreta, entre forças superficiais (traction) e deslocamentos relativos nas faces das superfícies.

Os materiais quase-frágeis como o concreto apresentam um complexo processo de microfissuração, inicialmente difuso em todo o volume do espécime, seguido de interconexão e crescimento das microfissuras com formação de macrofissuras (Mazars \& Bazant, 1989). Uma simulação mais realista da propagação de fissuras neste tipo de material seria uma modelagem que combinasse as teorias contínuas e discretas. Primeiro o 
material fissura sobre uma larga zona de fraturamento. Mais tarde as fissuras localizam-se numa zona relativamente pequena, que se propaga através da estrutura. Este tipo de transição da fissura é caracterizado pelo progressivo desenvolvimento da degradação do material, principalmente na forma de microfissuras distribuídas que se unem numa fratura distinta somente no fim do processo de fraturamento.

Ambas as famílias de modelos, baseadas na mecânica da fratura ou na mecânica do contínuo, são desenvolvidas para diferentes pontos de partida, freqüentemente, em diferentes ambientes de pesquisa. Isto resulta em uma falta de conexões teóricas e fundamentais entre elas. Entretanto, algumas tentativas para unir uma a outra já foram feitas (Oliver et al., 2002).

A aproximação de descontinuidades fortes proposta originalmente por Simó et al. (1993) estabelece as condições necessárias para que relações constitutivas do contínuo (entre tensões e deformações) sejam compatíveis com descontinuidades no campo de deslocamentos, estabelecendo assim as bases para a conexão entre as teorias contínuas e discretas.

Nesse capítulo são descritos as principais características, os campos de aplicação e as particularidades de cada modelo teórico no que se refere à correspondente formulação numérica da propagação de fissuras pelo MEF.

\subsection{MODELOS TEÓRICOS DISCRETOS}

Os modelos discretos consideram a zona de processo de fraturamento como uma superfície de descontinuidade no campo de deslocamentos, conhecida como superfície de descontinuidade forte. Os principais modelos deste grupo são os modelos da mecânica da fratura linear elástica e os modelos de fissura fictícia ou coesiva (Hilleborg, 1984).

\subsubsection{Mecânica da Fratura Linear Elástica}

A mecânica da fratura é a ciência que define a base racional para o cálculo da resistência de estruturas com descontinuidades iniciais e permite a determinação das taxas de propagação das mesmas. 
A mecânica da fratura linear estuda as condições do estado de tensões necessárias para ocorrer a propagação de uma fissura já existente, considerando o material como elástico-linear, negligenciando-se a zona não-linear na ponta da fissura (zona ativa), esquematizada na Figura 4.1. Nos modelos de fratura linear elástica, considera-se que a partir do momento que o estado de tensões na ponta da fissura alcança a condição de propagação, a fissura propaga mais um pouco e não existe nenhum tipo de interação entre as faces na fissura formada (zona inerte).

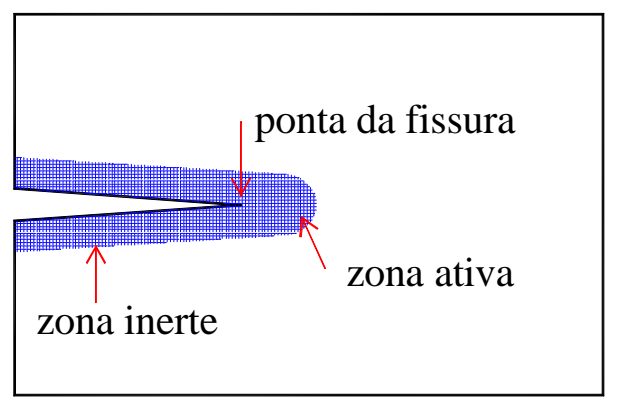

Figura 4.1. Propagação de fissuras na mecânica da fratura.

A mecânica da fratura linear não é diretamente aplicável para modelar concreto, rocha, cerâmica e outros materiais quase-frágeis nos quais, na verdade, antes da formação da fissura ocorre uma região não-linear na zona frontal da fissura, fazendo com que o material tenha suas propriedades elásticas alteradas. Para simular esse comportamento nãolinear anterior à formação da fissura real, surgiram os modelos de fissura coesiva, que consideram uma interação coesiva entre as faces da descontinuidade. Por isso são também chamados de modelos de fissura fictícia. Alguns autores consideram que o modelo coesivo corresponderia à mecânica da fratura não-linear.

\subsubsection{Modelos de Fissura Coesiva}

O modelo de fissura coesiva tem sido empregado para representar o comportamento do material do tipo quase-frágil frente ao processo de fraturamento. Em Hillerborg et al. (1976), o modelo é testado em ensaios laboratoriais, utilizando-se corpode-prova homogêneo e de área constante, solicitado até a ruptura. É definida uma zona de fratura (ou zona de processo) com largura limitada na direção da tensão. Esta zona de 
fratura perde gradualmente suas propriedades mecânicas à medida que o dano causado pelo surgimento de microfissuras aumenta e, portanto, tem-se um comportamento de material coesivo.

Da mesma forma, em Carpinteri (1989) são encontrados novos experimentos e análise através de modelagem numérica, constituindo-se em uma referência importante sobre o assunto.

O modelo de fissura coesiva apresentado por Hillerborg et al. (1976) é recomendado para os casos onde a zona plástica (ou zona de processo) é suficientemente fina a ponto de se poder representá-la por uma superfície sem que isso ocasione perda de precisão. A idealização do modelo é apresentada na Figura 4.2.

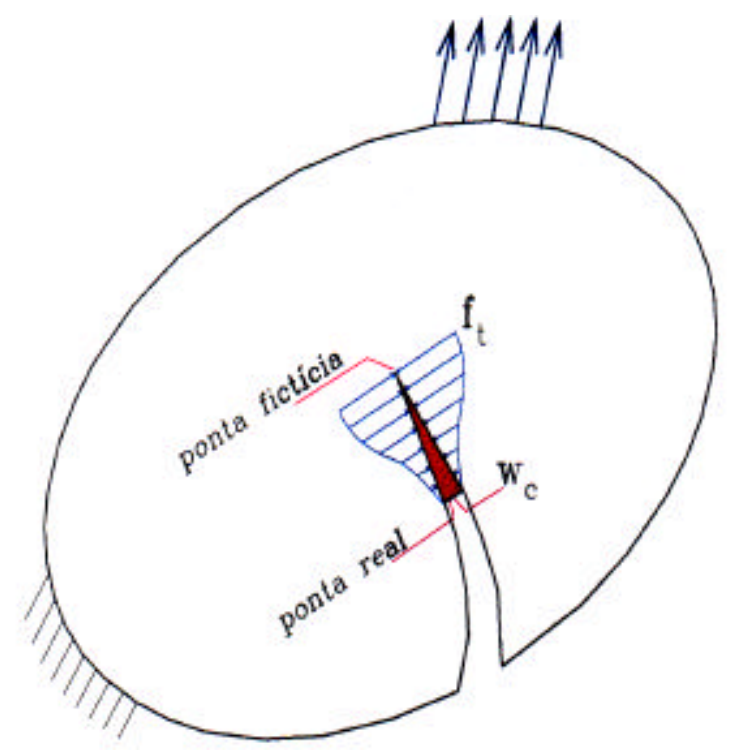

Figura 4.2. Modelo idealizado de distribuição de tensões na zona coesiva. (Barbirato, 1999)

Definem-se duas extremidades para a fissura: a real, localizada no ponto onde o valor crítico da abertura da fissura $w_{c}$ é atingido, sendo nula a tensão normal à superfície da fissura; e a fictícia, definida no ponto onde a tensão normal atinge o seu valor máximo $f_{\mathrm{t}}$, onde a abertura da fissura é nula.

O modelo de fissura coesiva baseia-se na linearidade geométrica, sendo o material considerado homogêneo e elástico linear, exceto na superfície de fraturamento. A zona de fissura coesiva ou zona de processo somente inicia seu desenvolvimento quando a tensão principal máxima atinge a resistência à tração do material, $f_{\mathrm{t}}$ 
Neste instante o material da zona de processo está parcialmente danificado, mas ainda consegue transmitir tensões. Quando a abertura da fissura atinge o deslocamento $w_{\mathrm{c}}$, o material não mais transmite tensões. Admite-se que a resistência do material sofre uma contínua redução até o valor zero, quando o comprimento da abertura da fissura chegar no seu valor limite $w_{\mathrm{c}}$.

\subsubsection{Simulação Numérica de Modelos Discretos pelo MEF}

Uma forma de simular numericamente os modelos discretos no âmbito dos elementos finitos consiste em considerar os lábios da descontinuidade como contornos adicionais do meio contínuo (ver Figura 4.3).
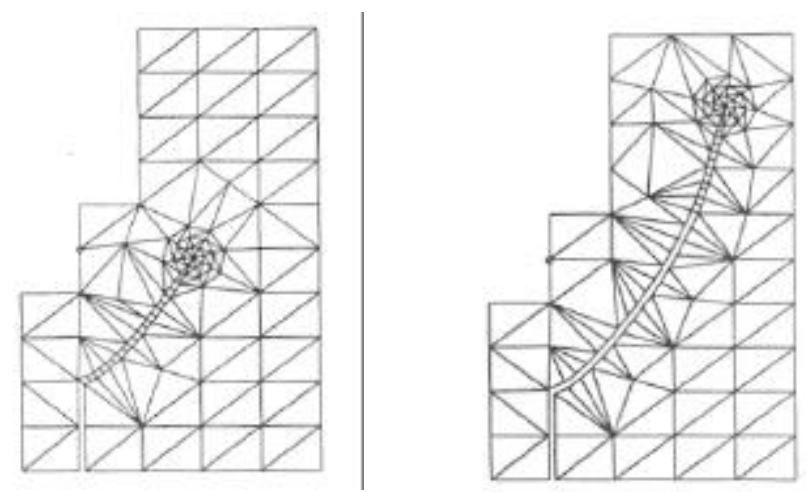

Figura 4.3. Malhas de elementos finitos adaptadas à fissura em distintos instantes do processo de carga. (Bocca, Carpinteri \& Valente, 1991)

O modelo de fissura coesiva emprega elementos especiais de interface entre os elementos finitos, que estabelecem a relação entre tensões e deslocamentos relativos entre os elementos que se separam.

O problema deste modelo de fissura coesiva com interface é a necessidade de saber a posição da fissura antes da análise para introduzir os elementos de interface no lugar certo. Mas, nos casos gerais a posição da fissura não é conhecida e é justamente o que se procura saber. Pode-se utilizar um processo de reconstrução da malha de elementos finitos. À medida que a fissura vai propagando o processador coloca os elementos de interface, mas isto é muito complexo e exige um esforço computacional elevado. 
Com o propósito de evitar o processo de reconstrução da malha de elementos finitos, desenvolveram-se os chamados elementos com descontinuidade incorporada (embedded discontinuity elements), que permitem a introdução de interfaces descontínuas em qualquer posição no interior do elemento. No trabalho de Jirásek (2002) encontra-se uma revisão detalhada das diversas formulações existentes de elementos finitos com descontinuidade incorporada.

\subsection{MODELO TEÓRICO BASEADO NA MECÂNICA DE MEIOS CONTÍNUOS}

Diferentemente dos modelos discretos baseados nos conceitos de fissura coesiva, os modelos baseados na mecânica do contínuo utilizam os conceitos macroscópicos de tensão e deformação também para representar o processo de fraturamento. A zona de processo de fraturamento associa-se à localização de deformações, já que o campo de deslocamentos permanece contínuo.

A hipótese de continuidade do meio não faz, obviamente, referência à estrutura interna do material, mas tem um papel fundamental na modelagem teórica. A partir dela definem-se conceitos como tensão e deformação, associados a pontos materiais. Esses conceitos não aparecem somente nas formulações teóricas, freqüentemente eles são quantificados em laboratório, de forma direta ou indireta, nas medidas de deslocamentos e de deformações.

Entretanto é importante observar que os mecanismos físicos reais de deformação, e de ruptura, ocorrem em escalas inferiores (micro e média escalas) àquela que permite interpretar o meio como contínuo (macro-escala).

Bazant \& Oh (1983) formularam o modelo de fissura em banda onde é empregado um modelo constitutivo contínuo entre tensões e deformações, considerando-se a região não-linear onde se processa a fissura como contínua e correspondente a uma banda estreita na região frontal da fissura (na ponta da fissura). No modelo em banda o comportamento não-linear antes da abertura da fissura real pode ser simulado com elementos finitos normais, que vão perdendo suas características elásticas até degradar inteiramente (softening).

De acordo com a teoria clássica da mecânica do contínuo, o fenômeno de localização corresponde à concentração de deformações anelásticas em bandas delimitadas 
por duas superfícies paralelas, ao longo das quais se produz uma descontinuidade no campo de deformações. A formação destas superfícies de descontinuidade, que se denominam superfícies de descontinuidade fraca, deve-se à perda de elipticidade local das equações de equilíbrio incrementais (bifurcação descontínua), caracterizada pela singularidade do tensor de localização. Para elasto-plasticidade clássica, local e independente da velocidade (rate independent), a singularidade do tensor de localização pode ocorrer quando se considera um regime de abrandamento de tensões (softening) e/ou regras de fluência não-associadas. O mesmo também pode ser dito para algumas famílias de modelos de dano contínuo, conforme estudos realizados por Manzoli e co-autores (Manzoli et al. 1999).

\subsubsection{Simulação Numérica de Modelos Contínuos pelo MEF}

A teoria clássica da mecânica do contínuo não estabelece um limite para o valor da largura da banda de localização, ou seja, não contém uma longitude intrínseca. Em decorrência disso, a forma mais estável de localização corresponde a formação de bandas de largura nula.

Dentro do contexto das aproximações numéricas por elementos finitos, as interpolações usuais das variáveis do problema geram campos de deformações contínuos no domínio do elemento. Esta restrição cinemática impõe que a superfície de descontinuidade fraca somente pode desenvolver-se nas interfaces entre elementos e, portanto, o domínio de um elemento corresponde à mínima dimensão que a largura da banda pode assumir. Em decorrência dessa limitação numérica, a resposta deixa de ser objetiva, podendo mudar substancialmente de acordo com o tamanho e a orientação dos elementos utilizados na discretização do domínio. Com o objetivo de minimizar os problemas de dependência da malha, foram desenvolvidas algumas técnicas que buscam capturar a banda de localização através de processos de reconstrução adaptável da malha ou mediante enriquecimento das funções interpoladoras do elemento. No sentido de conseguir objetividade com respeito ao tamanho dos elementos finitos, destacam-se as chamadas aproximações de fissura distribuída (smeared crack approach), nos quais a lei de abrandamento do modelo constitutivo é definida em função do tamanho do elemento e da energia de fratura (Manzoli, 1998). 


\subsection{APROXIMAÇÃO DE DESCONTINUIDADES FORTES}

\subsubsection{Introdução}

No trabalho pioneiro de Simó, Oliver \& Armero (1993) ficou demonstrado que, a partir de certas hipóteses, o modelo teórico discreto pode ser considerado como um caso limite do modelo teórico contínuo, quando a largura da banda de localização tende a zero, transformando-se em superfície (ou linha em 2D) de descontinuidade forte. Nessas condições, o campo de deformações adquire característica distribucional (é representado mediante a distribuição de Dirac), deixando de ser limitado ao longo da superfície de descontinuidade.

Segundo Oliver et al. (2002), do ponto de vista da modelagem mecânica, após o aparecimento das chamadas descontinuidades fortes, a capacidade última de carregamento e a integridade estrutural são fatalmente afetadas. Modelar o momento em que se inicia e a propagação das descontinuidades fortes tem se tornado um assunto importante na mecânica dos sólidos.

Antes do modelo de Simó, Oliver \& Armero (1993) somente era possível simular descontinuidade forte com o emprego de modelos discretos de fissura coesiva. A necessidade de se tratar o processo de formação e propagação das descontinuidades conduziu ao desenvolvimento da mecânica da fratura não-linear, essencialmente baseada na introdução de equações constitutivas discretas na interface da descontinuidade dentro de um meio contínuo elástico.

As principais características das aproximações de descontinuidades fortes são o uso de equações constitutivas contínuas padrão (tensão-deformação), não-linear e equipado com "softening" em deformação; a consideração das cinemáticas das descontinuidades fortes, isto é, cinemáticas descontínuas induzidas pelo aparecimento de saltos no campo de deslocamentos (as deformações são funções de delta de Dirac ilimitado) em formato de cinemática contínua; as análises matemáticas são dedicadas a manter a compatibilidade daquelas equações constitutivas contínuas com a cinemática de descontinuidades fortes (Oliver et al., 2002). 
Em recentes trabalhos (Oliver, Cervera \& Manzoli, 1998, 1999; Manzoli, Oliver \& Cervera, 1999; Oliver et al., 2002) propõe-se um mecanismo de formação de descontinuidade forte no qual a banda de localização de deformações tem sua largura, $h$, diminuída gradualmente até degenerar-se em uma superfície (ver Figura 4.4). Nesses trabalhos, consolida-se a conexão entre os modelos teóricos contínuos e discretos em meios elasto-plásticos e elasto-degradáveis (dano contínuo). Uma das principais conclusões obtidas nesse sentido é que em regime de descontinuidade forte (quando a largura da banda tende a zero), a relação constitutiva entre tensões e deformações que rege o comportamento da parte contínua, transforma-se automaticamente em uma relação do tipo discreta entre tensões e deslocamentos relativos nos lábios da descontinuidade (Figura 4.4). Isso fornece procedimentos para generalizar a aplicação de modelos constitutivos padrão além do contínuo, alcançando as aplicações típicas da mecânica da fratura.

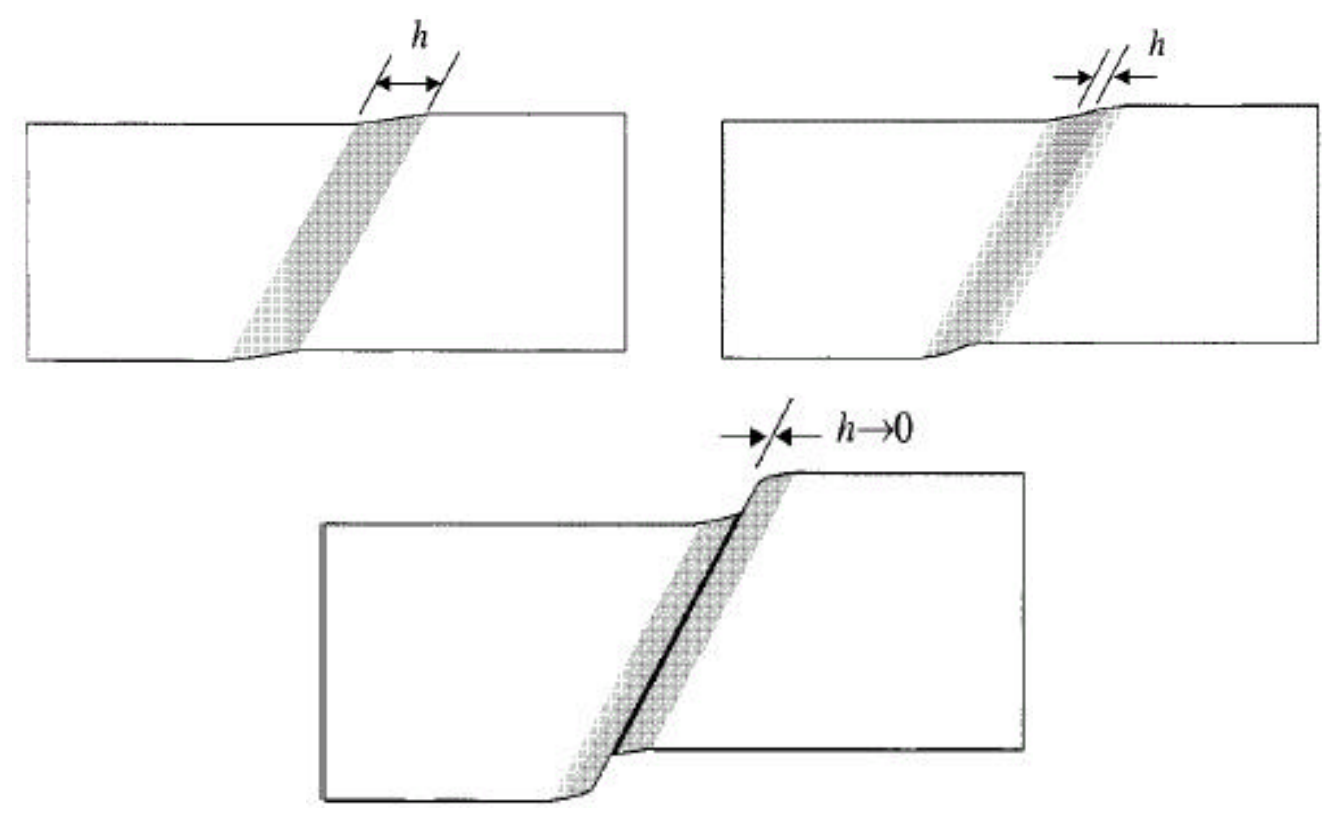

Figura 4.4. Evolução do colapso de uma descontinuidade fraca $(h \neq 0)$ em uma descontinuidade forte $(h \rightarrow 0)$. (Oliver, 2000; Manzoli et al., 1999)

De fato, o comportamento real dos materiais granulares sugere a existência de localização numa banda de largura inicial finita que progressivamente degenera num plano. Nos primeiros estágios de carregamento, o crescimento de microfissuras se dá de modo distribuído sobre o volume e, a partir de determinado nível, verificadas certas condições críticas, a danificação localizada numa faixa de largura finita prevalece. Com a evolução 
do processo, a largura da faixa em que o dano evolui diminui progressivamente tendendo a um plano de fratura.

\subsubsection{Aproximação de Descontinuidades Fortes pelo MEF}

Nos referidos trabalhos que abordam a aproximação de descontinuidades fortes, indica-se a formulação do método dos elementos finitos baseada no método das deformações melhoradas, proposto por Simó \& Rifai (1990) para representar o processo de colapso estrutural por localização, sem a necessidade de técnicas de adaptação da malha de elementos finitos e sem os problemas de dependência da malha. Essa formulação permite a simulação de descontinuidade no campo de deslocamentos usando os conceitos da mecânica do contínuo. De acordo com o trabalho recente de Jirásek (2002), esse tipo de formulação pertence às chamadas formulações de elementos com descontinuidade incorporada.

\subsection{MODELAGEM DE FADIGA}

\subsubsection{Modelo Discreto de Fadiga}

Utilizando-se modelos baseados no conceito de fissura coesiva para cargas monotônicas, estabelecido por Hillerborg et al. (1976), Hordijk \& Reinhardt (1992) fizeram um estudo de fadiga em concreto. $\mathrm{O}$ modelo considera que o crescimento da fissura pode ser representado mediante uma relação entre a tensão coesiva, $\sigma$, e a abertura dos lábios da descontinuidade, $w$. O efeito do acúmulo de degradação pode ser introduzido através do acréscimo da abertura em um ciclo de descarga-recarga (Figura 4.5). Conforme observado em experimentos, a envoltória da curva $\sigma-w$ cíclica deve coincidir com a curva correspondente para ação monotônica. 


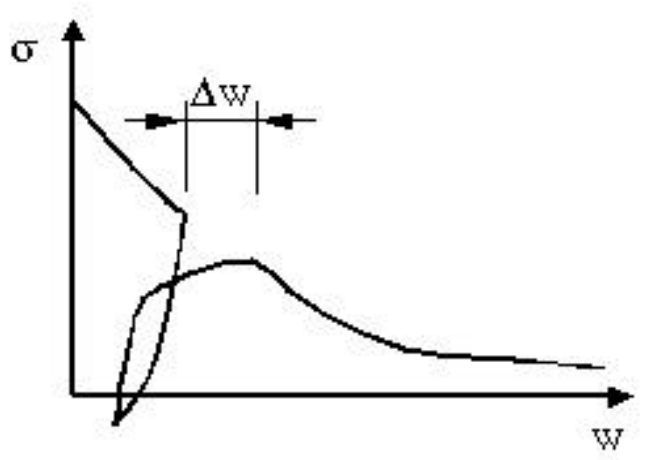

Figura 4.5 Representação do comportamento de um ciclo de descarga-recarga na curva $\sigma-w$ do modelo de fissura coesiva.

\subsubsection{Modelo Contínuo de Fadiga}

Alguns modelos constitutivos baseados na mecânica do dano contínuo foram desenvolvidos para reproduzir o crescimento da degradação por solicitações cíclicas (Papa, 1993; Papa \& Taliercio, 1996). Tais modelos são capazes de descrever os aspectos essenciais do comportamento de fadiga do concreto, sem depender explicitamente do número de ciclos.

\subsubsection{Modelagem de Fadiga Mediante a Aproximação de Descontinuidade Forte}

Apesar de ficar demonstrada que a aproximação de descontinuidade forte constitui uma ferramenta bastante promissora para a análise de propagação de fissuras, nenhum estudo no sentido de avaliar sua aplicabilidade na análise de problemas de fadiga foi realizado.

Os estudos de fadiga com modelos discretos coesivos ou com modelos de dano contínuo mencionados anteriormente sugerem que a aproximação de descontinuidade forte também pode servir como elo de ligação entre esses dois modelos.

A extensão do modelo de dano isotrópico de Oliver et al. (1996) para descrição do comportamento de fadiga, proposto por Manzoli \& Gonçalves (2002) e descrito detalhadamente no capítulo 3 do presente trabalho, apresenta as principais características encontradas nos modelos discretos e contínuos de fadiga e, ao mesmo tempo, contém os 
ingredientes necessários para sua introdução do contexto das aproximações de descontinuidades fortes. 


\section{Capítulo 5}

\section{ELEMENTOS FINITOS COM DESCONTINUIDADE FORTE INCORPORADA}

\subsection{DECOMPOSIÇÃO DO CAMPO DE DESLOCAMENTOS}

Considere o domínio de um elemento finito $\Omega_{e}$ dividido em duas regiões, $\Omega_{e}{ }^{+} \mathrm{e}$ $\Omega_{e}^{-}$, pela linha de descontinuidade $S_{e}$, como ilustra a Figura 5.1 (a). Seja $\mathbf{n}_{e}$ o vetor unitário normal a $S_{e}$ apontando para $\Omega_{e}^{+}$.

O campo de deslocamentos, $\mathbf{u}$, no elemento pode ser decomposto em uma componente associada à deformação da parte contínua, $\tilde{\mathbf{u}}$, e outra correspondente ao movimento de corpo rígido entre as duas partes do elemento, $\hat{\mathbf{u}}$, como ilustrado na Figura 5.1:

$$
\mathbf{u}=\widetilde{\mathbf{u}}+\hat{\mathbf{u}}
$$

Assumindo que o deslocamento relativo ao longo da interface é uniforme, a componente associada ao movimento de corpo rígido pode ser expressa como:

$$
\hat{\mathbf{u}}=H_{S_{e}}[[\mathbf{u}]]
$$

onde $\left.[[\mathbf{u}]]=\left(\left[\left[u_{x}\right]\right]: \llbracket u_{y}\right]\right)^{\mathrm{T}}$ é o vetor contendo as componentes do deslocamento relativo (salto) de acordo com o sistema de coordenadas $(x, y)$ e $H_{S_{e}}$ é a função de Heaviside em $\Omega_{e}$ $\left(H_{S_{e}}=0 \mathrm{em} \Omega_{e}^{-}\right.$e $\left.H_{S_{e}}=1 \mathrm{em} \Omega_{e}^{+}\right)$. 
(a)

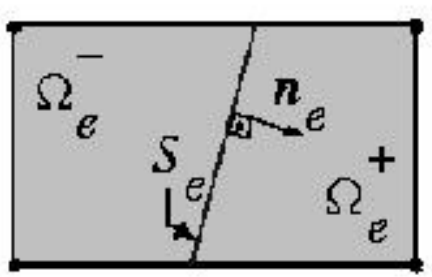

(c)

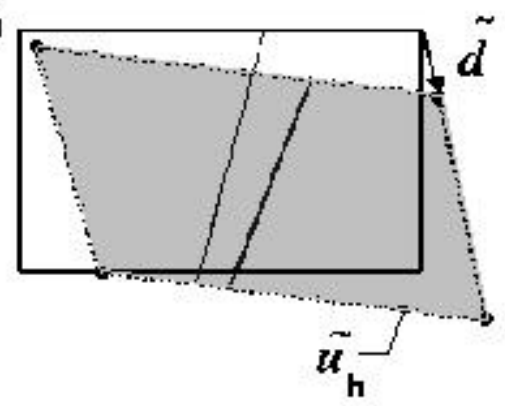

(b)

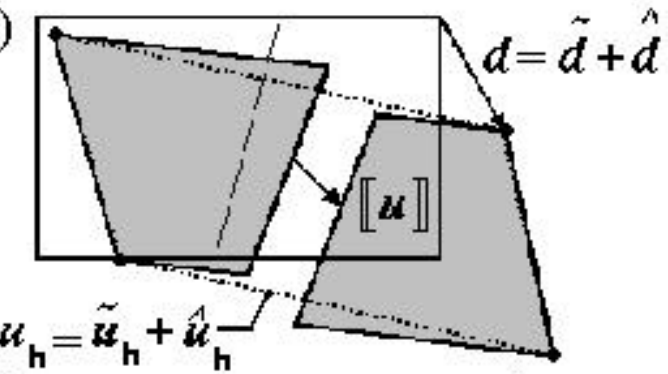

(d)

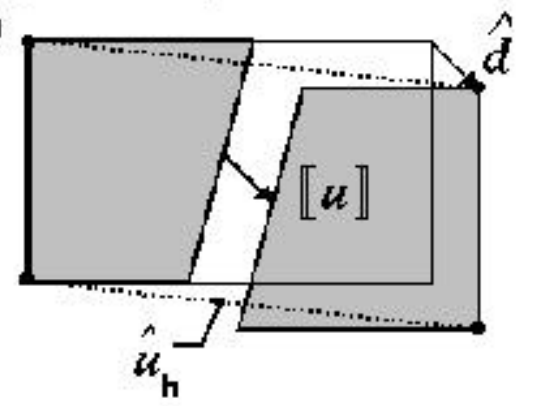

Figura 5.1. Decomposição do campo de deslocamentos.

\subsection{DESCRIÇÃO CINEMÁTICA E ESTÁTICA DA PARTE CONTÍNUA}

Sejam $\mathbf{u}_{h}$ e $\hat{\mathbf{u}}_{h}$ aproximações contínuas dos campos $\mathbf{u}$ e $\hat{\mathbf{u}}$, respectivamente, como ilustrados nas Figuras 5.1 (b) e 5.1 (d). Tais aproximações podem ser obtidas a partir de interpolações contínuas dos valores de $\mathbf{u}$ e $\hat{\mathbf{u}}$ nos nós do elemento. Com base na decomposição (5.1), o campo de deslocamentos da parte contínua pode ser aproximado como:

$$
\tilde{\mathbf{u}}_{h}=\mathbf{u}_{h}-\hat{\mathbf{u}}_{h}
$$

O campo de deformações correspondente fica:

$$
\widetilde{\boldsymbol{\varepsilon}}_{h}=\boldsymbol{\varepsilon}_{h}-\hat{\boldsymbol{\varepsilon}}_{h}
$$

onde $\varepsilon_{h}$, e $\hat{\boldsymbol{\varepsilon}}_{h}$ são, respectivamente, as aproximações contínuas dos campos de deformações totais e da componente associada ao deslocamento relativo de corpo rígido. 
Considerando-se que a parte contínua é elástica linear, o correspondente campo de tensão é diretamente obtido do campo de deformações (5.4), gerando a seguinte equação constitutiva:

$$
\boldsymbol{\sigma}_{h}=\mathbf{C} \tilde{\boldsymbol{\varepsilon}}_{h}=\mathbf{C}\left(\boldsymbol{\varepsilon}_{h}-\hat{\boldsymbol{\varepsilon}}_{h}\right)
$$

onde $\mathbf{C}$ é a matriz elástica material.

\subsection{DESLOCAMENTOS NODAIS}

Seja $\hat{\mathbf{d}}$ o vetor contendo os valores de $\hat{\mathbf{u}}$ nos nós do elemento. A partir da equação (5.2), $\hat{\mathbf{d}}$ pode ser escrito como:

$$
\hat{\mathbf{d}}=\mathbf{P}[[\mathbf{u}]]
$$

sendo $\mathbf{P}$ a matriz contendo os valores de $\mathbf{H}_{S_{e}}$ nos nós do elemento, ou seja:

$$
\mathbf{P}=\left[\begin{array}{cc}
H_{\mathrm{S}_{\mathrm{e}}}\left(x_{1}\right) & 0 \\
0 & H_{\mathrm{S}_{\mathrm{e}}}\left(x_{1}\right) \\
\vdots & \vdots \\
H_{\mathrm{S}_{\mathrm{e}}}\left(x_{n_{e n}}\right) & 0 \\
0 & H_{\mathrm{S}_{\mathrm{e}}}\left(x_{n_{e n}}\right)
\end{array}\right]
$$

onde $n_{e n}$ é o número de elementos e $x_{i}\left(i=1,2, \ldots, n_{e n}\right)$ são as coordenadas nodais do elemento.

\subsection{PRINCÍPIO VARIACIONAL}

A forma fraca das equações de equilíbrio pode ser escrita mediante o princípio variacional clássico:

$$
\int_{\Omega}(\mathbf{D} \delta \mathbf{u})^{\mathrm{T}} \mathbf{C}(\mathbf{D} \mathbf{u}-\mathbf{a}) \mathrm{d} \Omega-\int_{\Omega} \delta \mathbf{u}^{\mathrm{T}} \overline{\mathbf{b}} \mathrm{d} \Omega-\int_{\Gamma_{\mathrm{t}}} \delta \mathbf{u}^{\mathrm{T}} \overline{\mathbf{t}} \mathrm{d} \Gamma=\mathbf{0}
$$


no qual a equação constitutiva (5.5) foi levada em consideração. $\overline{\mathbf{b}}$ é o vetor de forças volumétricas prescritas no domínio do sólido, $\Omega, \overline{\mathbf{t}}$ é o vetor de forças de superfície prescritas na parte do contorno $\Gamma_{t}$ e $\mathbf{D}$ é o operador de deformação, tal que:

$$
\varepsilon=\mathbf{D} \mathbf{u}
$$

A equação (5.8) deve ser satisfeita para qualquer variação admissível $\delta \mathbf{u}$.

\subsection{APROXIMAÇÃO PELO MÉTODO DOS ELEMENTOS FINITOS}

A aproximação do campo de deslocamentos é expresso por:

$$
\mathbf{u}_{h}=\mathbf{N} \mathbf{d}
$$

onde $\mathbf{N}$ a matriz de funções de forma clássica e $\mathbf{d}$ é o vetor contendo os deslocamentos nodais. A aproximação do campo de deformações poder ser obtida como:

$$
\boldsymbol{\varepsilon}_{h}=\mathbf{D} \mathbf{u}_{h}=\mathbf{B} \mathbf{d}
$$

onde $\mathbf{B}=\mathbf{D}$ N é a matriz convencional de deformações do método dos elementos finitos.

A aproximação contínua do campo de deslocamentos associado ao salto pode ser construída de forma similar, gerando:

$$
\hat{\mathbf{u}}_{h}=\mathbf{N} \hat{\mathbf{d}}=\mathbf{N} \mathbf{P}[[\mathbf{u}]]
$$

O correspondente campo de deformações fica dado por:

$$
\hat{\boldsymbol{\varepsilon}}_{h}=\mathbf{D} \hat{\mathbf{u}}_{h}=\mathbf{B} \mathbf{P}[[\mathbf{u}]]
$$

A partir das equações (5.4), (5.11) e (5.13), o campo de deformações da parte contínua pode ser expresso como:

$$
\widetilde{\boldsymbol{\varepsilon}}_{h}=\mathbf{B}(\mathbf{d}-\mathbf{P}[[\mathbf{u}]])
$$


Introduzindo as aproximações (5.10), (5.11) e (5.13) na igualdade variacional (5.8) conduz ao seguinte conjunto de equações discretizadas:

$$
\mathbf{A}_{e=1}^{n_{e l}} \mathbf{f}_{i n t}-\mathbf{A}_{e=1}^{n_{e l}} \mathbf{f}_{e x t_{e}}=\mathbf{0}
$$

onde A representa o operador de montagem do método dos elementos finitos, $n_{e l}$ é o número de elementos, e $\mathbf{f}_{i n t_{\mathrm{e}}}$ e $\mathbf{f}_{\text {ext }_{e}}$ são os vetores de forças internas e externas, respectivamente:

$$
\begin{aligned}
\mathbf{f}_{\text {int }_{\mathrm{e}}} & =\tilde{\mathbf{K}}_{e}(\mathbf{d}-\mathbf{P}[[\mathbf{u}]]) \\
f_{\text {ext }_{e}} & =\int_{\Omega_{\mathrm{e}}} \mathbf{N}^{\mathrm{T}} \overline{\mathbf{b}} \mathrm{d} \Omega+\int_{\Gamma_{\mathrm{e}_{\mathrm{t}}}} \mathbf{N}^{\mathrm{T}} \overline{\mathbf{t}} \mathrm{d} \Gamma
\end{aligned}
$$

sendo que:

$$
\tilde{\mathbf{K}}_{\mathrm{e}}=\int_{\Omega_{\mathrm{e}}} \mathbf{B}^{\mathrm{T}} \mathbf{C B} \mathrm{d} \Omega
$$

é a matriz de rigidez elástica convencional.

\subsection{COMPORTAMENTO NÃO-LINEAR DA INTERFACE}

Até esse ponto da formulação, a posição e o valor salto, [[u]], foi considerado conhecido. Entretanto, na realidade a descontinuidade progride durante o processo de carregamento.

No âmbito da mecânica de fratura, a propagação da fissura é precedida por uma progressiva deterioração das propriedades físicas em uma região pequena. Essa região, chamada zona de processamento de fissura, dá lugar a uma descontinuidade real quando o material atinge completa degradação. Em materiais quase-frágeis como o concreto, em geral o tamanho da zona de processamento da fissura não é desprezível quando comparado com as dimensões do problema. Nesse caso, o comportamento não-linear prévio à formação da fissura deve ser considerado. 
Em simulações computacionais de problemas de fratura, considera-se a existência de uma interface descontínua desde o primeiro estágio da formação da fissura. $\mathrm{O}$ comportamento não-linear da zona de processamento é então representado por forças coesivas de interação entres os dois lados da interface. Na chamada aproximação de fissura discreta coesiva (Hillerborg et al., 1976), considera-se que essas forças superficiais variam segundo uma lei constitutiva expressa em termos do deslocamento relativo (salto) entre os lados da interface.

Por outro lado, de acordo com a aproximação de descontinuidades fortes proposta por Simó et al. (1993), uma relação constitutiva contínua (entre tensões e deformações) pode ser usada para descrever o comportamento da interface descontínua, que é considerada como uma degeneração do meio contínuo. No referido trabalho foram estabelecidas as condições para que as relações constitutivas contínuas sejam compatíveis com descontinuidades de deslocamentos (descontinuidades fortes).

O presente trabalho explora a aproximação de descontinuidades fortes, uma vez que permite o emprego do modelo constitutivo de dano contínuo proposto para análise de fadiga.

Considerando que o comportamento da interface é descrito por uma lei constitutiva contínua, a força de superfície na interface, $\mathbf{t}_{S_{e}}$, fica dada por:

$$
\mathbf{t}_{S_{e}}=\mathbf{N}_{n_{e}} \sum^{\mathrm{c}}(\boldsymbol{\varepsilon}) \quad \quad \text { em } S_{e}
$$

onde $\sum^{\mathrm{c}}(\bullet)$ representa formalmente a lei constitutiva contínua, que retorna as tensões para uma dada história de deformações. A matriz $\mathbf{N}_{n}$ projeta o vetor de tensões em uma superfície com vetor unitário normal n. Em duas dimensões a matriz de projeção é dada por:

$$
\mathbf{N}_{n}=\left[\begin{array}{ccc}
n_{x} & 0 & n_{y} \\
0 & n_{y} & n_{x}
\end{array}\right]
$$

onde $n_{x}$ e $n_{y}$ são as componentes de $\mathbf{n}$.

O campo de deformações totais, $\boldsymbol{\varepsilon}$, dever ser obtido a partir do campo de deslocamento descontínuo, que pode ser recuperado das aproximações contínuas mediante: 


$$
\mathbf{u}=\tilde{\mathbf{u}}_{h}+\hat{\mathbf{u}}
$$

Portanto, o correspondente campo de deformações é expresso por:

$$
\begin{aligned}
& \boldsymbol{\varepsilon}=\widetilde{\boldsymbol{\varepsilon}}_{h}+\mathbf{D}\left(H_{S_{e}}[[\mathbf{u}]]\right) \\
& \boldsymbol{\varepsilon}=\widetilde{\boldsymbol{\varepsilon}}_{h}+\boldsymbol{\delta}_{S_{e}} \mathbf{N}_{n_{e}}^{T}[[\mathbf{u}]]
\end{aligned}
$$

onde $\delta_{S_{e}}$ é a distribuição de Dirac situada em $S_{e}$. O último termo de (5.22) introduz uma parte não limitada no campo de deformações. Para fins numéricos, a distribuição de Dirac pode ser substituída pela seqüência regularizadora (Oliver, 1996):

$$
\delta_{\mathrm{S}_{\mathrm{e}}}(x) \approx \begin{cases}\frac{1}{k} & \text { if } x \in S_{e} \\ 0 & \text { if } x \notin S_{e}\end{cases}
$$

tal que, quando o parâmetro de regularização, $k$, tende a zero, a aproximação (5.23) transforma-se em uma identidade. A parâmetro $k$ pode ser interpretado como a largura de uma banda muito estreita contendo $S$, através da qual o salto $[[\mathbf{u}]]$ é regularizado.

A partir das equações (5.22), (5.14) e (5.23), a equação (5.19) transforma-se em:

$$
\mathbf{t}_{S_{e}}=\mathbf{N}_{n_{e}} \Sigma^{\mathrm{c}}\left(\mathbf{B}(\mathbf{d}-\mathbf{P}[[\mathbf{u}]])+\frac{1}{k} \mathbf{N}_{n_{e}}^{\mathrm{T}}[[\mathbf{u}]]\right)
$$

\subsection{ACOPLAMENTO ENTRE CONTÍNUO E INTERFACE}

A condição de continuidade entre as forças de superfície na interface e na parte contínua do elemento é expressa por:

$$
\mathbf{t}_{S_{e}}-\mathbf{N}_{n_{e}} \boldsymbol{\sigma}=0 \quad \text { em } S_{e}
$$


onde o termo $\mathbf{N}_{n_{e}} \boldsymbol{\sigma}$ fornece o vetor de componentes da força de superfície obtida a partir do estado de tensão da parte contínua vizinha à interface e $\mathbf{t}_{S}$ é o vetor de componentes da força de superfície no interior da interface.

No presente trabalho considera-se que a forma fraca da equação de continuidade de forças de superfícies corresponde à imposição da equação (5.25) em um ponto do elemento, $\mathrm{Q}_{\mathrm{e}}$, supostamente situado sobre a linha de interface (ver Figura 5.2). Assim, estabelece-se o seguinte conjunto de equações adicionais:

$$
\mathbf{t}_{S_{e}}-\mathbf{N}_{n_{e}} \boldsymbol{\sigma}_{h}=\mathbf{0} \text { em } Q_{e} \in S_{e} \quad\left(e=1, n_{e l}\right)
$$

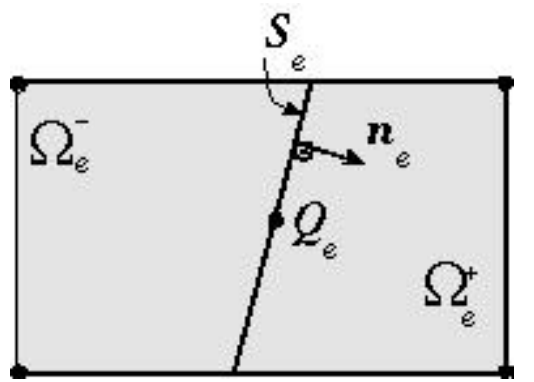

Figura 5.2. Ponto de colocação sobre a interface descontínua.

Tendo-se em conta a relação constitutiva para a parte contínua (5.5), a aproximação por elementos finitos (5.14) e a expressão de $\mathbf{t}_{S_{e}}$ dada por (5.24), as equações de equilíbrio (5.26) ficam dadas por:

$$
\mathbf{t}_{s_{e}}-\hat{\mathbf{K}}_{e}(\mathbf{d}-\mathbf{P}[[\mathbf{u}]])=\mathbf{0} \text { em } Q_{e} \in S_{e} \quad\left(e=1, n_{e l}\right)
$$

com:

$$
\hat{\mathbf{K}}_{e}=\mathbf{N}_{n_{e}} \mathbf{C} \mathbf{B}
$$




\subsection{SISTEMA COMPLETO DE EQUAÇÕES}

As equações de equilíbrio (5.15) juntamente com as de continuidade (5.27) formam o sistema completo de equações discretizadas que regem o problema de sólidos com interface descontínua:

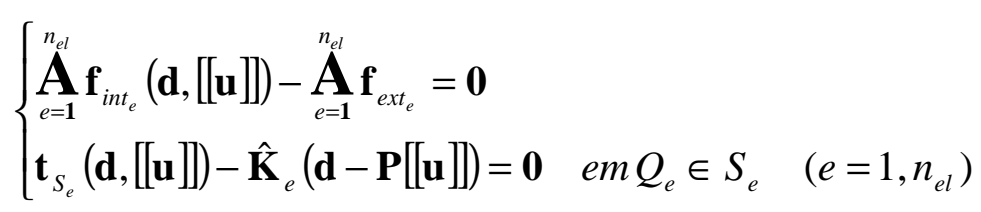

\subsection{ESQUEMA DE SOLUÇÃO}

Em um esquema incremental e iterativo convencional de solução do sistema nãolinear de equações de equilíbrio, deve-se verificar a primeira igualdade da equação (5.29) em cada iteração para uma dada estimativa dos deslocamentos nodais. Assim, o vetor de forças internas e a matriz de rigidez tangente devem ser calculados em cada iteração.

Note na primeira igualdade da equação (5.29) que, na formulação de elementos com interface incorporada, o vetor de forças internas depende não só dos deslocamentos nodais, mas também das componentes do salto. Assim, para uma dada estimativa dos deslocamentos nodais, deve-se obter os valores das componentes do salto para cada elemento antes de calcular o vetor de forças internas. Isso pode ser feito a nível de cada elemento, resolvendo-se o sistema não-linear da segunda igualdade da equação (5.29) em termos de $[[\mathbf{u}]]$.

A nível de cada elemento, a forma incremental das equações (5.16) e (5.27) pode ser expressa em formato matricial por:

$$
\left[\begin{array}{ll}
\mathbf{K}_{e}^{d d} & \mathbf{K}_{e}^{d u} \\
\mathbf{K}_{e}^{u d} & \mathbf{K}_{e}^{u u}
\end{array}\right]\left\{\begin{array}{c}
\dot{\mathbf{d}} \\
\ddot{\dot{\mathbf{u}}}]]
\end{array}\right\}=\left\{\begin{array}{c}
\dot{\mathbf{f}}_{\text {int }_{e}} \\
\mathbf{0}
\end{array}\right\}
$$

onde:

$$
\begin{aligned}
& \mathbf{K}_{e}^{d d}=\tilde{\mathbf{K}}_{e} \\
& \mathbf{K}_{e}^{d u}=-\tilde{\mathbf{K}}_{e} \mathbf{P}
\end{aligned}
$$




$$
\begin{aligned}
& \mathbf{K}_{e}^{u d}=-\mathbf{N}_{n_{e}}\left(\mathbf{C}-\partial_{\varepsilon} \Sigma^{\mathrm{c}}\right) \mathbf{B}_{Q_{e}} \\
& \mathbf{K}_{e}^{u u}=\mathbf{N}_{n_{e}}\left(\mathbf{C}-\partial_{\varepsilon} \Sigma^{\mathrm{c}}\right) \mathbf{B}_{Q_{e}} \mathbf{P}+\frac{\mathbf{1}}{k} \mathbf{N}_{n_{e}} \partial_{\varepsilon} \Sigma^{c} \mathbf{N}_{n_{e}}^{T}
\end{aligned}
$$

sendo $\mathbf{B}_{Q_{e}}$ a matriz $\mathbf{B}$ calculada no ponto $Q_{e}$ do elemento.

Eliminando-se $[[\mathbf{u}]]$ em (5.30), chega-se à seguinte matriz de rigidez condensada:

$$
\mathbf{K}_{e}=\mathbf{K}_{e}^{d d}-\mathbf{K}_{e}^{d u}\left(\mathbf{K}_{e}^{u u}\right)^{-1} \mathbf{K}_{e}^{u d}
$$

que pode ser usada para estimar os deslocamentos nodais da próxima iteração.

\subsection{ANÁLISE DE DISSIPAÇÃO DO MODELO DE DANO}

A evolução da energia dissipada devido à degradação do material é expressa pela seguinte equação (Oliver, 1996 ):

$$
\begin{aligned}
& \dot{D}=\dot{d} \frac{1}{2} \varepsilon^{T} \mathbf{C} \varepsilon \\
& \dot{D}=-\frac{1}{2} \frac{d}{d t}(q \alpha)+q \dot{\alpha}
\end{aligned}
$$

onde:

$$
\begin{aligned}
& q=(1-d(r)) r \\
& \alpha=r d(r)
\end{aligned}
$$

A energia dissipada por unidade de volume em um ponto material submetido a um processo de carregamento que tem início no tempo $t=0 \mathrm{com}$ o material intacto $\left((r, d)_{t=0}=\left(r_{\mathrm{o}}, 0\right)\right)$ e termina em $t=t_{u}$ com o material degradado $\left((r, d)_{t=t u}=\left(r_{\mathrm{u}}, 1\right)\right)$, fica dada por:

$$
G=\int_{0}^{t_{u}} \dot{D} d t
$$




$$
\begin{aligned}
& G=-\left.\frac{1}{2} q \alpha\right|_{0} ^{t_{u}}+\int_{t_{o}}^{t_{u}} q d \alpha \\
& G=\int_{r_{o}}^{r_{u}}(1-d(r)) r\left(d(r)+r \frac{d}{d r} d(r)\right) d r
\end{aligned}
$$

Tomando-se a evolução de dano exponencial (equação 3.27):

$$
d=1-\frac{r_{o}}{r} e^{A \cdot\left(1-\frac{r}{r_{o}}\right)}
$$

a integral (5.35) resulta em:

$$
G=\frac{1}{2} \frac{r_{o}^{2}}{A}(2+A)
$$

Define-se como energia de fratura, $G_{f}$, a energia consumida por unidade de superfície durante o processo de formação da fissura. Portanto, levando-se em conta a regularização (5.23), a energia dissipada na banda de regularização de largura $k$ pequena contendo $S$ fica expressa por:

$$
G_{f}=G k=\frac{1}{2} \frac{r_{o}^{2}}{A}(2+A) k
$$

da qual, pode-se obter o parâmetro de abrandamento da evolução do dano em termos da energia de fratura e do parâmetro de regularização:

$$
A=-\frac{2 r_{o}^{2} k}{r_{o}^{2} k-2 G_{f}}
$$

Note que, no caso limite de descontinuidade forte, quando $\mathrm{k}$ tende a zero, a equação (5.39) pode ser expressa como:

$$
\frac{1}{A}=\lim _{k \rightarrow 0}-\frac{G_{f}}{r_{o}{ }^{2}} \frac{1}{k}=-\frac{G_{f}}{r_{o}{ }^{2}} \delta_{S_{e}}
$$


ou seja, o inverso do parâmetro de abrandamento $A$ deve ter característica distribucional. Caso contrário, a energia dissipada em regime de descontinuidade forte seria nula, não tendo correspondência com o princípio físico do processo de formação de fissura. A equação (5.40) é a condição necessária para que o modelo constitutivo de dano contínuo seja compatível com o regime de descontinuidade forte. 


\section{Capítulo 6}

\section{EXEMPLOS NUMÉRICOS}

\subsection{EXEMPLO 1 - Tração Uniaxial: Verificação dos Modelos}

Mediante a simulação de tração uniaxial repetida, analisa-se a capacidade dos modelos constitutivos propostos de reproduzir as principais características do comportamento do concreto tracionado, assim como a eficiência numérica dos algoritmos de integração empregados. Para essa finalidade, empregando-se os modelos apresentados, calculam-se as tensões para uma seqüência de deformações incrementais que seguem uma determinada função cíclica.

Nesse exemplo foram utilizadas as seguintes propriedades do modelo:

$$
\begin{aligned}
& E=30000 \mathrm{MPa} ; \\
& f_{t}=3,0 \mathrm{MPa} ; \\
& A=0,45 ; \\
& B=40 ; \\
& C=4,0 ; \\
& N=4,0 .
\end{aligned}
$$

Para representar adequadamente o comportamento do concreto, a curva da resposta estática monotônica deve ser a envoltória limite da curva da resposta cíclica (Hordijk \& Reinhardt, 1992).

As Figuras 6.1 e 6.2 mostram as curvas de tensão versus deformação obtidas para diferentes funções cíclicas de deformações com amplitude crescente, segundo os modelos apresentados. As linhas cheias representam as respostas para as diferentes histórias de 
deformações cíclicas, enquanto que as linhas descontínuas representam as respostas obtidas para uma deformação crescente monotônica.

Verifica-se que o modelo 1 (Figura 3.8) não apresenta uma envoltória única definida pela resposta monotônica (ver Figura 6.1). Nota-se que para diferentes histórias de deformações impostas (Figuras 6.1a, 6.1b e 6.1c), obtém-se diferentes curvas que não apresentam a resposta monotônica como limite. O modelo 2 (figura 3.9) apresenta, para as distintas ações cíclicas, a resposta monotônica como envoltória limite única (ver Figuras $6.2 \mathrm{a}, 6.2 \mathrm{~b}$ e $6.2 \mathrm{c})$.

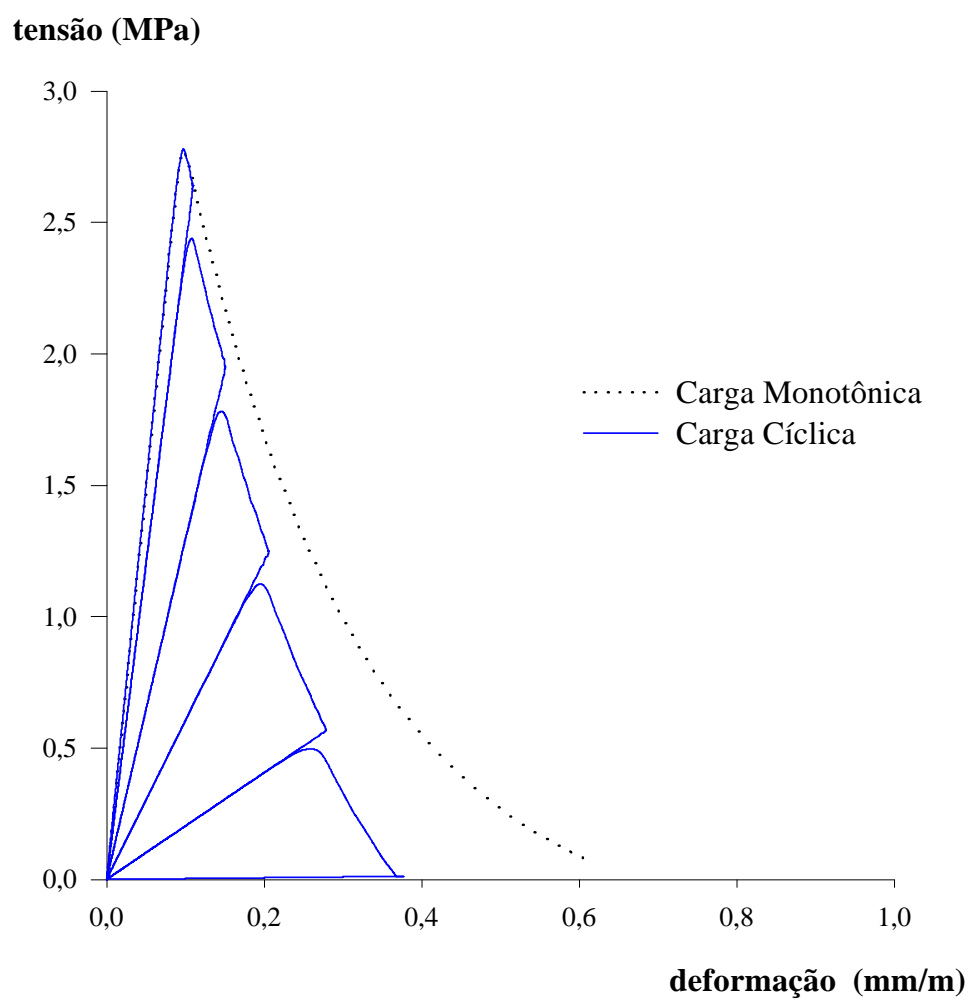

(a) 


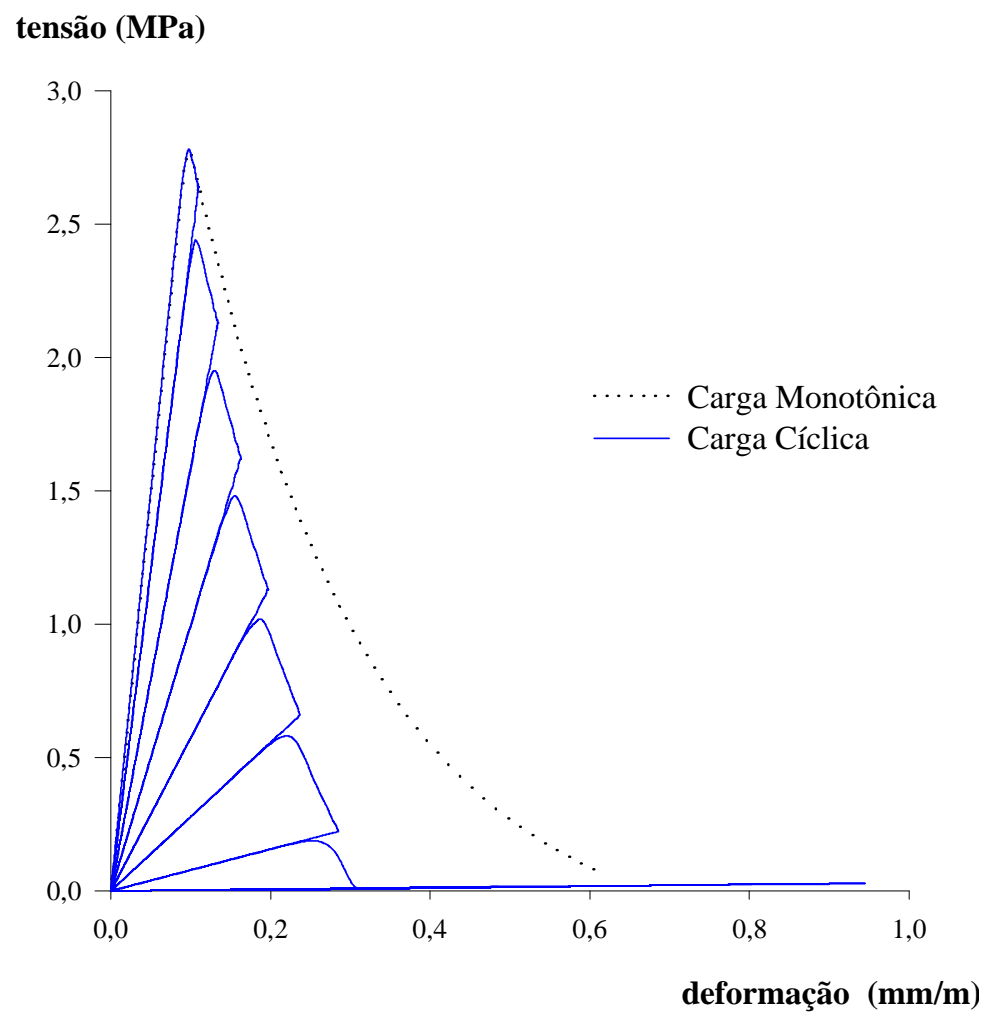

(b)

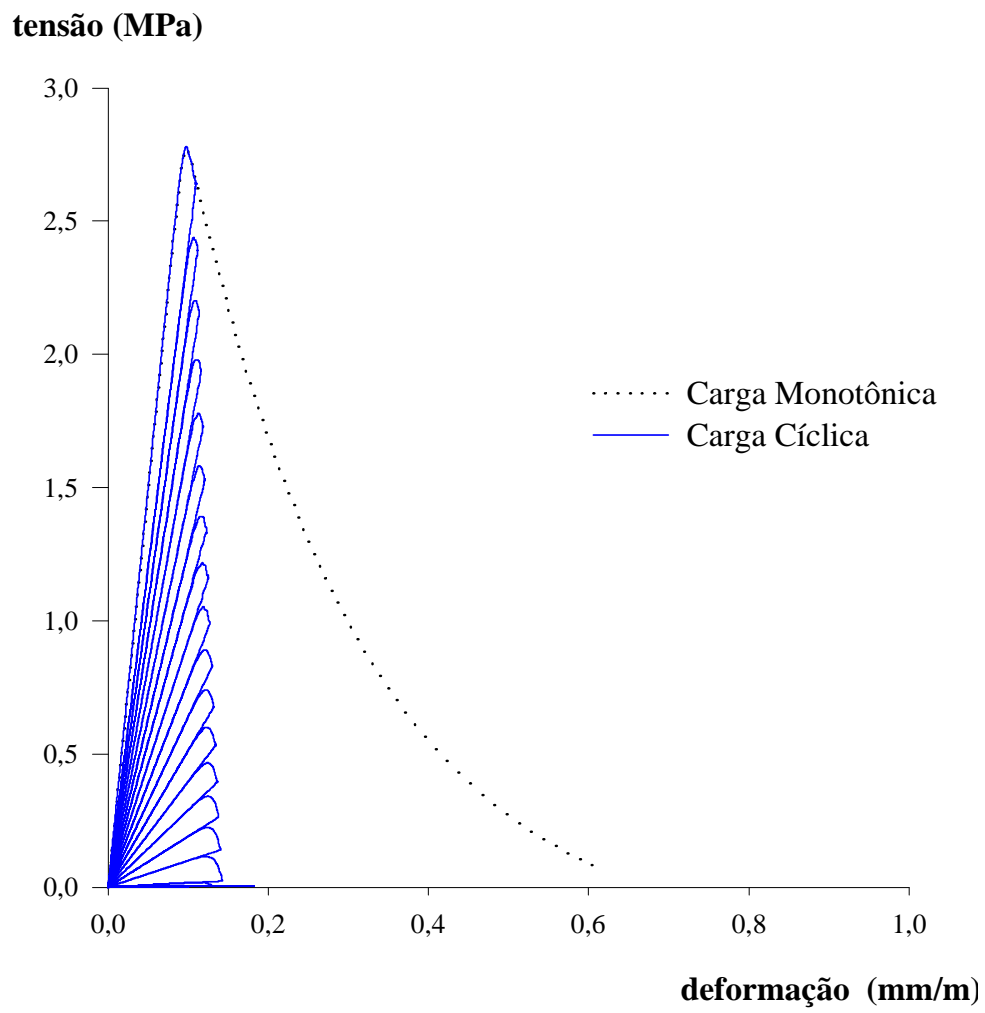

(c)

Figura 6.1. Curvas tensão $x$ deformação obtidas pelo MODELO 1 para diferentes histórias de deformações cíclicas. 


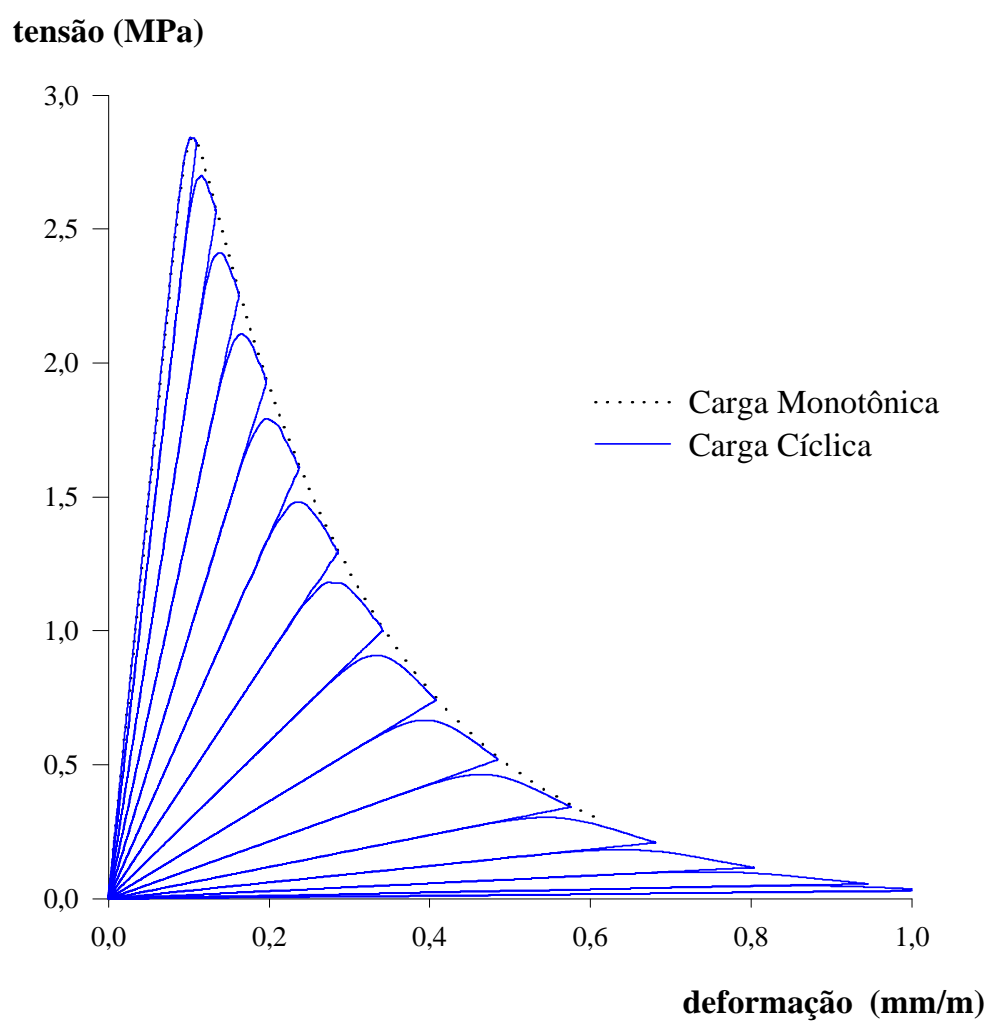

(a)

\section{tensão (MPa)}

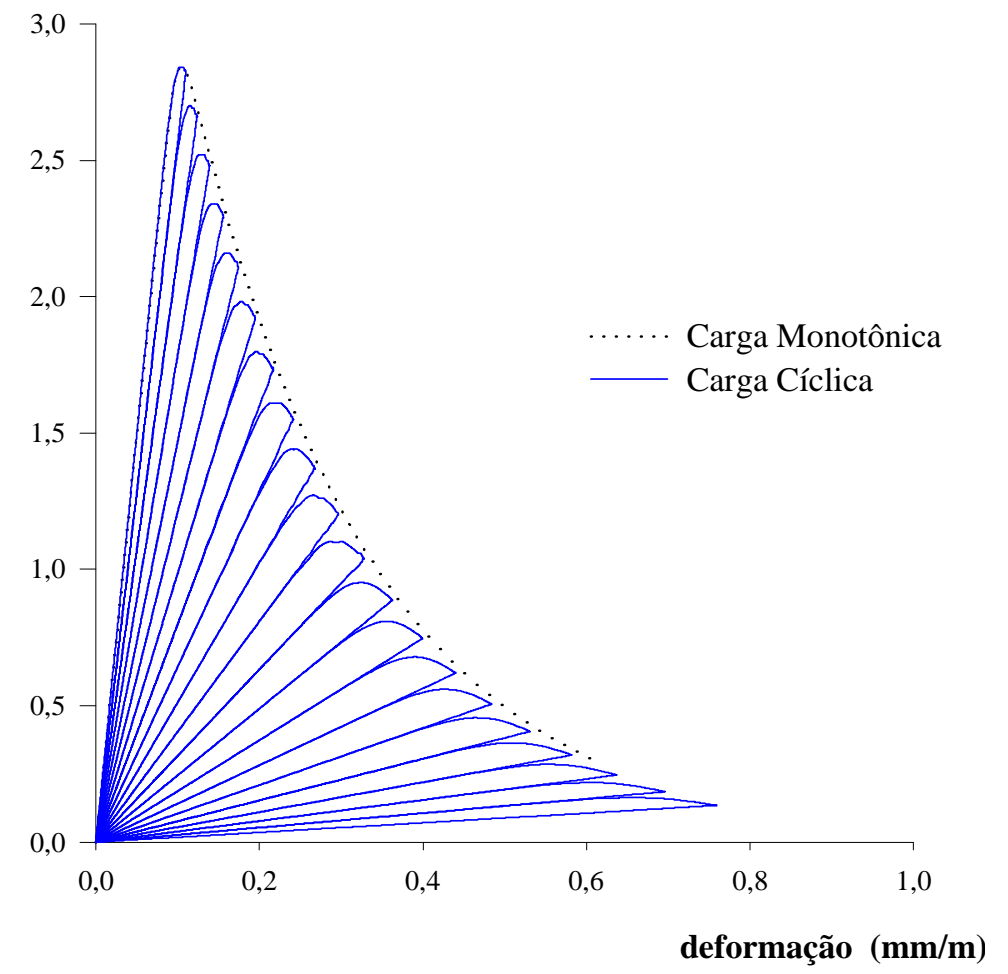

(b) 


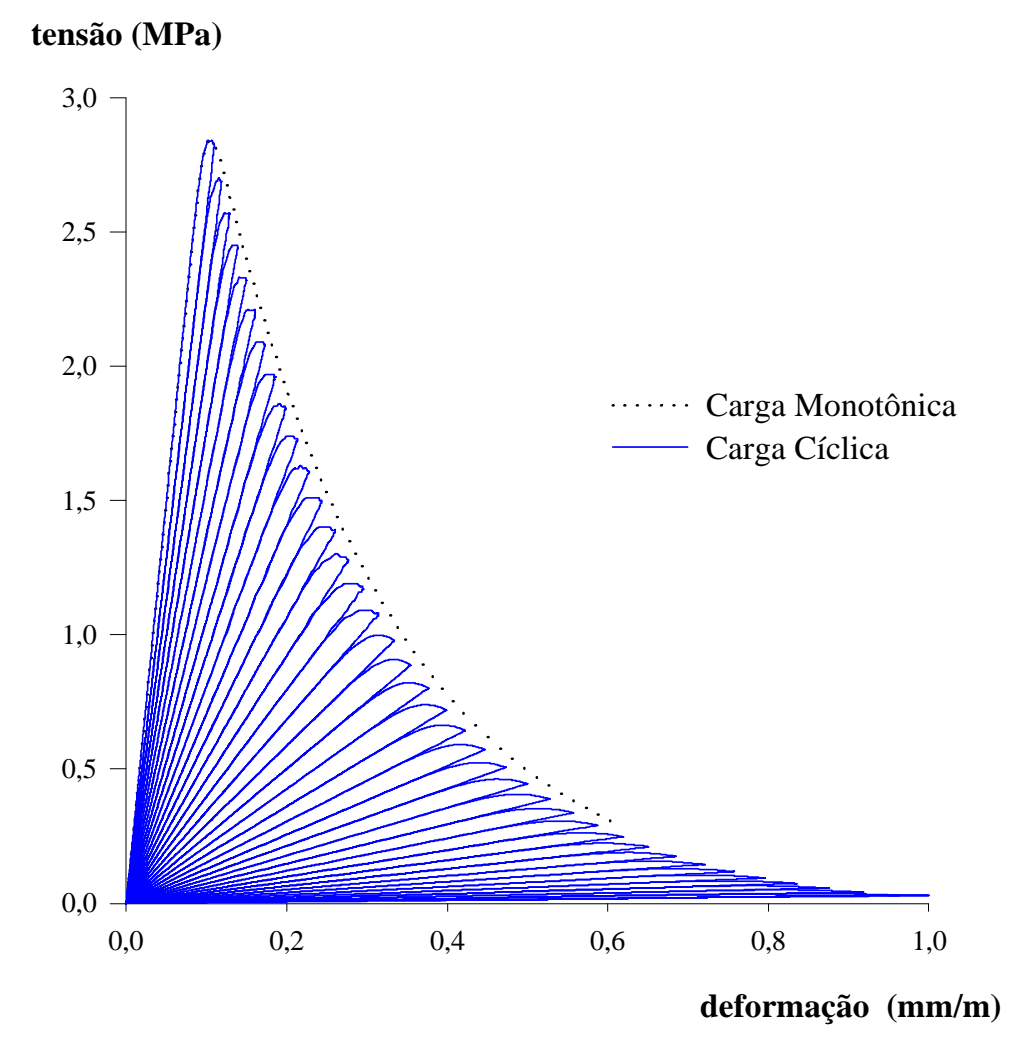

(c)

Figura 6.2. Curvas tensão $x$ deformação obtidas pelo MODELO 2 para diferentes histórias de deformações cíclicas.

Portanto, apesar de ter uma implementação mais complexa, somente o modelo 2 é capaz de representar adequadamente uma das características essenciais do concreto.

As Figuras 6.3, 6.4 e 6.5 ilustram a resposta obtida com o modelo 2 para ação cíclica de tração uniaxial em uma peça de seção transversal 50 x $50 \mathrm{~mm}$ e $150 \mathrm{~mm}$ de comprimento, com amplitude de tensão constante em $85 \%$ da tensão máxima para carregamento monotônico.

Observa-se que a curva deformação $x$ número de ciclos (Figura 6.4) e a curva de variação do módulo elástico secante com o número de ciclos (Figura 6.5) apresentam o mesmo comportamento obtido experimentalmente por Hordijk \& Reinhardt (1992). 


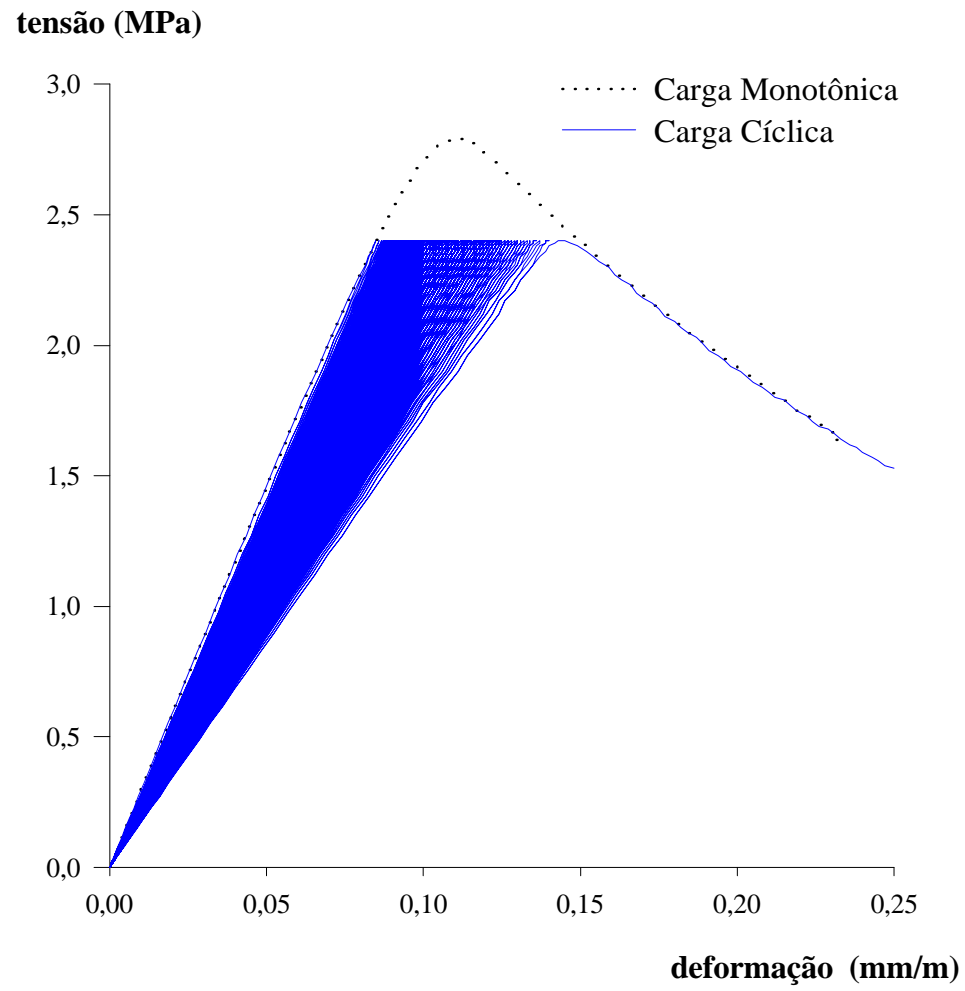

Figura 6.3. Curvas tensão $x$ deformação obtidas pelo MODELO 2 para amplitude de tensão constante em $85 \%$ da tensão máxima.

\section{deformação $(\mathrm{mm} / \mathrm{m})$}

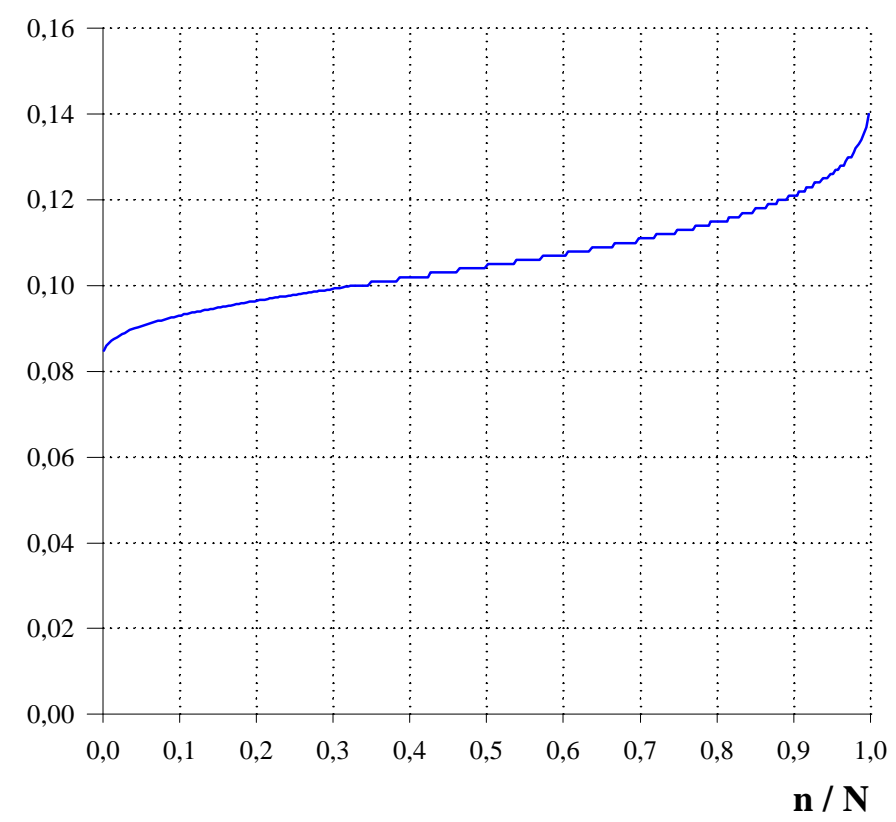

Figura 6.4. Evolução da deformação máxima com o número de ciclos obtida pelo MODELO 2 para amplitude de tensão constante em $85 \%$ da tensão máxima. 


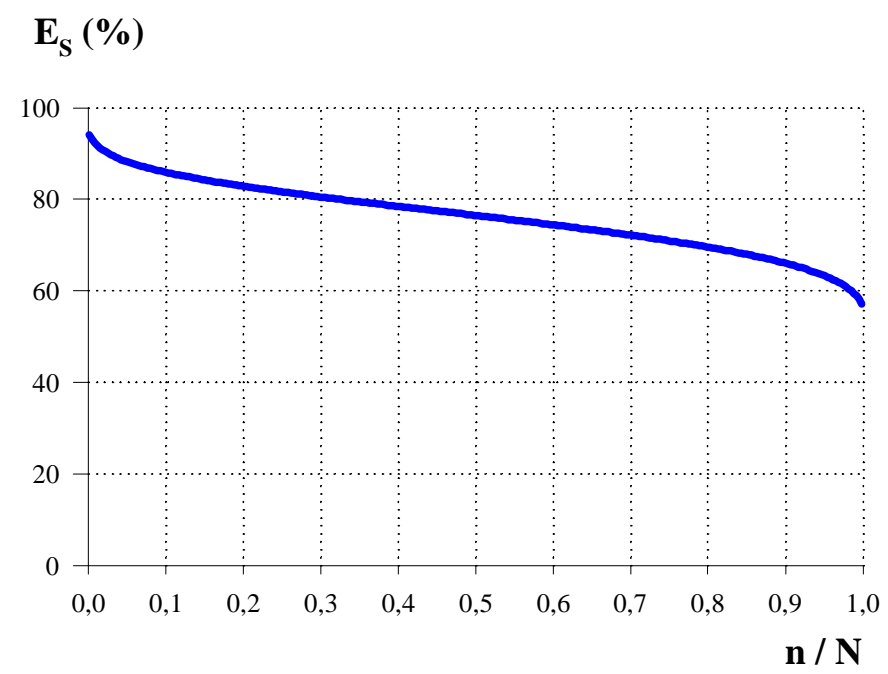

Figura 6.5. Variação do módulo elástico secante com o número de ciclos obtida pelo MODELO 2 para amplitude de tensão constante em $85 \%$ da tensão máxima.

\subsection{EXEMPLO 2 - Tração Uniaxial: Calibração dos Parâmetros}

Para calibrar os parâmetros do modelo inicialmente foram feitos diversos testes para um cubo de concreto de $10 \mathrm{~cm}$ de aresta submetido a ciclos repetidos de tração simples (Figura 6.6).

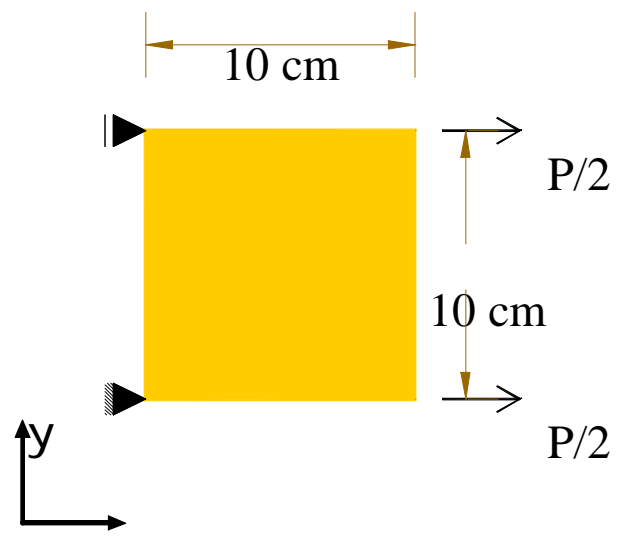

Figura 6.6. Elemento submetido a ciclos de carga para calibração dos parâmetros.

Para a análise do cubo de concreto apresentado na figura foram utilizadas as seguintes propriedades do material: 


$$
\begin{aligned}
& E=30000 \mathrm{MPa} ; \\
& v=0,2 ; \\
& f_{t}=3,0 \mathrm{MPa} ; \\
& G_{f}=0,11 \mathrm{kN} / \mathrm{m} .
\end{aligned}
$$

Este cubo foi analisado com um único elemento finito retangular de quatro nós e cinco pontos de Gauss, com descontinuidade forte incorporada. Para a simulação da descontinuidade forte escolheu-se a seguinte largura da banda regularizadora $(k)$, suficientemente pequena para o elemento em questão:

$$
k=0,001 \mathrm{~m} \text {. }
$$

Primeiramente analisou-se a independência dos parâmetros com relação ao sistema de unidades. Para tal, o cubo foi analisado com as unidades no sistema métrico $([\mathrm{kgf}]$ e $[\mathrm{cm}])$ e com as unidades no sistema internacional $([\mathrm{kN}]$ e $[\mathrm{m}])$.

Calculando-se o parâmetro $A$ em $[\mathrm{kgf}]$ e $[\mathrm{cm}]$ :

$$
\begin{array}{ll}
\text { Da equação (3.14): } & r_{o}=\frac{f_{t}}{\sqrt{E}}=\frac{30}{\sqrt{300000}}=0,055 \\
\text { Da equação (5.40): } & A=\frac{r_{o}^{2} \cdot k}{G_{f}}=\frac{0,055^{2} \cdot 0,1}{0,11}=0,0027
\end{array}
$$

E em $[\mathrm{kN}]$ e $[\mathrm{m}]$ :

$$
\begin{aligned}
& r_{o}=\frac{f_{t}}{\sqrt{E}}=\frac{3000}{\sqrt{30000000}}=0,55 \\
& A=\frac{r_{o}{ }^{2} \cdot k}{G_{f}}=\frac{0,55^{2} \cdot 0,001}{0,11}=0,0027
\end{aligned}
$$

Restando definir apenas os parâmetros $B, C$ e $N$, que neste estudo foram assim adotados:

$$
\begin{aligned}
& B=-10 \\
& C=0,1 \\
& N=-0,4
\end{aligned}
$$


Com os resultados da análise, plotou-se o gráfico tensão $x$ deformação para carga monotônica e carga cíclica para os 2 sistemas de unidades utilizados (Figura 6.7). A curva de carregamento cíclico foi plotada apenas com os valores máximos a fim de facilitar a visualização do gráfico. A ruptura é caracterizada pela falta de convergência no processo numérico de solução.

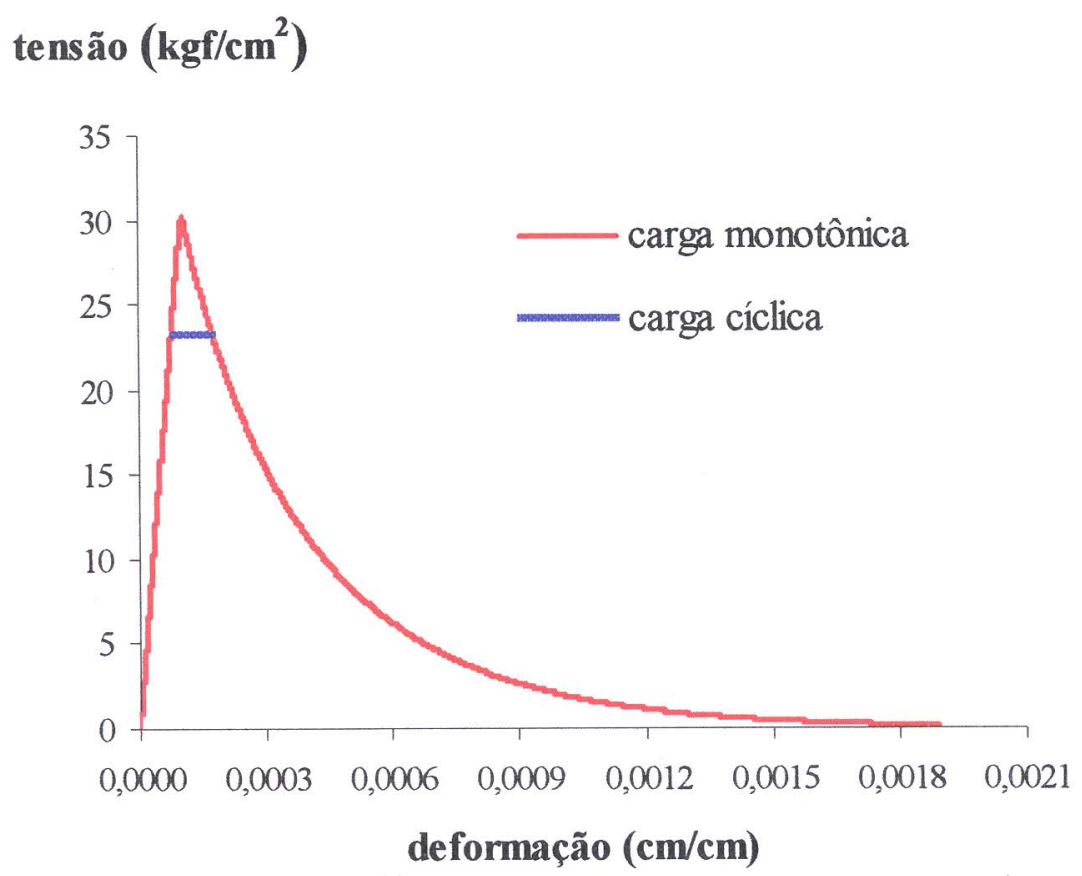

\section{tensão $\left(\mathrm{kN} / \mathrm{m}^{2}\right)$}

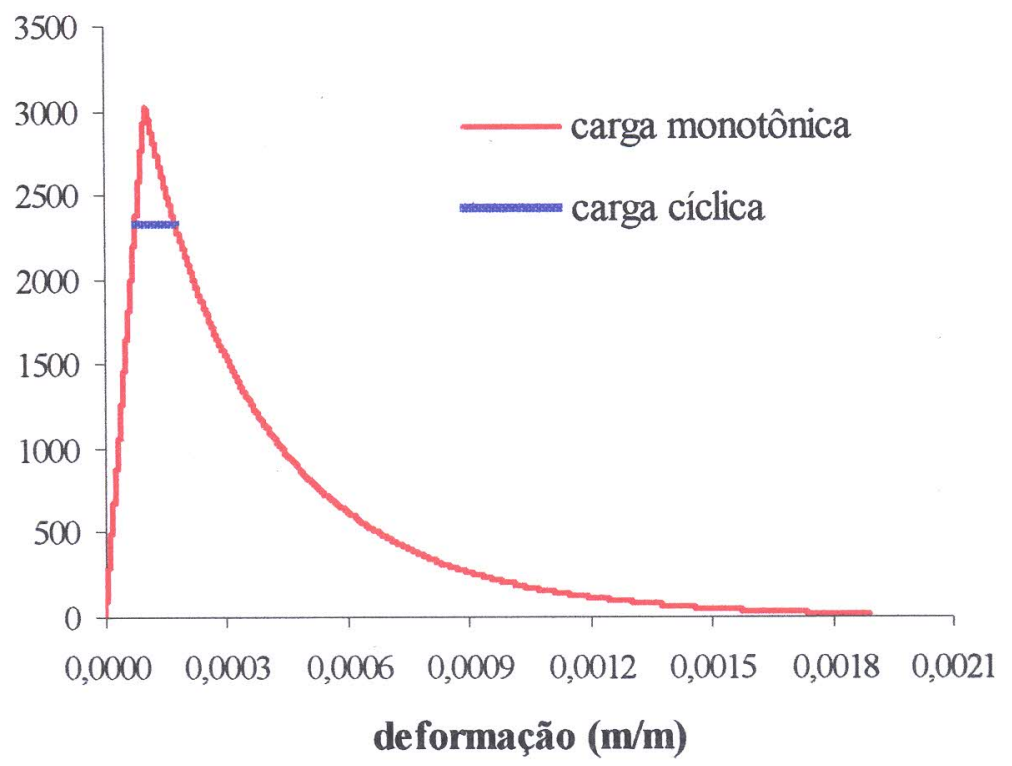

Figura 6.7. Tensão $x$ deformação para carregamento monotônico e cíclico para amplitude de tensão constante em $80 \%$ da tensão máxima, com as unidades no sistema métrico e internacional. 
E para comparar os resultados dos 2 sistemas de unidades, plotou-se o gráfico deformação $x$ número de ciclos para carga cíclica com amplitude de tensão constante em 80\% da tensão máxima (Figura 6.8).

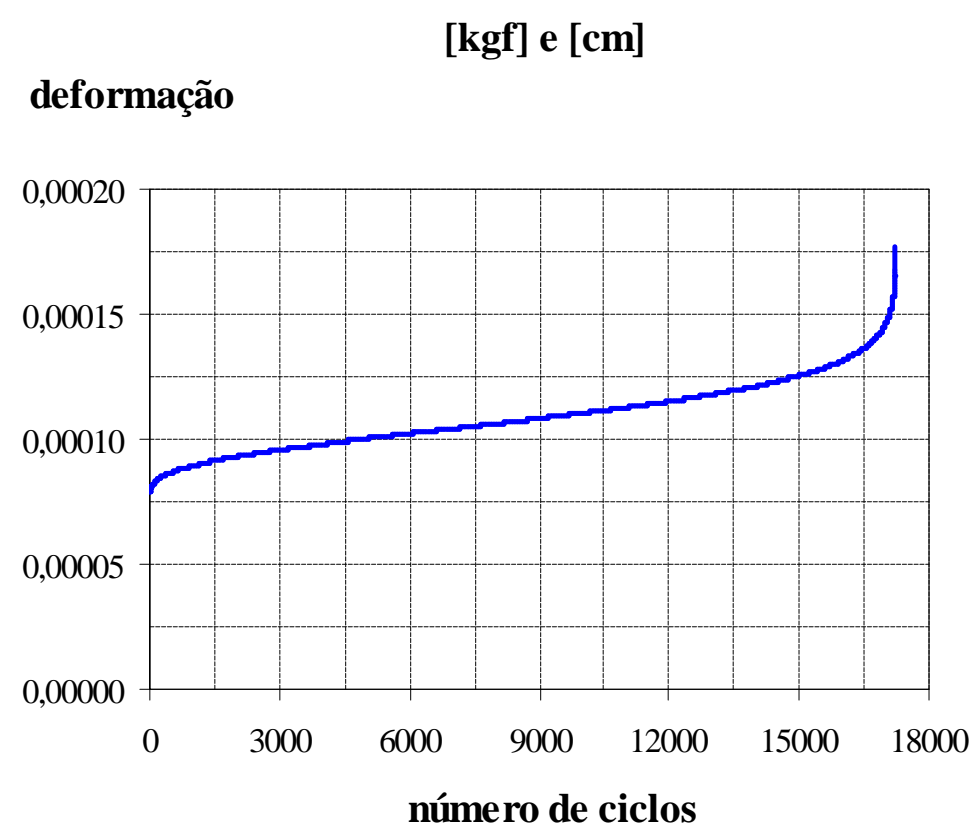

\section{deformação \\ $[\mathbf{k N}] \mathbf{e}[\mathbf{m}]$}

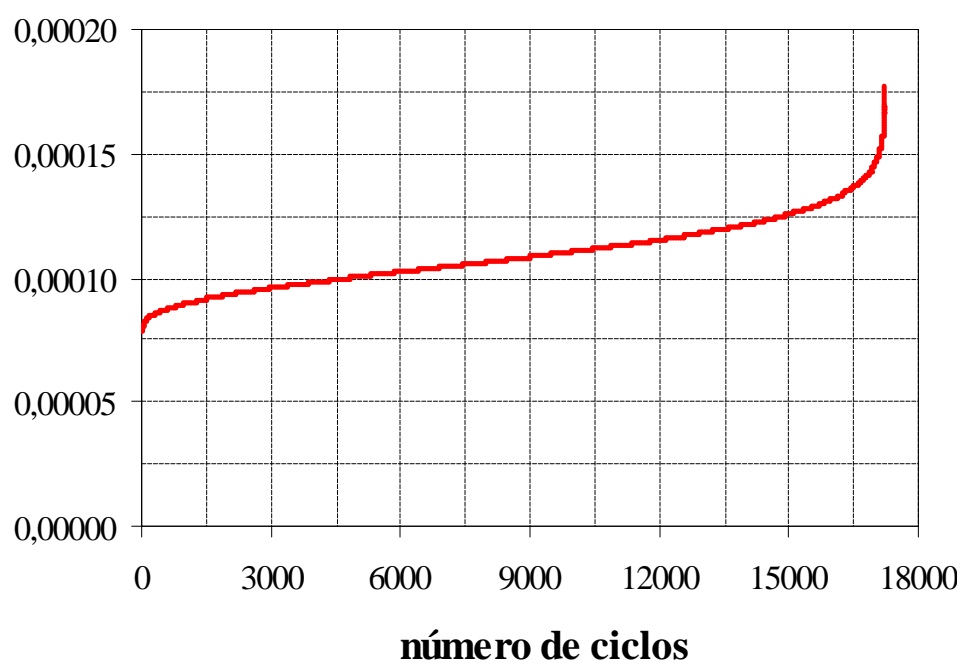

Figura 6.8. Deformação $x$ número de ciclos para carregamento cíclico para amplitude de tensão constante em $80 \%$ da tensão máxima, com as unidades no sistema métrico e internacional. 
Observando-se a Figura 6.8 percebe-se que os resultados são idênticos quaisquer que sejam as unidades utilizadas, sendo os parâmetros do modelo invariantes.

O passo seguinte foi definir os parâmetros $B, C$ e $N$, que melhor representassem o comportamento do concreto em tração. Para isso foram escolhidas várias combinações dos parâmetros citados (ver Tabela 6.1). Aplicaram-se carregamentos repetidos de amplitude de tensão constante em 70, 75, 80, 85, 90 e 95\% da tensão máxima, a fim de traçar curvas da amplitude de tensão $x$ número de ciclos (curvas $\mathrm{S}-\mathrm{N}$ ).

Tabela 6.1. Parâmetros $B, C$ e $N$.

\begin{tabular}{|c|c|c|c|c|c|}
\hline $\begin{array}{r}\text { Curva } \\
\text { Parâmetros } \\
\end{array}$ & $\mathbf{0}$ & 1 & 2 & 3 & 4 \\
\hline $\mathbf{B}$ & $-10,0$ & $-9,0$ & $-2,0$ & $-3,0$ & $-0,5$ \\
\hline $\mathrm{C}$ & 0,1 & 0,1 & 0,1 & 0,1 & 0,1 \\
\hline $\mathbf{N}$ & $-0,4$ & $-0,35$ & $-0,62$ & $-0,54$ & $-0,93$ \\
\hline
\end{tabular}

Compararam-se as curvas S-N obtidas com a curva S-N dada pela equação (2.2), sugerida pelo Fatigue of Concrete Structures - CEB (1988), conforme pode ser visualizado na Figura 6.9.

\section{Curva S-N}

$\sigma_{\text {máx }} / \mathbf{f}_{\text {ctm }}$

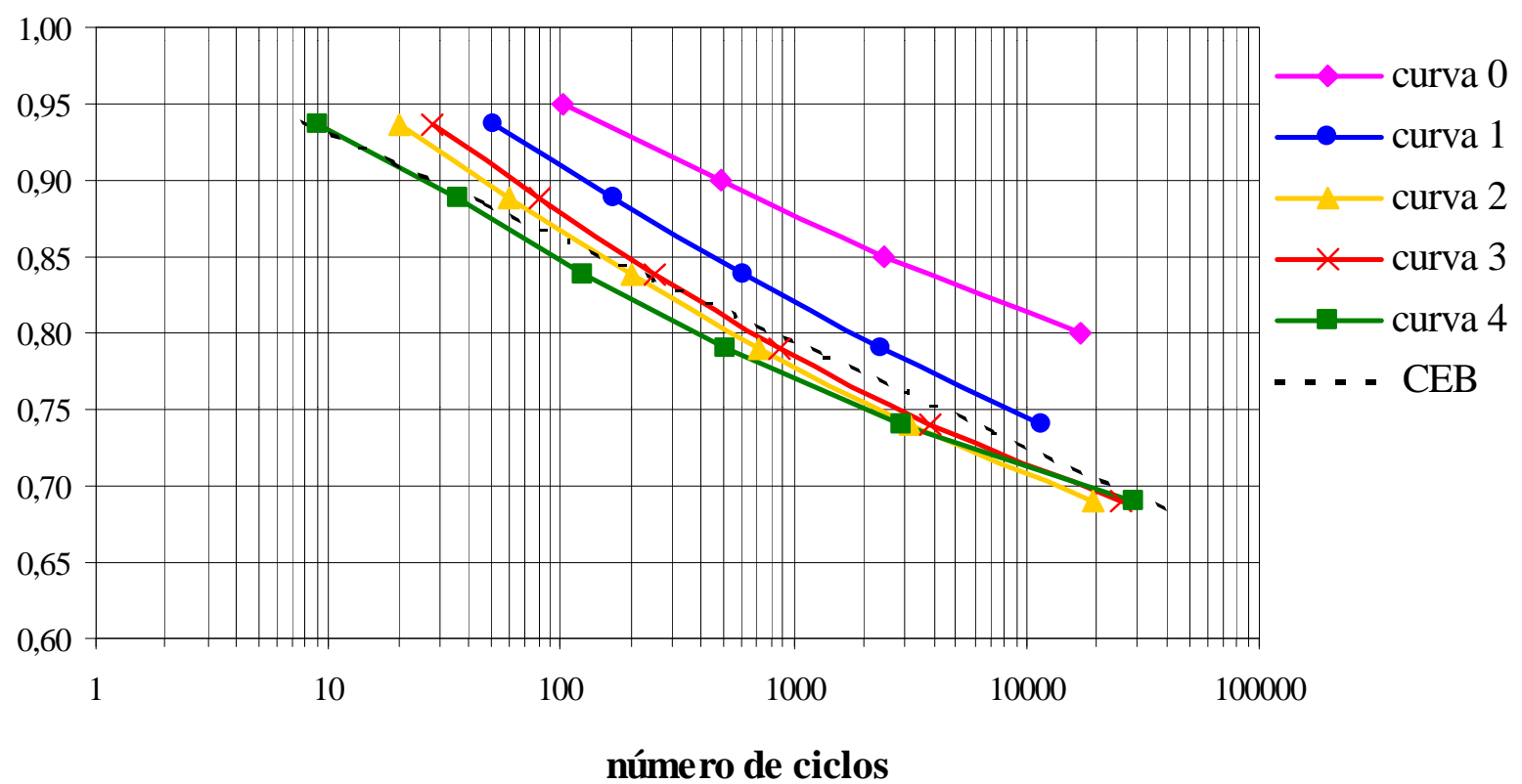

Figura 6.9. Curvas $\mathrm{S}-\mathrm{N}$ para calibração dos parâmetros com o CEB. 
Com base na Figura 6.9 optou-se por trabalhar com os parâmetros da curva 4 por apresentar resultados bem próximos aos valores obtidos pelo CEB. A Figura 6.10 apresenta a curva tensão $x$ deformação para carregamento monotônico e carregamento cíclico para amplitude de carga em $70 \%, 80 \%$ e $90 \%$ da carga última obtida com os parâmetros da curva 4.

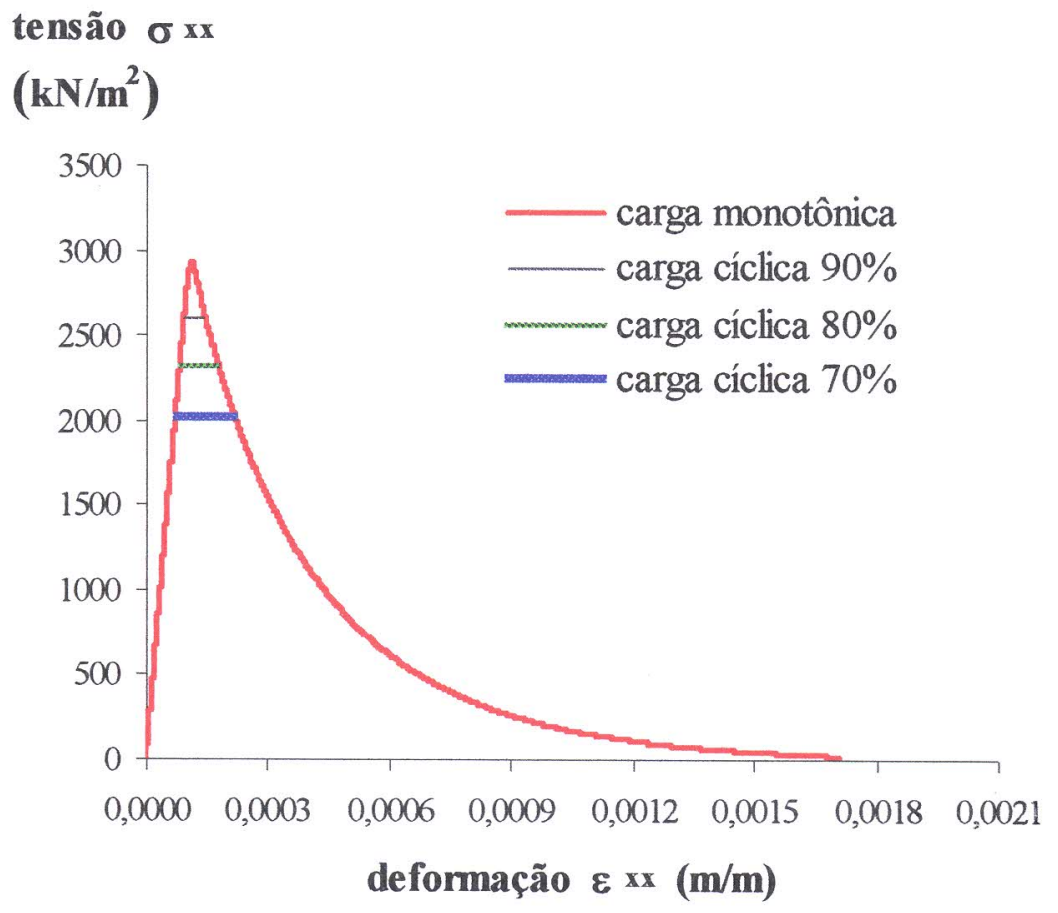

Figura 6.10. Tensão $x$ deformação para carregamento monotônico e cíclico para amplitude de tensão constante em 70, 80 e 90\% da tensão máxima para os parâmetros da curva 4.

Na Figura 6.11 pode-se observar a curva deformação $x$ número de ciclos para carregamento cíclico com amplitudes de carga em $75 \%, 80 \%$ e $85 \%$ da carga última obtida com os parâmetros da curva 4 . 

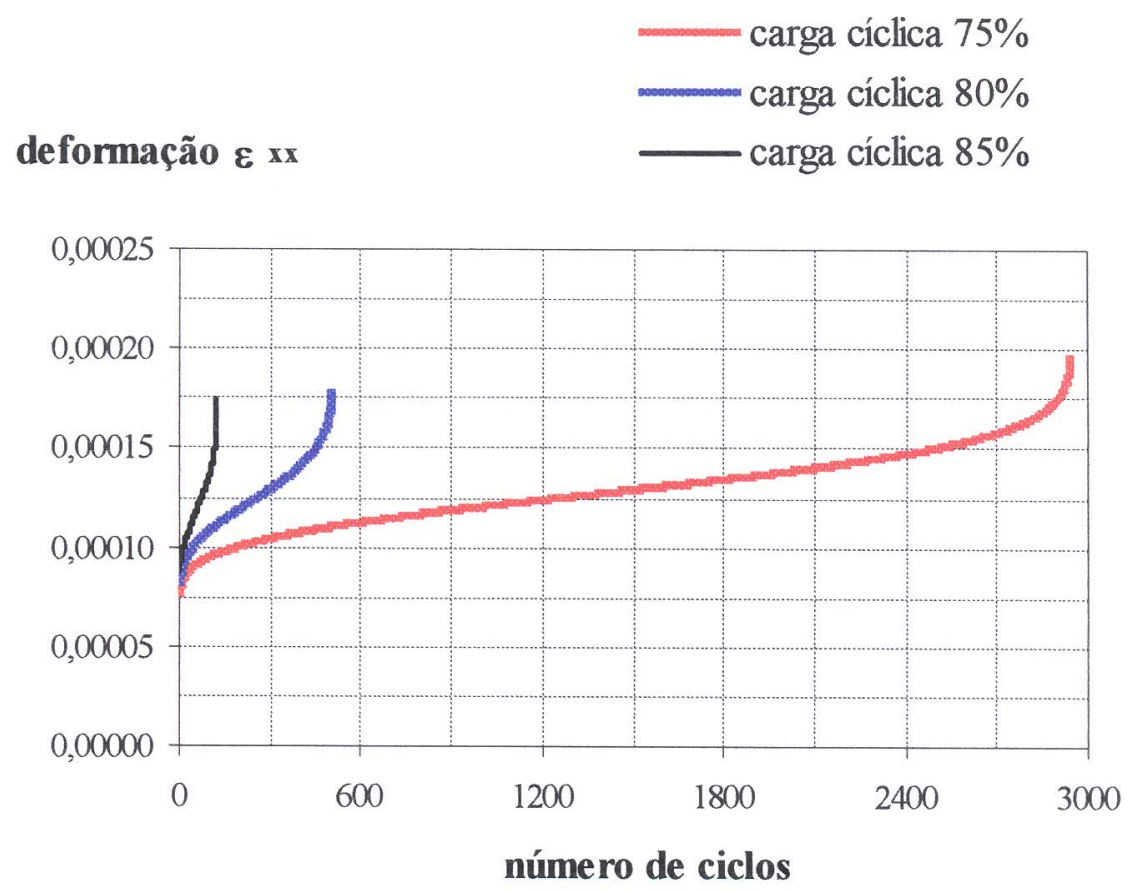

Figura 6.11. Deformação $x$ número de ciclos para carregamento cíclico com amplitudes de tensão constante em 75,80 e $85 \%$ da tensão máxima para os parâmetros da curva 4.

\subsection{EXEMPLO 3 - Ensaio de Provetas em Tração (Hordijk \& Reinhardt, 1992)}

Neste exemplo reproduziu-se as provetas em tração uniaxial simples apresentado no trabalho de Hordijk \& Reinhardt (1992) cuja representação esquemática pode ser visualizada na Figura 6.12. 


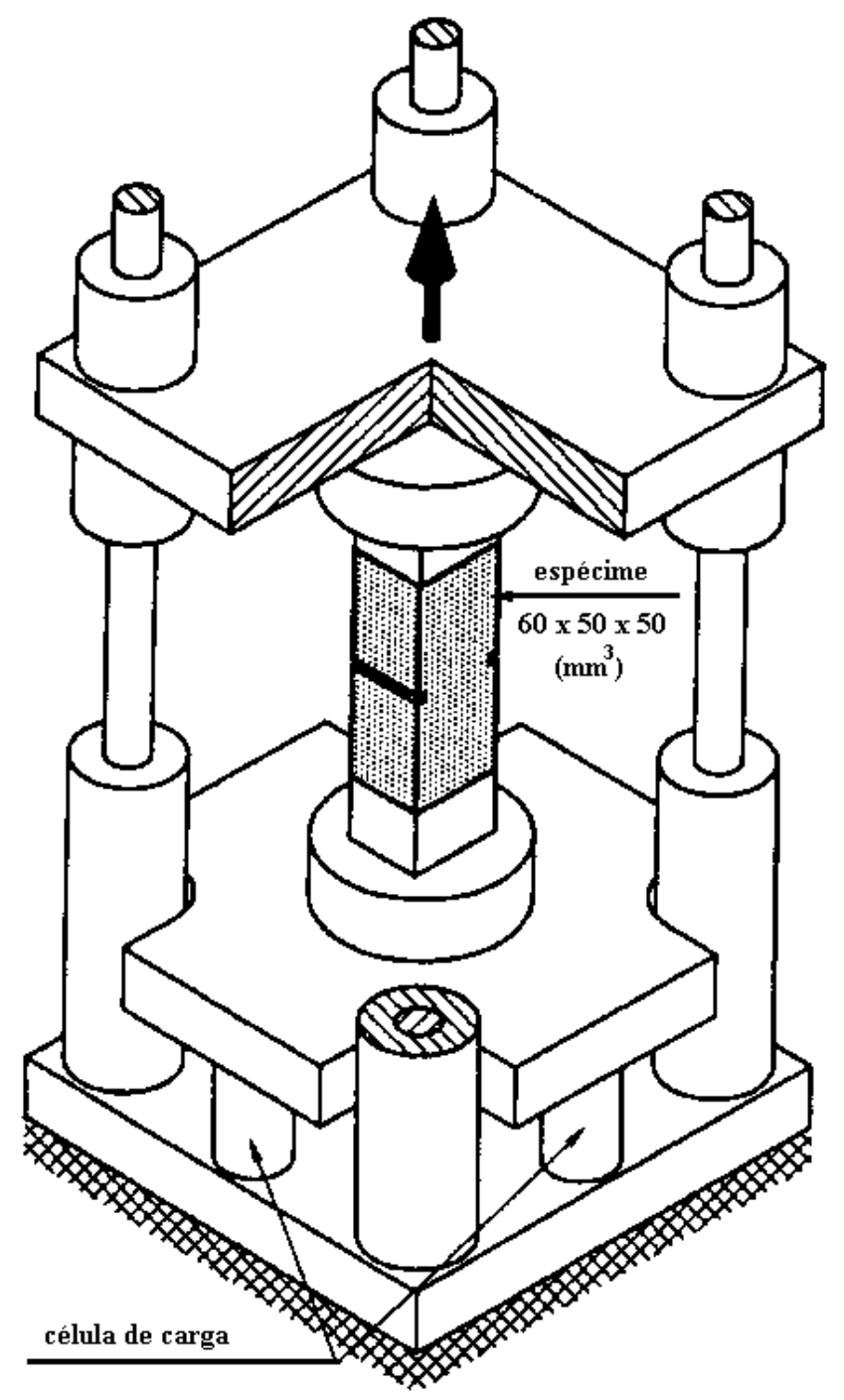

Figura 6.12. Representação esquemática das provetas do ensaio realizado por Hordijk \& Reinhardt (1992).

Nesse exemplo foram utilizadas as seguintes propriedades do modelo, com base nos resultados obtidos no Exemplo 2:

$$
\begin{aligned}
& E=30000 \mathrm{MPa} ; \\
& f_{t}=3,0 \mathrm{MPa} ; \\
& A=0,0027 \\
& B=-0,5 ; \\
& C=0,1 ; \\
& N=-0,93 .
\end{aligned}
$$


As Figuras 6.13 (a) e 6.13 (b) apresentam o modelo e a malha de elementos finitos utilizada para discretizar a proveta, respectivamente. Nesta discretização foram utilizados 250 elementos retangulares, com quatro nós, sendo cinco pontos de Gauss. Na figura 6.13 (c) é mostrado o modelo na sua constituição deformada e a figura 6.13 (d) ilustra um detalhe da malha deformada dos elementos centrais com a formulação de descontinuidade forte incorporada.

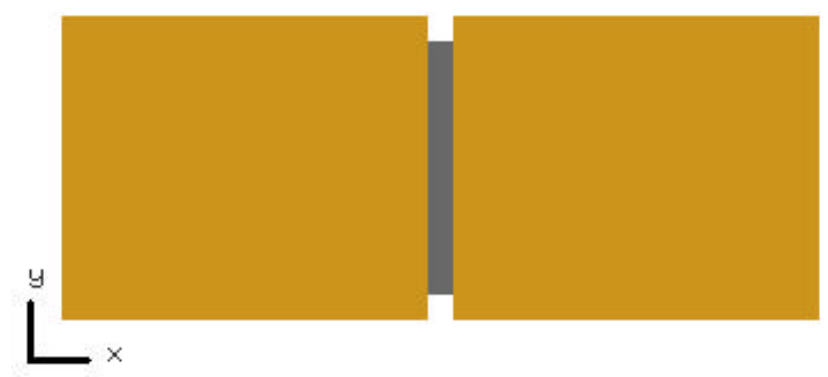

(a)

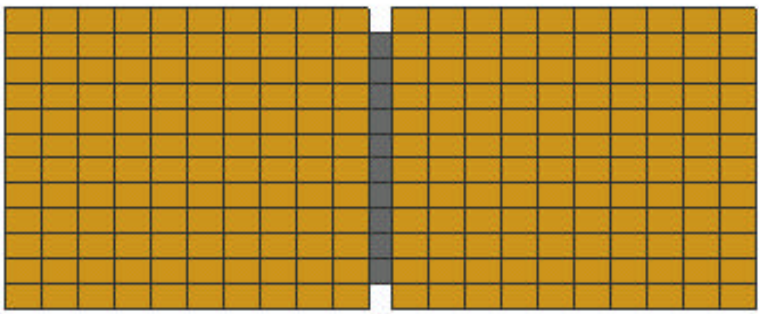

(b)

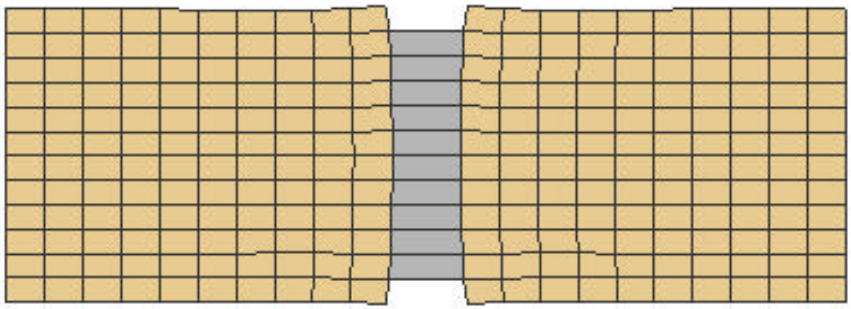

(c)

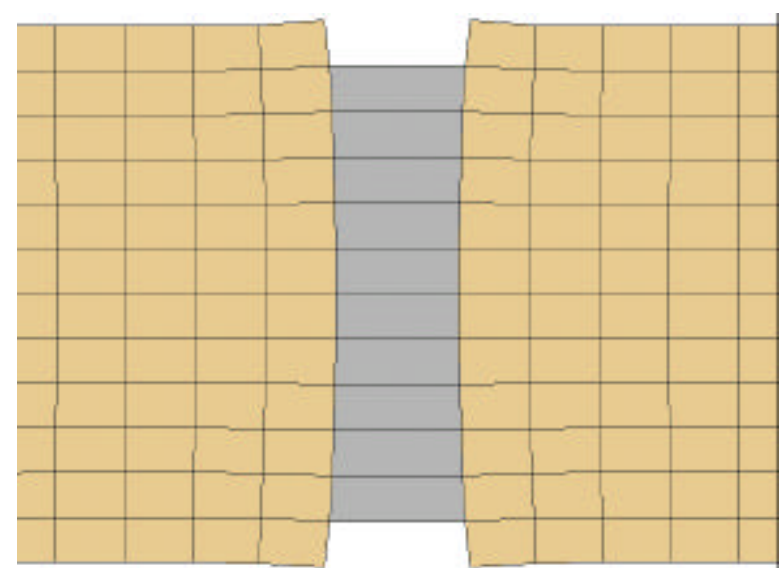

(d)

Figura 6.13. Malha de elementos finitos do ensaio da proveta. 
O modelo da proveta foi analisado para o caso de carregamento monotônico e para carregamentos repetidos de amplitude de força de tração constante em 70, 75, 79, 83, 91 e 95\% da força máxima obtida com carregamento monotônico. Os ciclos de carga foram aplicados segundo uma função senoidal, variando a força aplicada de 0 até amplitude de força.

Com os resultados das análises, plotou-se a curva amplitude de tensão nominal $x$ número de ciclos (curva S-N) apresentada na Figura 6.14.

\section{Curva S-N}

$\sigma_{\text {máx }} / \mathbf{f}_{\mathbf{c t m}}$

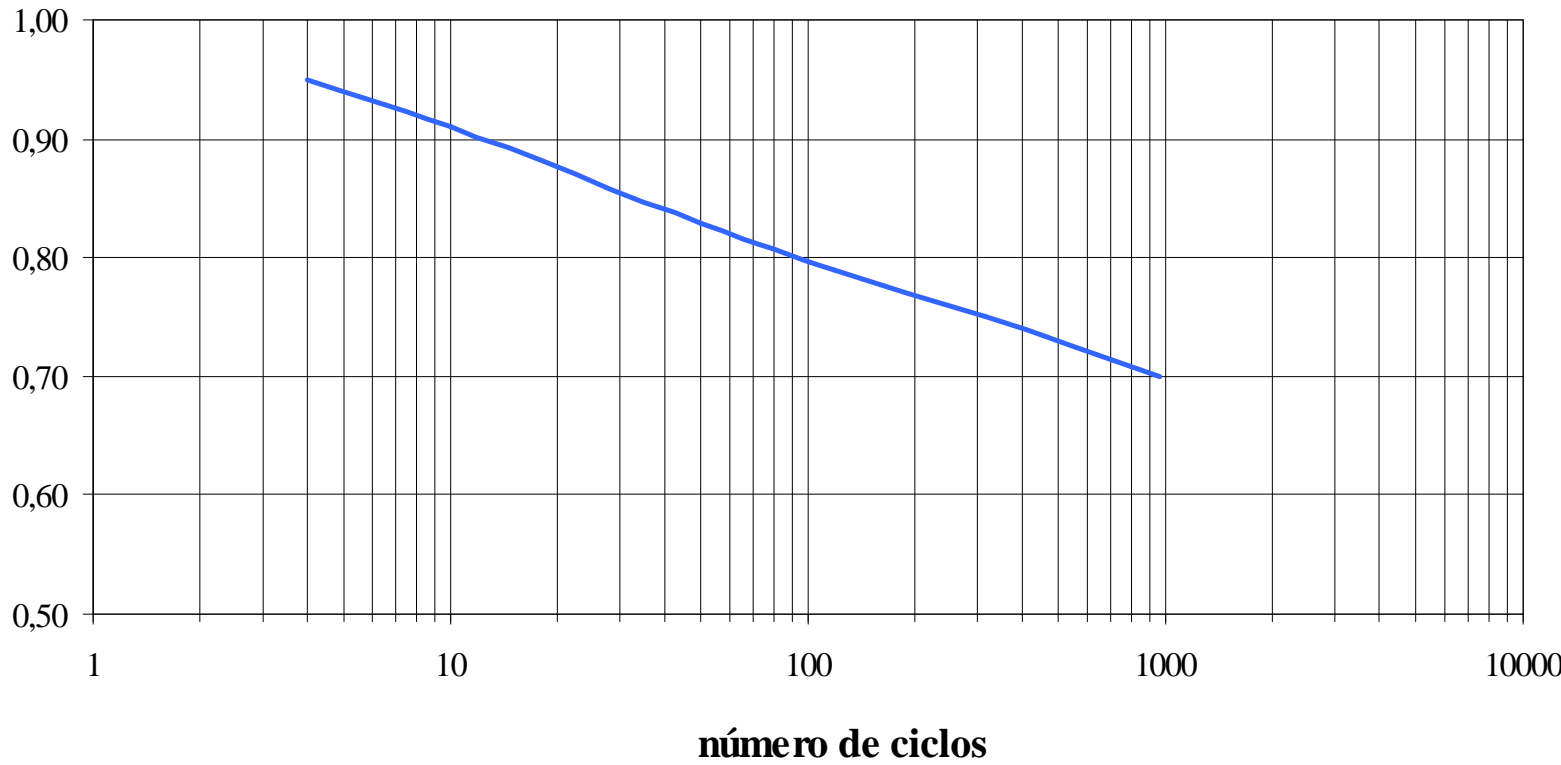

Figura 6.14. Curva S-N para o ensaio da proveta.

Tomando em particular o caso do carregamento cíclico com amplitude de força constante em $83 \%$ da força máxima, plotou-se o gráfico tensão $x$ deformação para carga monotônica e carga cíclica (Figura 6.15) e o gráfico de força $x$ deslocamento (Figura 6.16). A Figura 6.15 corresponde ao gráfico de tensão-deformação para um elemento situado na parte inferior da seção central. As curvas de carregamento cíclico foram plotadas apenas com os valores máximos para facilitar a visualização do gráfico. 


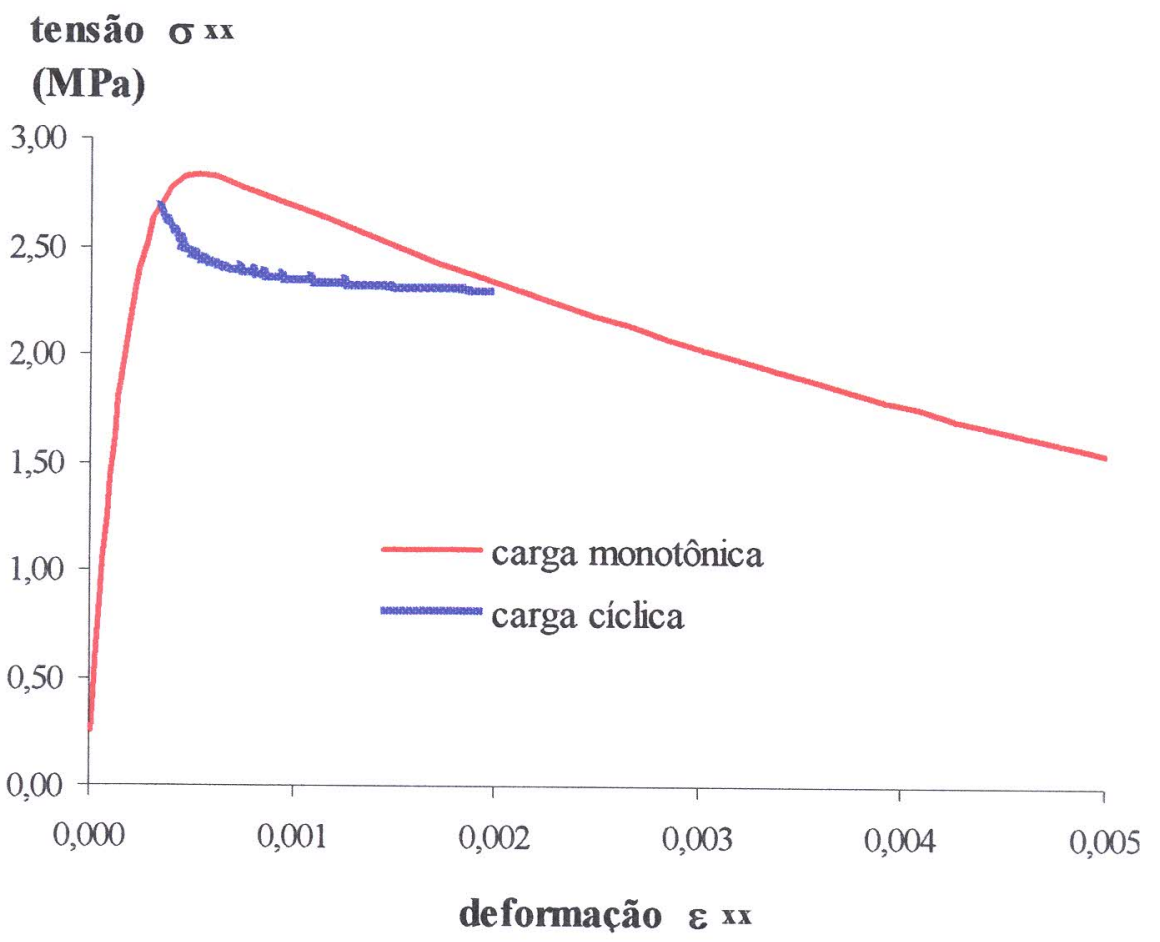

Figura 6.15. Curva tensão $x$ deformação no elemento próximo à ponta do entalhe para carga monotônica e carga cíclica com amplitude de força constante em $83 \%$ da força máxima.

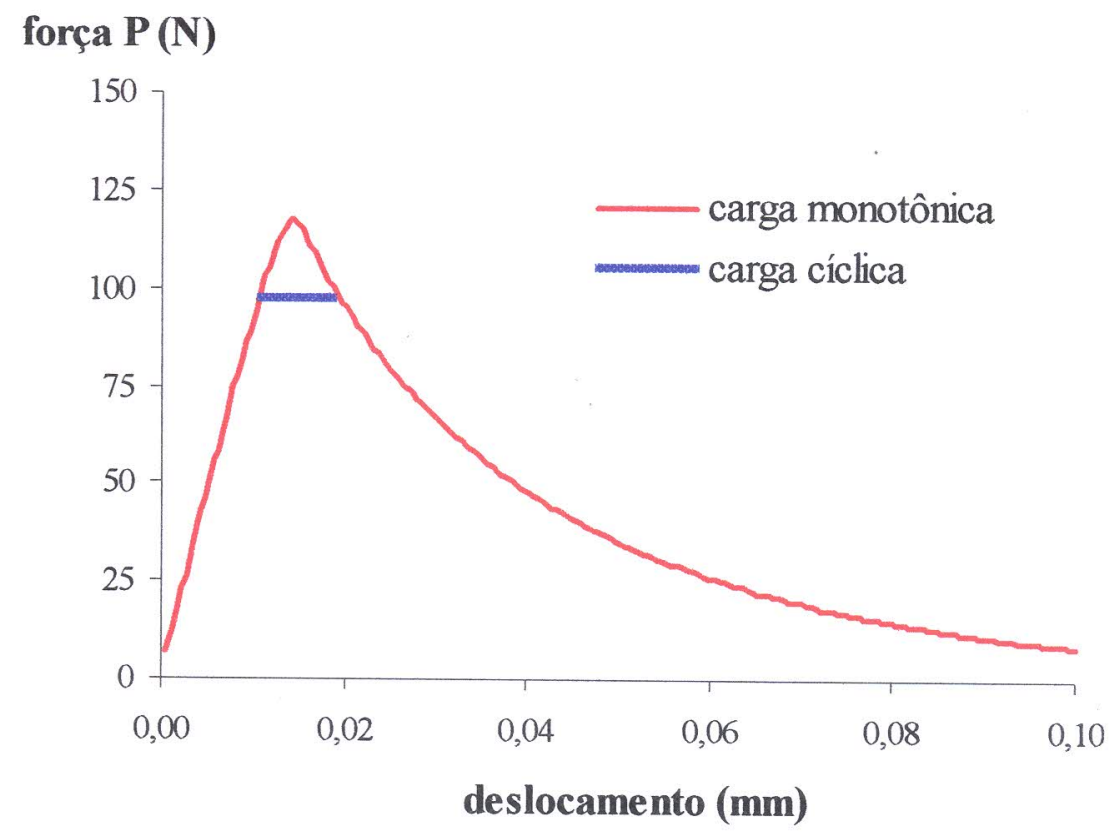

Figura 6.16. Curva força $x$ deslocamento para o ensaio da proveta para carga monotônica e carga cíclica com amplitude de força constante em $83 \%$ da força máxima. 
Na Figura 6.17 é apresentada a curva de deslocamento $x$ número de ciclos para carregamento cíclico com amplitude de força constante em $83 \%$ da força máxima. A evolução da deformação no elemento próximo à ponta do entalhe pode ser visualizada na Figura 6.18. Pode-se observar que as curvas definem bem as três fases do processo de fadiga: primeiramente ocorre um rápido incremento, até aproximadamente $10 \%$ do total de ciclos. Em seguida o incremento do deslocamento (ou deformação) torna-se uniforme até aproximadamente $80 \%$ do total de ciclos, e logo se produz de novo um rápido aumento até a ruptura.

\section{deslocamento}

(mm)

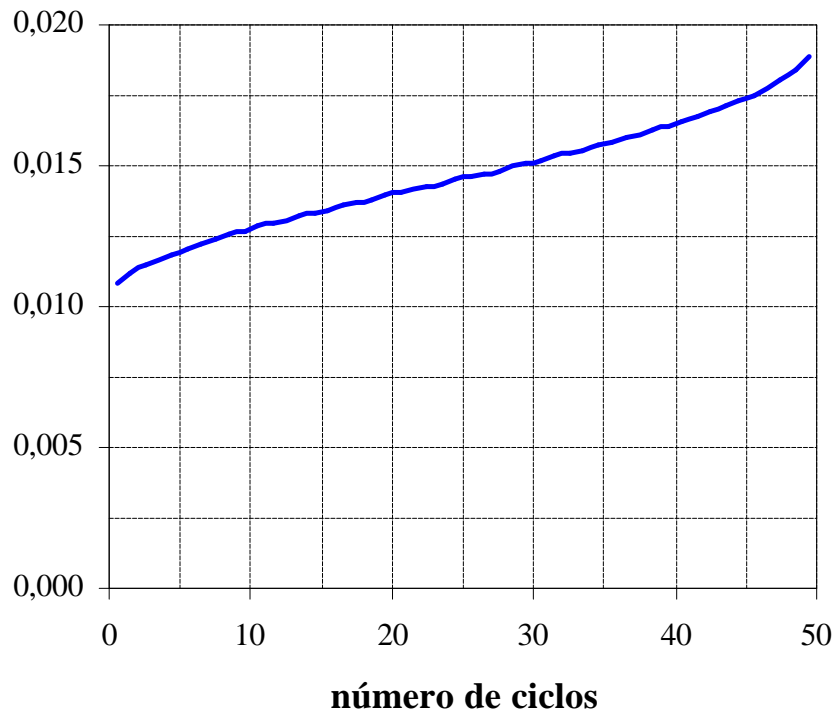

Figura 6.17. Curva deslocamento $x$ número de ciclos para o ensaio da proveta para carga cíclica com amplitude de tensão constante em $83 \%$ da tensão máxima. 


\section{deformação}

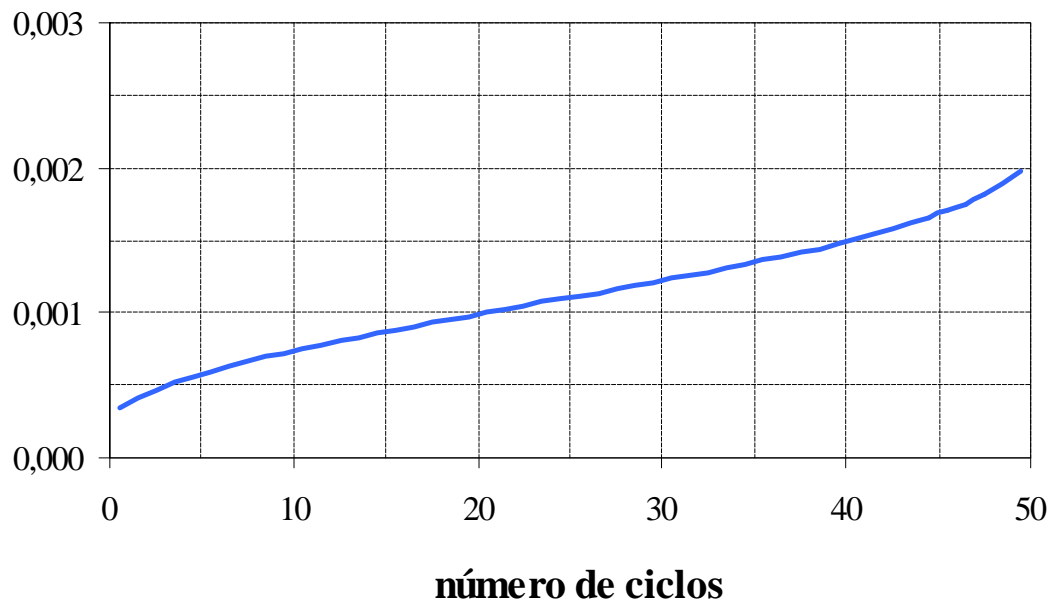

Figura 6.18. Curva deformação $x$ número de ciclos para o ensaio da proveta para carga cíclica com amplitude de força constante em $83 \%$ da força máxima.

Qualitativamente os resultados obtidos representam satisfatoriamente os ensaios da proveta de Hordijk \& Reinhardt (1992). Infelizmente os valores não puderam ser comparados diretamente, pois os ensaios experimentais dos autores foram feitos para carregamento alternado (compressão e tração alternadamente) e o modelo proposto neste trabalho contempla apenas degradação por tração cíclica.

\subsection{EXEMPLO 4 - Viga Bi-Apoiada}

Neste exemplo analisou-se uma viga bi-apoiada de $10 \mathrm{~cm}$ de largura, com carga concentrada vertical para baixo no meio do vão e um entalhe inferior também no meio do vão (Figura 6.19).

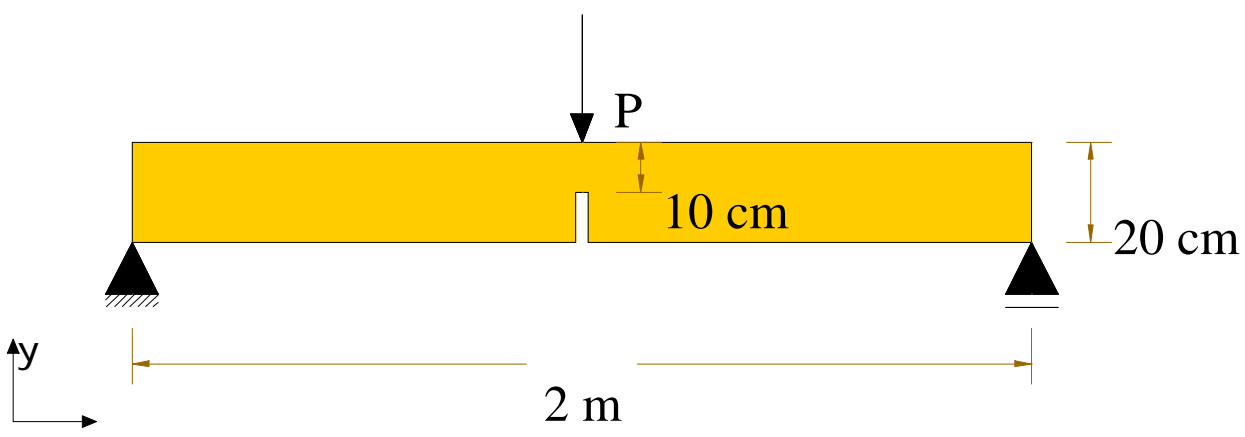

Figura 6.19. Esquema da viga entalhada. 
Para a análise da viga foram adotadas as seguintes propriedades do modelo:

$$
\begin{aligned}
& E=30000 \mathrm{MPa} ; \\
& f_{t}=3,3 \mathrm{MPa} ; \\
& G_{f}=0,124 \mathrm{kN} / \mathrm{m} ; \\
& B=-0,5 ; \\
& C=0,1 ; \\
& N=-0,93 \\
& k=0,002 \mathrm{~m} .
\end{aligned}
$$

Calculando-se o parâmetro $A$ :

$$
\begin{aligned}
& r_{o}=\frac{f_{t}}{\sqrt{E}}=\frac{3300}{\sqrt{30000000}}=0,60 \\
& A=\frac{r_{o}{ }^{2} \cdot k}{G_{f}}=\frac{0,60^{2} \cdot 0,002}{0,12}=0,0061
\end{aligned}
$$

A Figura 6.20 (a) apresenta a malha de elementos finitos utilizada para discretizar a viga. Nesta discretização foram utilizados 1110 elementos triangulares, com três nós, sendo um ponto de Gauss. Pode-se observar na Figura 6.20 (b) um detalhe da região próxima ao entalhe, onde se utilizou uma malha mais refinada. Os elementos em amarelo são elementos finitos com descontinuidade forte incorporada, enquanto que os demais são elementos finitos de comportamento elástico-linear. Na figura 6.20 (c) a viga é visualizada na sua constituição deformada. A figura 6.20 (d) ilustra um detalhe da malha deformada, destacando os elementos centrais com a formulação de descontinuidade forte incorporada.

Como o modelo constitutivo utilizado na análise é um modelo de dano à tração, os esforços de compressão não produzem danificação no material. Ou seja, a norma energética $\tau$ da equação (3.12) é dada por:

$$
\tau=\sqrt{\overline{\mathbf{o}}^{+}: \mathbf{C}^{-1}: \overline{\mathbf{o}}^{+}}
$$

onde $\overline{\text { ó }}^{+}$é o tensor de tensões efetivas positivas (de tração). 


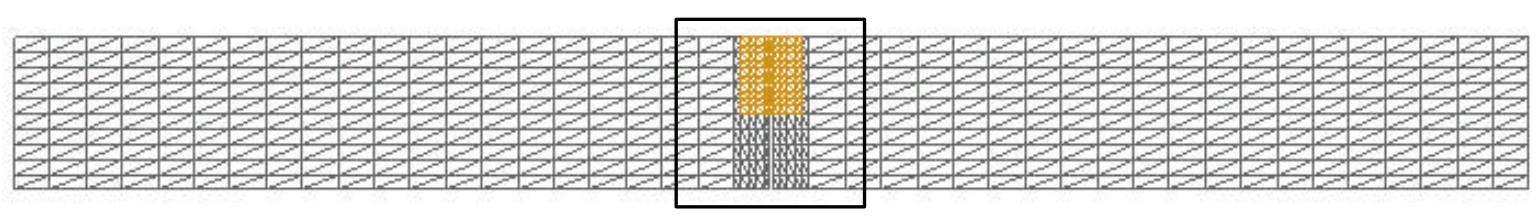

(a)

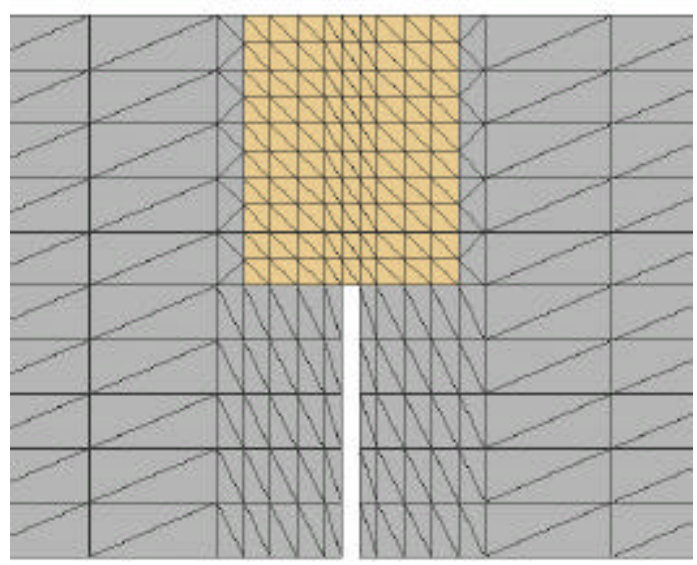

(b)

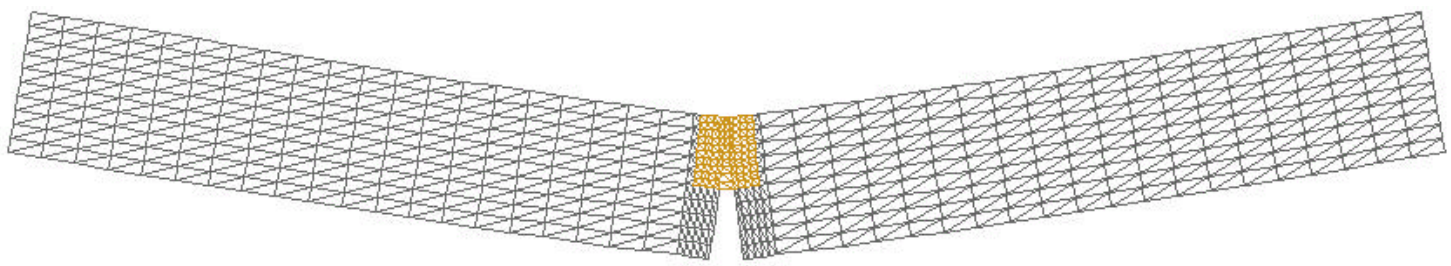

(c)

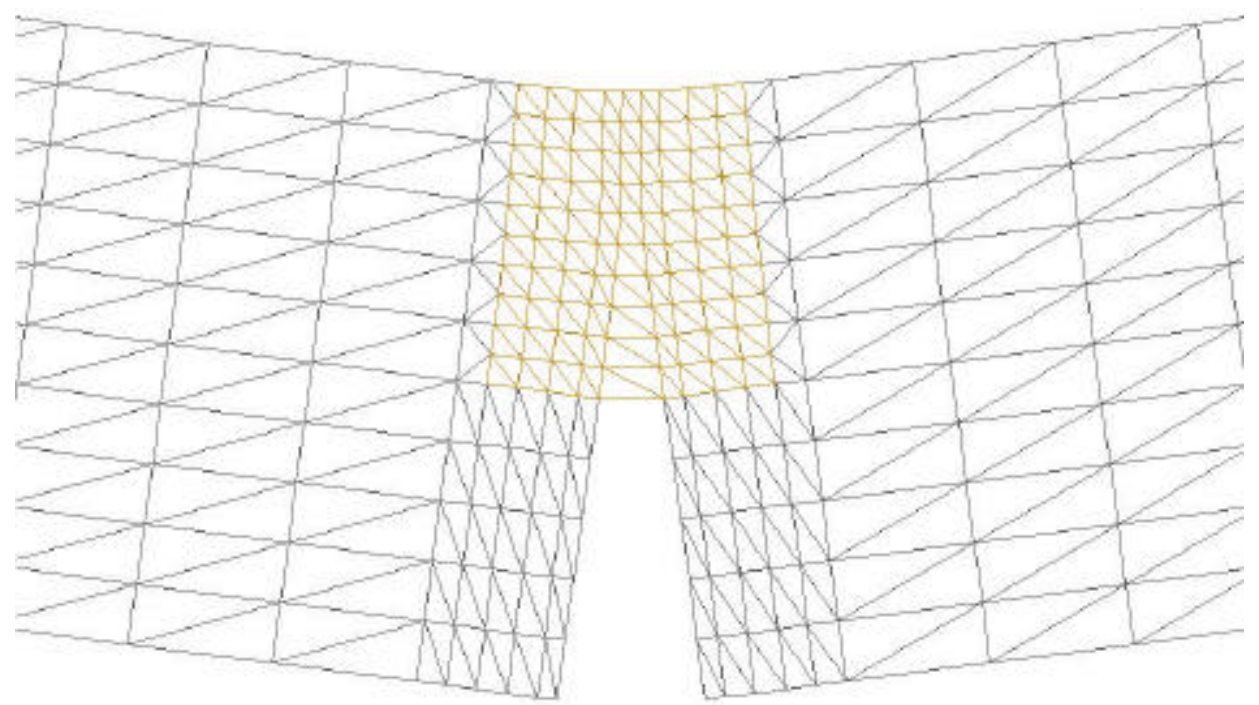

(d)

Figura 6.20. Malha de elementos finitos da viga entalhada. 
Assim como para a proveta, a viga entalhada também foi analisada para o caso de carregamento monotônico e para carregamentos repetidos de amplitude de força constante. Para o caso de carregamentos repetidos, os ciclos iniciaram-se após a aplicação de carga monotônica, conforme Figura 6.21, onde o valor da tensão de início do carregamento cíclico é a própria amplitude de tensão. Os ciclos de carga foram aplicados segundo uma função senoidal, variando a força aplicada de 0 a $P$, com amplitude de força $P$ constante em 81, 87, 90 e $95 \%$ da força máxima obtida com carregamento monotônico.

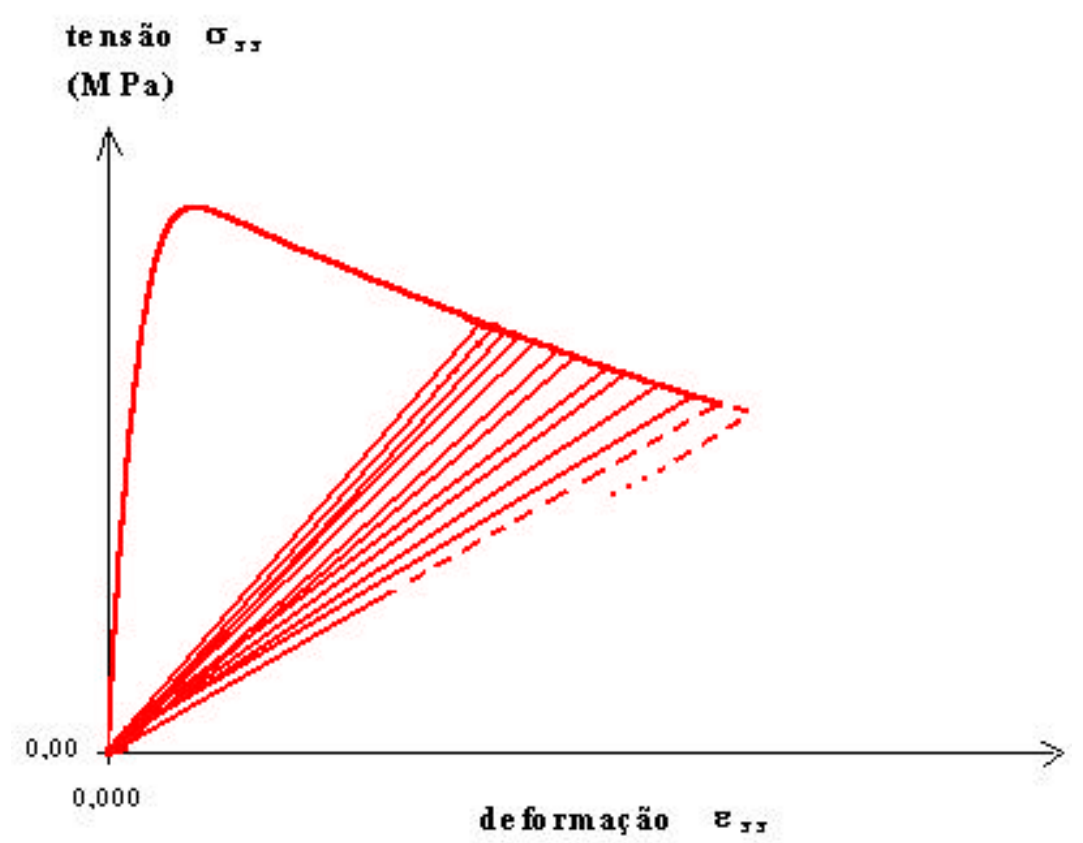

Figura 6.21. Esquema de aplicação do carregamento cíclico para a viga entalhada.

Com os resultados das análises plotou-se a curva amplitude de tensão nominal $x$ número de ciclos (curva S-N) apresentada na Figura 6.22. 


\section{Curva S-N}

$\sigma$ máx $/ \mathbf{f}_{\text {ctm }}$

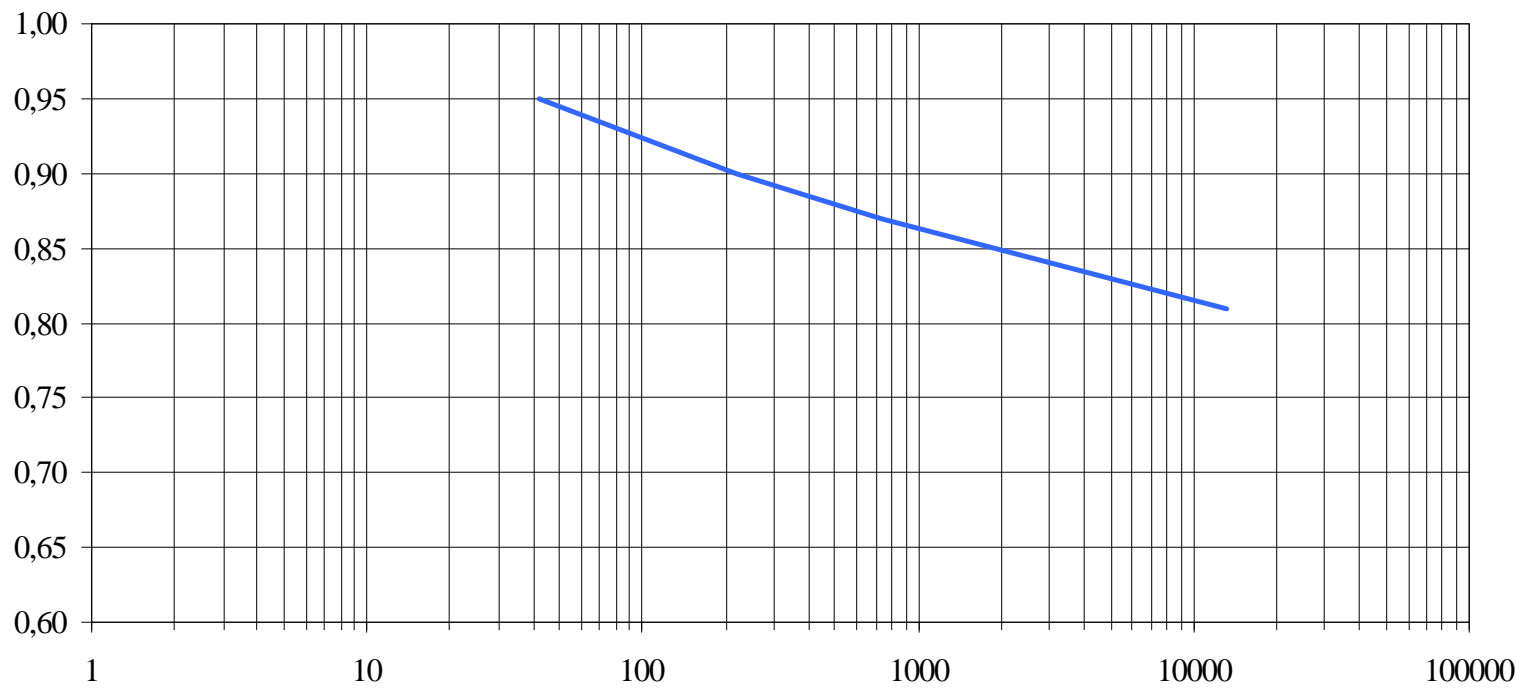

número de ciclos

Figura 6.22. Curva S-N para a viga entalhada.

Tomando em particular o caso do carregamento cíclico com amplitude de força constante em $87 \%$ da força máxima, plotaram-se as evoluções da tensão no elemento próximo da ponta do entalhe (Figura 6.23) e da força aplicada (Figura 6.24). Novamente, optou-se por plotar as curvas de carregamento cíclico apenas com os valores máximos a fim de facilitar a visualização do gráfico. 


\section{tens ão $\sigma_{\mathrm{xx}}$}

(MPa)

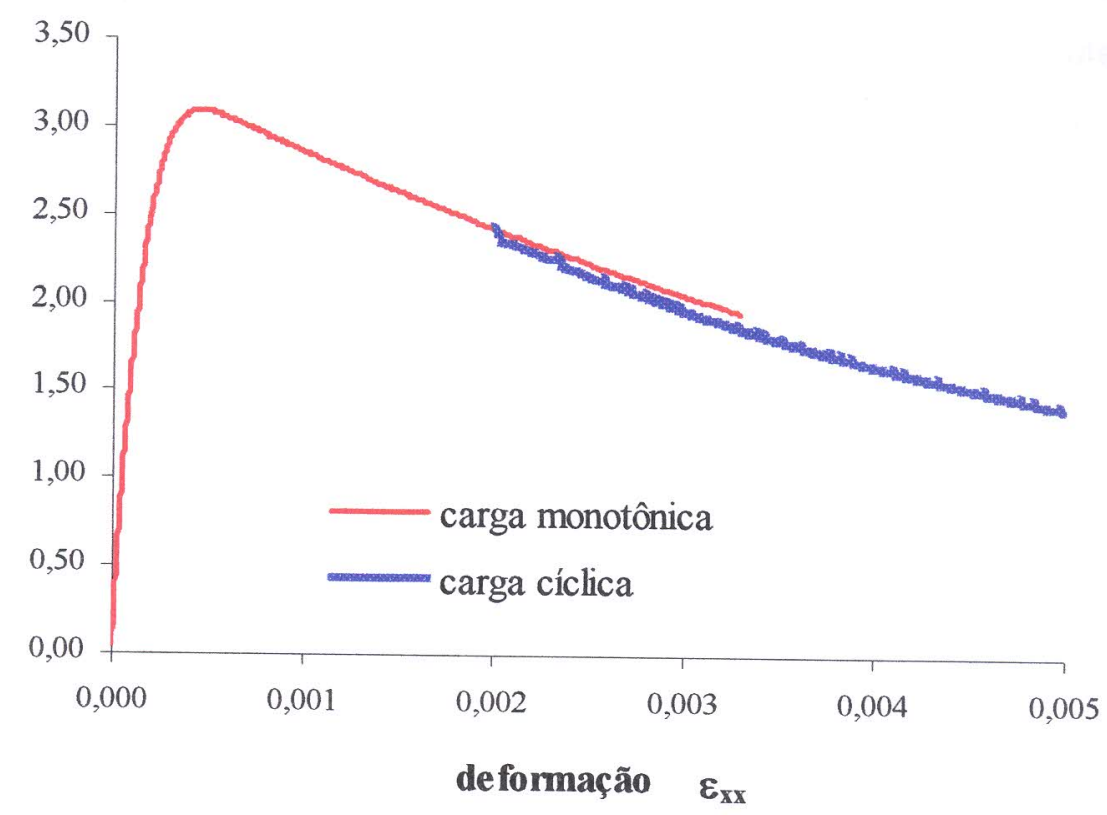

Figura 6.23. Curva tensão $x$ deformação no elemento próximo à ponta do entalhe para a viga entalhada para carga monotônica e carga cíclica com amplitude de força constante em $87 \%$ da força máxima.

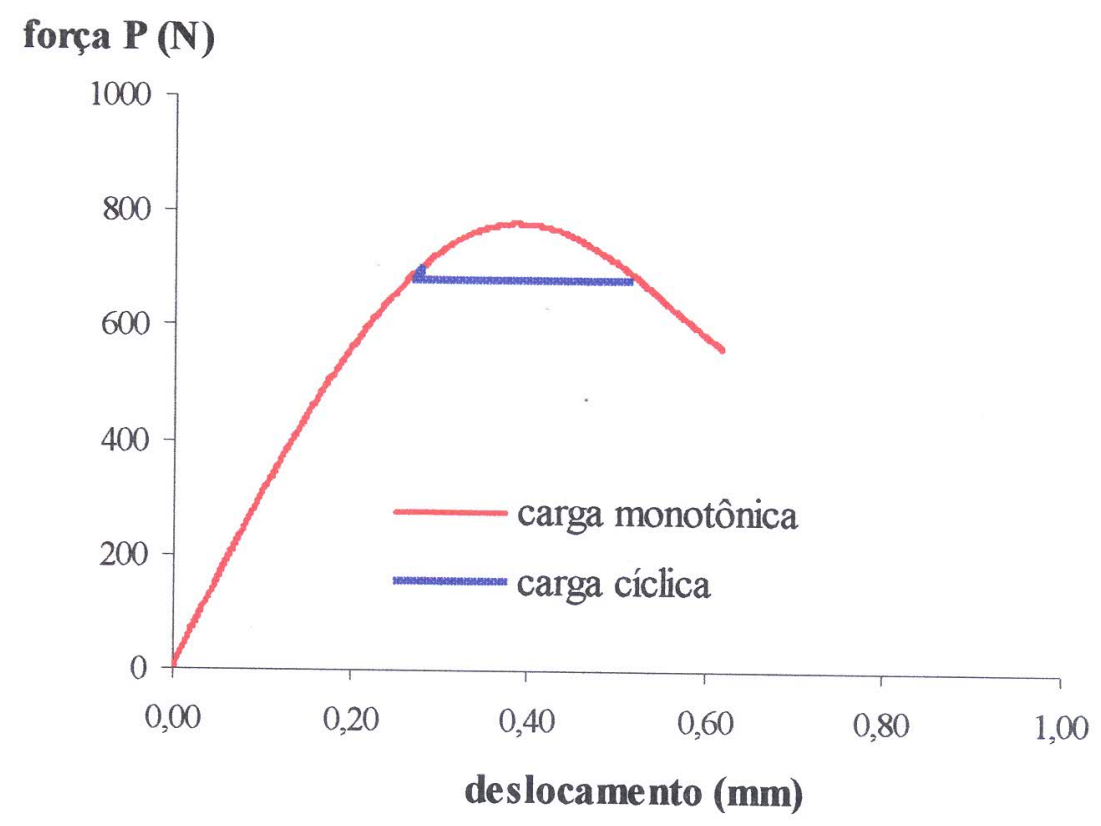

Figura 6.24. Curva força $x$ deslocamento para a viga entalhada para carga monotônica e carga cíclica com amplitude de força constante em $87 \%$ da força máxima. 
Na Figura 6.25 pode ser visualizada a curva de deslocamento $x$ número de ciclos para carregamento cíclico com amplitude de força constante em $87 \%$ da força máxima. A evolução da deformação no elemento próximo a ponta do entalhe é apresentada na Figura 6.26. Novamente observa-se as três fases do processo de fadiga reproduzidas pelas curvas.

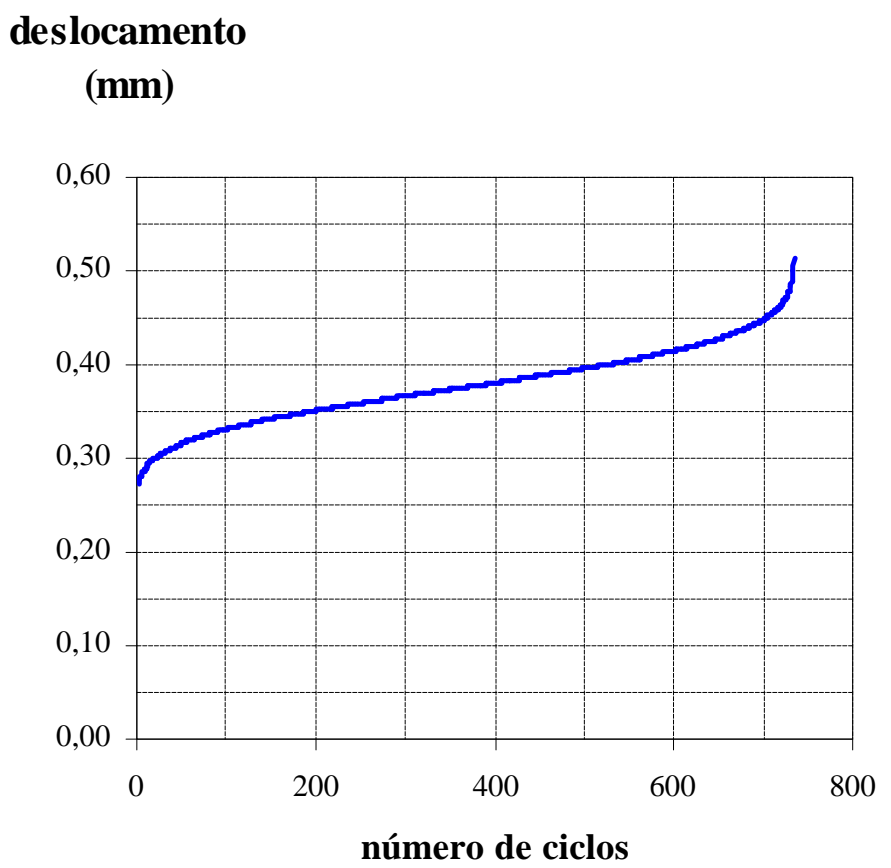

Figura 6.25. Curva deslocamento $x$ número de ciclos para a viga entalhada para carga cíclica com amplitude de força constante em $87 \%$ da força máxima.

\section{deformação}

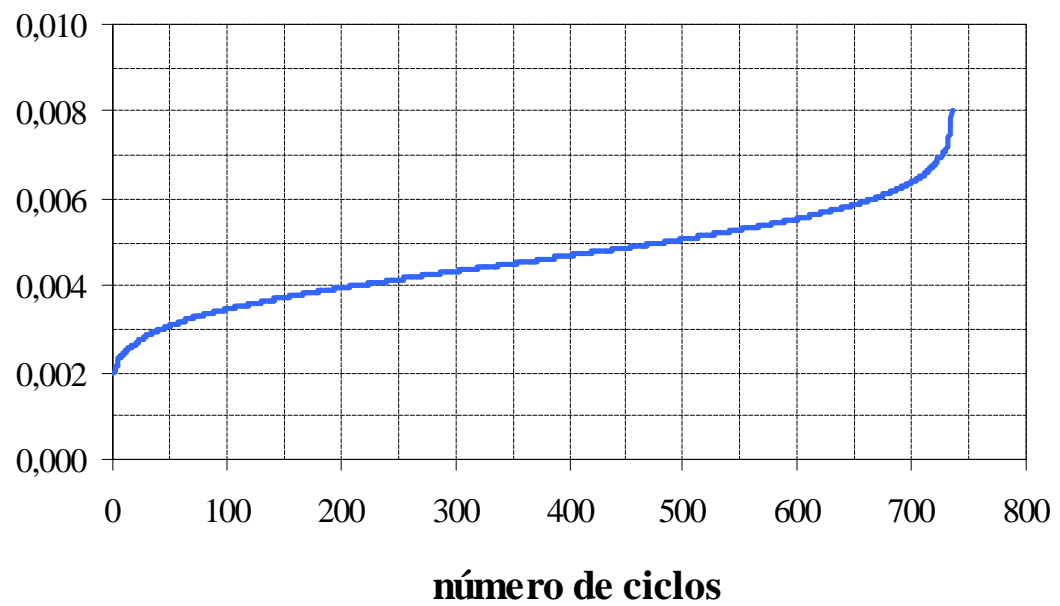

Figura 6.26. Curva deformação $x$ número de ciclos no elemento da ponta do entalhe para a viga entalhada para carga cíclica com amplitude de força constante em $87 \%$ da força máxima. 
A Figura 6.27 mostra as tensões principais máximas $\left(\sigma_{1}\right)$ atuantes na proveta e na Figura 6.28 podem ser visualizadas as tensões normais $\left(\sigma_{\mathrm{xx}}\right)$. As figuras reproduzem o estágio final do processo de carregamento cíclico.
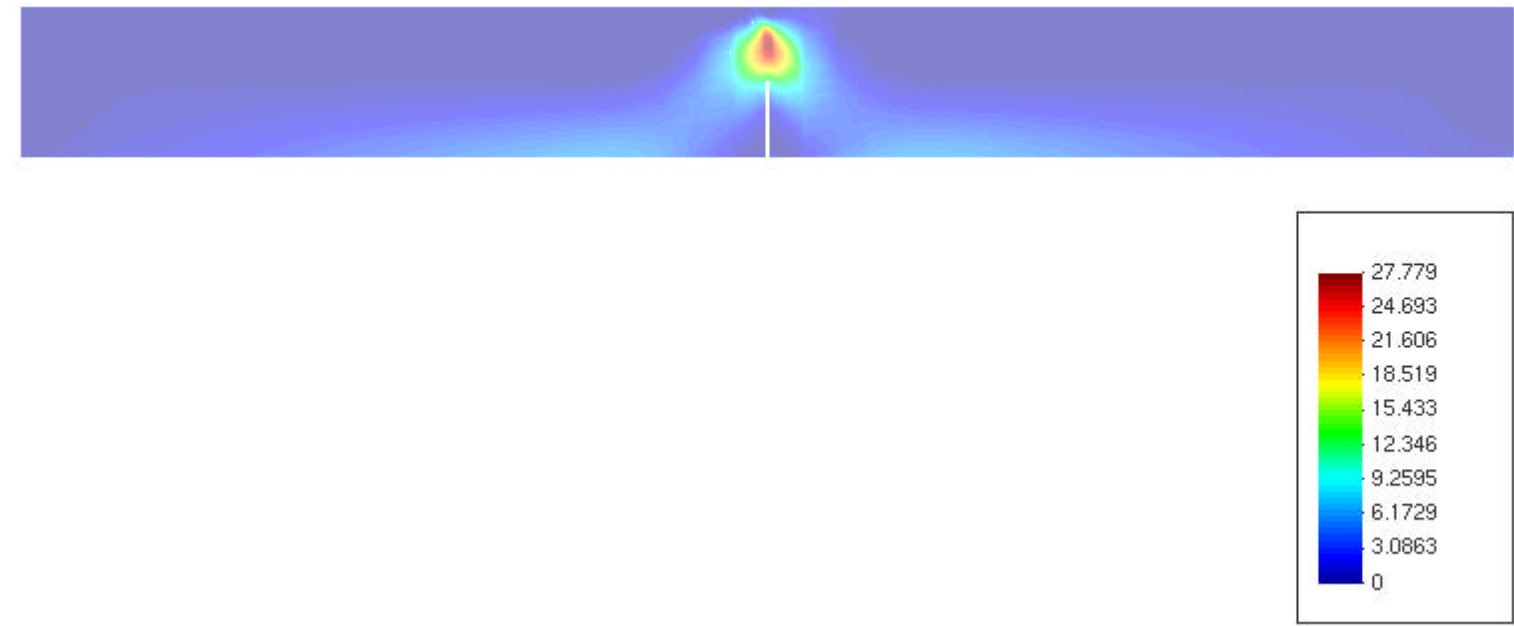

Figura 6.27. Tensões principais máximas $\sigma_{1}\left[10^{-1} \mathrm{MPa}\right]$ atuantes na viga entalhada para carga cíclica com amplitude de força constante em $87 \%$ da força máxima.
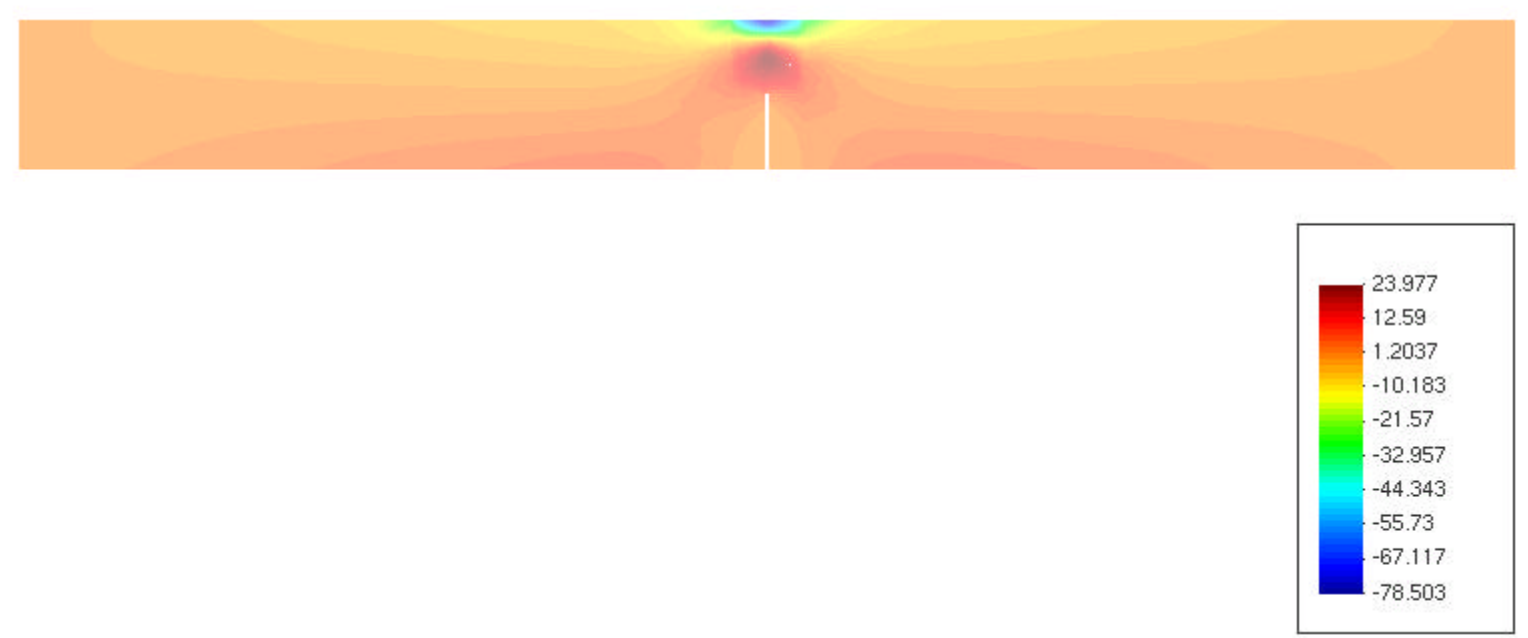

Figura 6.28. Tensões normais $\sigma_{\mathrm{xx}}\left[10^{-1} \mathrm{MPa}\right]$ atuantes na viga entalhada para carga cíclica com amplitude de força constante em $87 \%$ da força máxima.

A Figura 6.29 apresenta o gráfico de evolução do comprimento da fissura a partir do entalhe com o número relativo de ciclos $(\mathrm{n} / \mathrm{N}=$ número de ciclos $/$ número total de 
ciclos). Verifica-se que o modelo proposto é capaz de simular a propagação de fissuras, mesmo sem nenhum aumento no nível de carregamento aplicado, ou seja, a propagação deve-se somente à fadiga do material.

\section{comprimento \\ da fissura}

(cm)

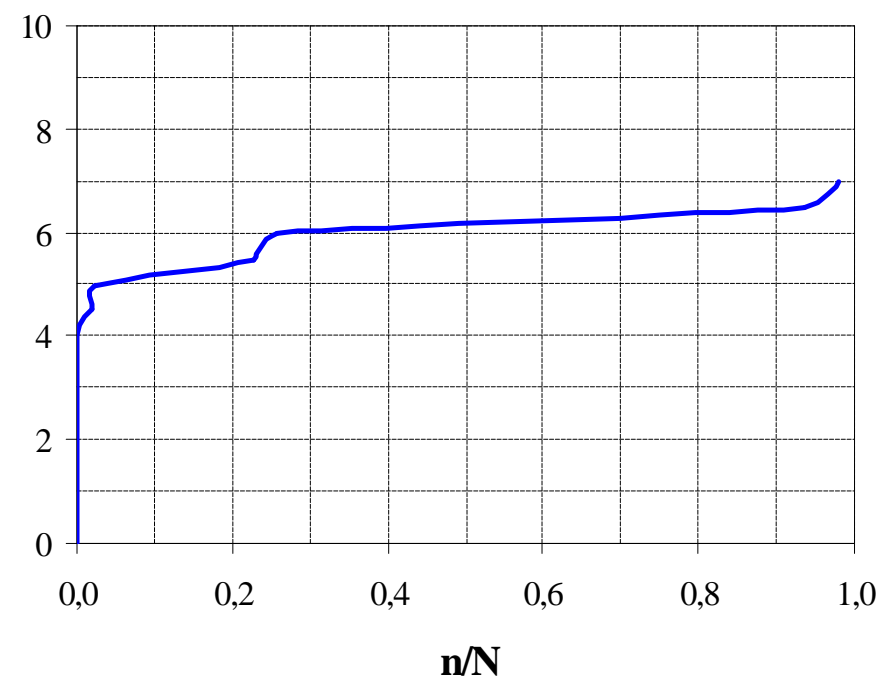

Figura 6.29. Curva comprimento da fissura $x$ número de ciclos para a viga entalhada para carga cíclica com amplitude de força constante em $87 \%$ da força máxima.

A viga entalhada é um exemplo clássico para análise de propagação de fissuras através da mecânica da fratura (three point notched beam). Manzoli (1998) analisou a mesma viga do exemplo estudado também utilizando elementos finitos com descontinuidade forte incorporada e lei de abrandamento exponencial para o modelo constitutivo, na análise da viga com carregamento monotônico. Os resultados numéricos reproduziram com sucesso os resultados experimentais obtidos por Peterson (1981).

Ensaios experimentais de fadiga da viga entalhada podem ser encontrados em Toumi \& Bascoul (2002). Os resultados obtidos no presente trabalho reproduziram qualitativamente o comportamento da viga obtido nos experimentos dos referidos autores. Entretanto, segundo os próprios autores, esse tipo de análise (em fadiga) é bastante complexo e apresenta muitas dificuldades na obtenção de resultados mais completos, o que dificultou uma comparação quantitativa. 


\section{Capítulo 7}

\section{CONSIDERAÇÕES FINAIS}

Foram propostas duas opções para estender o modelo de dano contínuo escalar de Oliver et al. (1999) para a simulação de fadiga em concreto. A primeira opção (Modelo 1) mostrou-se incapaz de representar umas das principais propriedades verificadas experimentalmente (Hordijk \& Reinhardt, 1992). Somente a segunda opção (Modelo 2) propiciou uma envoltória fixa para as curvas das distintas ações cíclicas. Essa envoltória coincide com a curva da resposta monotônica.

Além disso, esse modelo também foi capaz de reproduzir a redução da rigidez e o acréscimo da deformação com o número de ciclos verificados por Hordijk \& Reinhardt (1992) em seus ensaios experimentais. Os resultados numéricos reproduziram as três fases típicas do processo de fadiga: até aproximadamente 10\% do total de ciclos ocorre um rápido incremento na deformação, tornando-se o incremento de deformação uniforme até aproximadamente $80 \%$ do total de ciclos, e logo se produz novamente um rápido aumento na deformação até a ruptura.

Dada versatilidade do modelo, resultados quantitativos, tais como curvas S-N (ou curvas de Wöhler), podem ser reproduzidos mediante o ajuste adequado dos parâmetros adimensionais a partir de dados experimentais. Inclusive os parâmetros do modelo puderam ser calibrados a fim de reproduzir o comportamento do concreto em tração cíclica proposto pelo Fatigue of Concrete Structures - CEB (1988), tendo-se sugerido para tal os parâmetros $B=-0,5, C=0,1$ e $N=-0,93$. Pode-se considerar inclusive a retirada do parâmetro C da equação (3.40), visto que este pouco influencia no desempenho da função $\psi$.

Deve-se salientar que o modelo proposto, por apresentar as mesmas características do modelo original, pôde ser empregado no contexto da aproximação numérica de 
descontinuidades fortes (Oliver, 1996), permitindo a análise numérica eficiente de propagação de fissuras em problemas práticos, como os casos da proveta e da viga entalhada. Essas análises permitiram concluir que os resultados estruturais refletem as principais características do modelo constitutivo. A envoltória da curva estrutural para carregamento cíclico também corresponde à curva de resposta monotônica e a evolução dos deslocamentos com os ciclos também apresenta as três fases distintas do processo de fadiga.

Além disso, nos carregamentos cíclicos de amplitude de carga constante, a degradação contínua do material produziu aumento do comprimento da fissura com o número de ciclos, demonstrando que a formulação é capaz de simular a propagação de fissuras devido à fadiga do material.

Portanto, conclui-se que a formulação de elementos finitos com descontinuidade forte incorporada constitui uma promissora ferramenta para representar propagação de fissuras por fadiga. A qualidade da análise estrutural depende diretamente da capacidade do modelo constitutivo empregado em descrever o comportamento do material solicitado por ações cíclicas.

A fim de aperfeiçoar a modelagem de problemas de fadiga em estruturas de concreto ficam aqui algumas sugestões:

- verificar casos de carregamento alternado, com implementação do modelo de dano para compressão cíclica;

- verificar casos em que o carregamento cíclico não apresenta amplitude de tensão constante, ou seja, carregamento cíclico com carga variável;

- verificar casos em que a amplitude do carregamento cíclico não necessariamente varia de zero a um valor máximo, mas com o carregamento variando entre uma tensão mínima e uma tensão máxima. 


\section{Capítulo 8}

\section{REFERÊNCIAS BIBLIOGRÁFICAS}

AGUADO, A.; HEREI, A.; MARI, A. R.; OLIVEIRA, M. O. F. \& ROSELL, J. J. El Comportamiento a Fatiga de Estructuras de Hormigon en Masa, Armado y Pretensado. E.T.S. D’Enginyers de Camins, Canals i Ports. Barcelona, 1990.

BARBIRATO, J. C. C. Método dos Elementos de Contorno com a Reciprocidade Dual para a Análise Transiente Tridimensional da Mecânica do Fraturamento. Tese de Doutorado, Departamento de Estruturas, Escola de Engenharia de São Carlos. São Carlos, 1999.

BAZANT, Z. P. \& OH, B. H. Crack Band Theory for Fracture of Concrete. Materiaux et Construction. Vol. 16, $\mathrm{n}^{\circ}$ 93, 1983.

BAZANT, Z. P. \& XU, K. Size Effect in Fatigue Fracture of Concrete. ACI Mater. J., 88(4), 390-399, 1991.

BHATTACHARYA, B. \& ELLINGWOOD, B. Continuum Damage Mechanics Analysis of Fatigue Crack Initiation. Int. J. Fatigue, 20(9), 631-639, 1998.

BOCCA, P.; CARPINTERI, A. \& VALENTE, S. Mixed Mode Fracture of Concrete. Int. J. Solids Structures 27(9), 1139-1153, 1991.

BUCH, A. Fatigue Strength Calculation. Trans Tech Publications, Inglaterra, 1988.

CARPINTERI, A. Softening and Snap-Back Instability in Cohesive Solids. International Journal for Numerical Methods in Engineering, 28, 1521-1537, 1989.

CARPINTERI, A. Applications of Fracture Mechanics to Reinforced Concrete. Elsevier Science Publishers Ltd. New York, USA, 1992. 
CARPINTERI, A. Meccanica dei Materiali e della Frattura. Bologna, Pitagora, 1992.

CHABOCHE, J. L. Le Concept de Contrainte Effective Apliquée a l'Elasticité et a Viscoplasticité en Presence d'un Endomagement Anisotrope. Colloquium Euromech. Grenoble, 1979.

COMITE EURO-INTERNATIONAL DU BETON. Fatigue of Concrete Structures, Bulletin D'Information, n.188, 1988.

DRIEMEIER, L. Considerações sobre a Fadiga em Metais e o Comportamento do Concreto sob Solicitação Cíclica. Dissertação de Mestrado, Departamento de Estruturas, Escola de Engenharia de São Carlos. São Carlos, 1995.

FORREST, T. Fatigue of Metals. Oxford, Headington Hill Hall, 1970.

HILLERBORG, A.; MODÉER, M. \& PETERSSON, P. E. Analysis of crack formation and crack growth in concrete by means of fracture mechanics and finite elements. Cement Concrete Res., 6, 773-782, 1976.

HILLEBORG, A. Numerical Methods to Simulate Softening and Fracture of Concrete. In: Fracture Mechanics Applied to Concrete Structures. G. C. Shih, Ed. Martinus Nijhoff. The Hague, 1984.

HORII, H.; SHIN, H. C. \& PALLEWATTA, M. T. Mechanism of Fatigue Crack Growth in Concrete. Cement \& Concrete Composites, v. 14, p. 83-89, 1992.

HORDIJK, D. A. \& REINHARDT, H. W. Numerical and Experimental Investigation into the Fatigue Behavior of Plain Concrete. VII International Congress on Experimental Mechanics, Las Vegas, 1992.

JIRÁSEK, M. Comparative Study on Finite Elements with Embedded Discontinuities. Comput. Methods in Appl. Mech. Eng., 188, p. 307-330, 2002.

KACHANOV, M. Continuum Model of Nectium with Cracks. J. Eng. Mech. Div. ASCE, $\mathrm{n}^{\circ} 106,1980$.

KRAJCINOVIC, D. Constitutive Equations for Damaging Materials. J. Appl. Mech., ASCE, Vol. 50, 1983.

LEMAÎTRE, J. How to use Damage Mechanics. Nucl. Eng. And Design, nº 80, 1984. 
MANZOLI, O. L. Um Modelo Analítico y Numérico para la Simulación de Discontinuidades Fuertes em la Mecánica de Sólidos. Tese de Doutorado, Escola Tècnica Superior D’Enginyers de Camins, Canals i Ports, Universitat Politècnica de Catalunya, Barcelona, 1998.

MANZOLI, O. L., OLIVER, J. \& CERVERA, M. Localización de Deformaciones: Análisis y Simulación Numérica de Discontinuidades en Mecánica de Sólidos. Centro Internacional de métodos numéricos en Ingeniería (CIMNE), Monografía N. 44, p. 240, Barcelona, 1999.

MANZOLI, O. L. \& VENTURINI, W. S. Uma Nova Formulação do MEC para a Simulação Numérica de Descontinuidades Fortes na Mecânica de Sólidos. 21st CILAMCE, Rio de Janeiro, 2000.

MANZOLI, O. L. \& GONÇALVES, R. Um Modelo Constitutivo de Dano Contínuo para a Simulação de Propagação de Fissuras por Fadiga. XXX Jornadas SulAmericanas de Engenharia Estrutural, Brasília, 2002.

MAZARS, J. \& BAZANT, Z. P. Cracking and Damage: Strain Localization and Size Effect. Elsevier Applied Science, New York, USA, 1989.

MEHTA, P. K. \& MONTEIRO, P. J. M. Concreto: Estrutura, Propriedades e Materiais. Pini, São Paulo, SP, 1994.

OLIVER, J.; CERVERA, M.; OLLER, S. \& LUBLINER, J. Isotropic Damage Models and Smeared Crack Analysis of Concrete. In N. B. et. al., editor, SCI-C Computer Aided Analysis and Design of Concrete Structures, Swansea, 1990.

OLIVER, J. Modeling Strong Discontinuities in Solid Mechanics via Strain Softening Constitutive Equations. Int. J. Num. Meth. Eng., 39 (21), 1996.

OLIVER, J.; CERVERA, M. \& MANZOLI, O. L. On the Use of Strain-softening Models for the Simulation of Strong Discontinuities in Solids. In: René de Borst and Erik van der Giessen. Material Instability in Solids. John Wiley \& Sons Ltd. 1998.

OLIVER, J., CERVERA, M. \& MANZOLI, O. L. Strong Discontinuity and Continuum Plasticity Models: the Strong Discontinuity Approach. Int. J. Plasticity. 15, 319$351,1999$. 
OLIVER, J. On the Discrete Constitutive Models induced by Strong Discontinuity Kinematics and Continuum Constitutive Equations. Int. Journal of Solids and Structures, 37 (48-50), 7207-7229, 2000.

OliVER, J; HUESPE A. E.; PUlido M. D. G. \& CHAVES E. From Continuum Mechanics to Fracture Mechanics: the Strong Discontinuity Approach. Engineering Fracture Mechanics, 69 (2), 113-136, 2002.

ORTIZ, M. A Constitutive Theory for the Inelastic Behaviour of Concrete. Brown Univ. Repport., 1984.

PAPA, E.; MAIER, G. \& PROENÇA, S. P. B. Meccanica del Danneggiamento di Materiali e Strutture: Applicazioni al Calcestruzzo. Milano, Politecnico di Milano, 1991.

PAPA, 1993. A Damage Model for Concrete Subjected to Fatigue Loading. Eur. J. Mech., A/Solids 12, 429 - 440, 1993.

PAPA, E. \& TALIERCIO A. Anisotropic Damage Model for the Multiaxial Static and Fatigue Behaviour of Plain Concrete. Engineering Fracture Mechanics, 55 (2), 163 179, 1996.

PARIS, P. C \& ERDOGAN, F. Critical Analysis of Propagation Laws. J. Basic Eng., 85, 528-534, 1963.

PETERSSON, P. E. Crack Growth and Development of Fractures Zones in Plain Concrete and Similar Materials. Division of Building Materials, Rep. № 1006, 1981.

REINHARDT, H. W., Cornelissen, H. A. W. \& HORDJK, D. A. Tensile Tests and Failure Analysis of Concrete. ASCE Journal, 1986.

SAITO, M. \& IMAI, S. Direct Tensile Fatigue of Concrete by the Use of Friction Grips. ACI Journal, Vol. 80, $\mathrm{n}^{\circ}$ 5, p. 431-438, 1983.

SIMÓ, J. C.; OLIVER, J. \& ARMERO, F. An Analysis of Strong Discontinuities Induced by Strain-softening in Rate-independent Inelastic Solids. Comp. Mech., 12, 227-296, 1993.

SIMÓ, J. C. \& JU, J. W. Strain and Stress-Based Continuum Damage Models Formulation. Int. J. Solids Structures, 1997. 
TEPFERS, R. \& KUTTI, T. Fatigue Strength of Plain, Ordinary and Lightweight Concrete. ACI Journal, p. 635-652, Maio, 1979.

TOUMI, A. \& BASCOUL, A. Mode I Crack Propagation in Concrete under Fatigue:

Microscopic Observations and Modelling. Int. J. Numer. Anal. Meth. Geomech., 26, p. 1299-1312, 2002.

VAN MIER, J., Fracture Processes of Concrete, CRC Press, 1997. 


\section{BIBLIOGRAFIA COMPLEMENTAR}

ELICES, M.; GUINEA, G. V.; GÓMEZ, J.; \& PlANAS, J. The Cohesive Zone Model: Advantages, Limitations and Challenges. Engineering Fracture Mechanics, 69, 137$163,2002$.

HARTRANFT, R. J. Stress Singularity for a Crack with an Arbitrary Curved Crack Front. Eng. Fracture Mech., 7, 705-718, 1977.

IRWIN, G. R. Analysis of Stresses and Strains Near the End of a Crack Transversing a Plate. Trans. ASME, J. Appl. Mech., 1957.

LOPES JR., M. C. Modelagem Numérica do Crescimento de Fraturas Através do Método dos Elementos de Contorno. Dissertação de Mestrado, Departamento de Estruturas, Escola de Engenharia de São Carlos. São Carlos, 1996.

PEERLINGS, R. H. J.; BREKELMANS, W. A. M.; BORST, R. \& GEER, M. G. D. Gradient-enhanced Damage Modelling of High-cycle Fatigue. Int. J. Numer. Meth. Eng., 49, p. 1547-1569, 2000.

PIJAUDIER-CABOT, G. \& BAZANT, Z. P. Nonlocal Damage Theory. Journal of Eng. Mech. Vol. 113 n $^{\circ}$ 10, 1512-1533, 1987.

WILliaM, K. J.; HURLBUT, B. \& STURE, S. Experimental, Constitutive and Computational Aspects of Concrete Failure. In: Preprints, U.S. - Japan Seminar of Finite Analysis of Reinforced Concretes. Tokyo, 1985. 